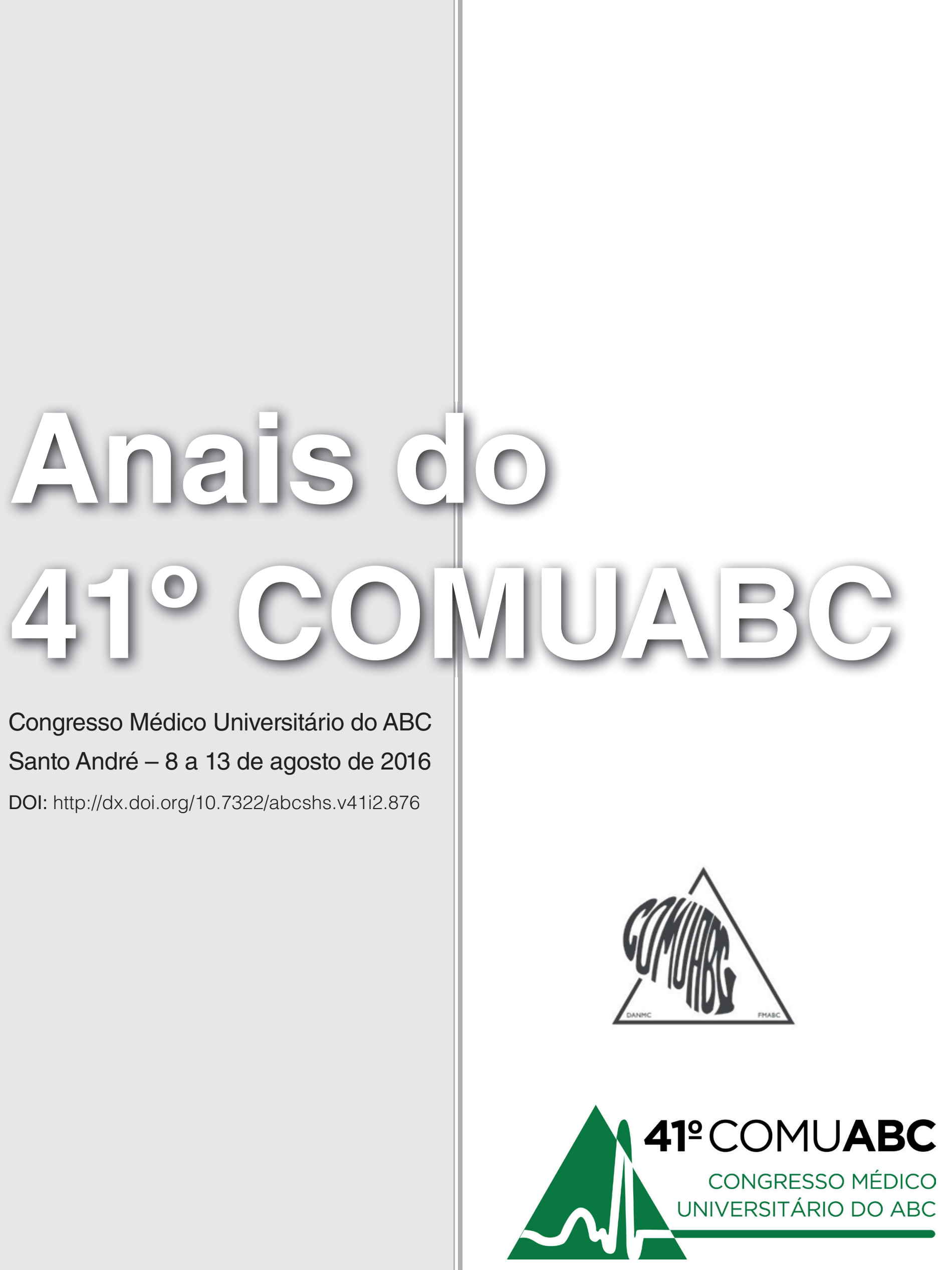




\section{COMISSÃO TÉCNICA}

DEPARTAMENTO DE DIVULGAÇÃO COORDENADORES:

Arthur Monicci Navas

Danielle Yumi Akashi

Heide França Seraphim Gonçalves

MEMBROS:

Alexandre dos Santos Wakim

Andréia Yumi Jouti Motomura

Bruna Mancini Zago da Costa

Bruna Simas Pedreiro

Caique Fonseca

Débora Terra Cardial

Gabriela Camilo Teixeira

Isabella Tomé Sant'Anna

Juliana Seidler

Lucca Lima

Marcella Canato Toloi

Marina Werneck de Almeida Avellar

Matheus Prado Nascimento

Monica Yhasmin de Lima Redondo

Pedro Raya Cozzolino

Regina Maria Costa Biselli

Thais Torrado

\section{DEPARTAMENTO SOCIAL}

\section{COORDENADOR:}

Beatriz Soares de Azevedo Sardano

MEMBROS:

Daniela Moretti Pessoa

Fernanda Esteves Simoes Ramos

Fernanda Ferreira Banhos

Julia Barbizan Previdi

Juliana Teixeira Gomes

Luiz Felipe Avila Carvalho Custodio da Silva

Marina Ramos Jardim

Paola Mortean dos Santos

Rafaela Tiemi Iwamoto Vicentin

Renan Fortes Itagyba

Renata Takeyama de Oliveira

Sandra Carina Lopez Calcines

Vanessa Lopes Mathia

\section{DEPARTAMENTO DE TRABALHOS CIENTÍFICOS} COORDENADORES:

Júlia Basílio Santoro

Rodrigo Goldenstein Schainberg

MEMBROS:

Adriana Wisnik de Campos

Alexia Dias Fontes Rosa

Giovana Moreira Minchillo

Giovana Tiemi Takara

Glauco Sérgio Avelino de Aquino

Laura Ramos de Almeida Lamberte

Lia Vineyard Steuer

Marina Alves Pinto

Marina Guitti de Souza

Michelle Fu Min Tong

Willany Veloso Reinaldo

\section{DEPARTAMENTO CULTURAL E CIENTIIFICO COORDENADORA:}

Thais Suelotto Machado Fonseca MEMBROS:

Carolina Bistacco Moreira

Daniel Henrique Madureira de Assis

Fábio lazzetti Lopes

Giovana de Lima Cebrian

Helena Costa Barros Silva

Igor Luiz Argani

Júlia Fernanda Pellegrim

Lucas Quaglia Timbó

Marina de Martino Lee

Marina lantevi Bortman

Mirella Regina Cimino Scaff

Nathalia Basile Mariotti

Paula Amato

Philip Hoover

Roberta Ferraz Salles Kesselring

DEPARTAMENTO SECRETARIA COORDENADORAS:

Carolina Lavacchini Ramunno Amaral

Letícia Silva Thomé

MEMBROS:

Carolina Fuin Zauith

Carolina Lavacchini Ramunno Amaral

Caroline Awoki Ferrandez

Elainna de Souza Alves

Gabriela Anzai Pavoni

Gabrielle Christina Santos da Silva

Gabrielle Ellert de Almeida

Giovana Chrispim

Giovanna Altafini Nasser Ribeiro Nogueira

Isabela Corralo Ramos

Juliana Jorge Romano

Larissa Yukari Tozaki Tamada

Leticia Mota de Souza

Lisa Maki Umeda

Liya Serikawa Sato

Maria Isabel Cardoso dos Passos Carvalho

Maria Isabel Sacchi Mendonça

Rafaella da Costa Oliveira

DEPARTAMENTO MÍDIA

COORDENADORES:

Isabella Secol Corteze

Marta Maria Arcoverde Cavalcanti

MEMBROS:

Isabella Messias Pires

Leticia Buzachero Bevilacqua

Maria Laura Jorge Micheletto

Thainá Altarejo Marin

\section{COMISSÃO CIENTÍFICA}

Adriano Meneghini

Afonso Oetting Junior

Andres Ricardo Perez Riera

Antônio Carlos Lima Pompeu

Arthur Guerra de Andrade

Bianca Alves Viera Bianco

Caetano Cardeal

Caio Parente Barbosa

Carina Mello

David Feder

Edigê dos Santos

Eduardo Grecco
Fábio José Nascimento

Francisco Winter dos Santos Figueiredo

Gerson Vilhena Pereira Filho

José Antônio Bento

José Jorge Namura

Leandro Luongo de Matos

Lígia de Fátima Nobre Reato

Luciano de Melo Pompei

Marcelo Rodrigues Bacc

Maria Alice Melo Rosa Tavares da Silva

Mário Paulo Faro Junior
Marisa Lazzer Poit

Mônica Silveira Lapa

Neusa Falbo Wandalsen

Odete Miranda

Renato Oliveira

Roberto Bahdu

Rogério Tadeu Palma

Sandra di Felice Boratto

Sônia Hix

Vânia Barbosa do Nascimento

Wilson Roberto Catapani 


\section{Palavra da Presidente}

É com grande satisfação que apresentamos a $41^{\text {a }}$ edição do Congresso Médico Universitário do ABC! Com 40 anos de história e experiência, o COMUABC é considerado hoje um dos maiores congressos de sua categoria e a cada ano tem mostrado a dedicação e o comprometimento dos alunos da Faculdade de Medicina do $\mathrm{ABC}$ com o seu objetivo: oferecer uma semana de atividades capazes de promover reflexões que ultrapassem a sala de aula, atualizando seus participantes com o que há de mais recente em pesquisa e atuação médica.

Entre 8 e 13 de agosto de 2016, serão realizadas palestras com profissionais renomados, cursos teóricos, workshops, painéis, mesas-redondas e apresentações de trabalhos científicos, tudo planejado para uma experiência diferenciada, a fim de aprimorar o conhecimento médico e permitir que ele seja colocado em prática. Para encerrar, contaremos com uma noite de gala, em que serão anunciadas as premiações dos melhores trabalhos apresentados.

Aguardamos a presença de todos no COMUABC de 2016 para mais um evento de grande sucesso!

Flávia Yumi Ataka

Presidente

Beatriz de Santana Soares

Vice-presidente 


\section{BÁSICO EXPERIMENTAL}

\section{BAS-01 AVALIAÇÃO DA PERSISTÊNCIA PARASITÁRIA DO TRYPANOSOMA CRUZI EM ORGÃOS SÓLIDOS TRANSPLANTÁVEIS, TUBO DIGESTIVO E SUPRA-RENAL DE PACIENTES CHAGÁSICOS CRÔNICOS}

Marta Maria Arcoverde, Luiz Alberto Benvenuti

\section{Email: mamarta21@gmail.com}

INTRODUÇÃO: A Doença de Chagas é causada pelo protozoário Trypanosoma cruzi, e em sua fase crônica caracteriza-se pela presença de cardiopatia ou por dilatações segmentares do tubo digestivo (megas). A persistência do parasita na fase crônica tem sido demonstrada pela reativação da doença em situação de imunossupressão e por relatos esporádicos de transmissão pelo transplante de órgãos de doadores chagásicos OBJETIVO: Avaliar a persistência do T. cruzi em órgãos de pacientes chagásicos crônicos, para definir possíveis reservatórios que funcionariam como sítios de origem do parasita para a continuidade da agressão tecidual, para a reativação da doença em situação de imunossupressão e para a transmissão da doença pelo transplante de órgãos. MÉTODO: Utilizamos amostras de tecido do coração, pulmão, fígado, rim, pâncreas, supra-renal, esôfago e trato gastrointestinal de 21 pacientes chagásicos crônicos submetidos a necropsia, fixadas em formol e emblocadas em parafina. A persistência parasitária foi investigada através da histologia, pesquisa imuno-histoquímica de antígenos do T. cruzi, e pela reação em cadeia da polimerase (PCR), qualitativa e em tempo real. RESULTADO: Obtivemos sucesso na recuperação do DNA em 121/166 $(72,9 \%)$ amostras. A persistência parasitária foi detectada em $12 / 21 \quad(57,1 \%)$ amostras de coração, geralmente pela técnica do PCR. O parasita foi também detectado, através da histologia e por imuno-histoquímica, no músculo liso da veia central de 1/21 (4,8\%) amostras de supra-renal. Nenhuma amostra dos outros órgãos testados mostrou-se positiva pela histologia, imuno-histoquímica ou PCR. Dos órgãos utilizados na pesquisa, os transplantáveis são coração, pulmão, fígado, rim e pâncreas. Através das técnicas de análise obtivemos resultado positivo para persistência parasitária apenas no coração, de forma significativa, com vários casos positivos, e em apenas uma amostra de supra-renal. Além desses dois órgãos nenhum outro se mostrou como possível reservatório do T. cruzi, inclusive o tubo digestivo, um dos órgãos alvo da doença CONCLUSÃO: O coração é um grande reservatório do T. cruzi em pacientes chagásicos crônicos, mas os parasitas podem também se albergar na veia central da supra-renal. O pulmão, fígado, rim e pâncreas, mas não o coração de portadores da doença de Chagas pode ser considerado para doação.

Palavras-chave: Chagas; persistência; reativação; reservatório

\section{BAS-02 AVALIAÇÃO DOS EFEITOS ANTI-NEOPLÁSICOS DA TESTOSTERONA SOBRE CÉLULAS DE GLIOBLASTOMA}

\section{Igor Luiz Argani, Vitor Augusto Queiroz Mauad}

\section{Email: igorlargani@gmail.com}

NTRODUCÃO: Glioblastoma multiforme (GB) é o mais agressivo câncer primário no cérebro. Pacientes com GBs apresentam uma sobrevida média menor do que um ano, sendo um câncer extremamente infiltrante e frequentemente não pode ser tratado apenas com cirurgia. Testosterona é um hormônio que promove aumento do metabolismo celular. Ainda não é conhecido o efeito da testosterona sobre células de glioblastoma. OBJETIVO: O objetivo desse estudo foi observar os efeitos da testosterona em diferentes concentrações sobre a proliferacão e viabilidade de células de glioblastoma. MÉTODOS: Na cultura das células, utilizou-se DMEM alta glicose com $1 \%$ de penicilina-estreptomicina e $10 \%$ de soro bovino fetal. Aplicouse a testosterona dissolvida em DMSO nas concentracõos 10uM, 1uM, 0,1uM e 0,01uM. Teste com LDH: fez-se uma análise colorimétrica para avaliar o efeito citotóxico da testosterona. Repetiu-se cada dose em 3 pocos diferentes com 10.000 células em cada. Teste com MTS: fez-se uma análise colorimétrica para avaliar o efeito proliferativo da testosterona. Repetiu-se cada dose em 3 poços com 5.000 células em cada. Teste com anexina $\mathrm{V}$ e Iodato de Propídio: fez-se uma citometria de fluxo para avaliar a viabilidade das células com a testosterona. RESULTADOS: Teste com LDH: foi observado a morte de $42,5 \%$ das células com DMSO; com testosterona a $10 \mathrm{uM}$, morte de $76 \%(\mathrm{OR}=4,41$; IC $95 \%: 2,4-8,1)$; com $1 \mathrm{uM}, 60 \%$ $(\mathrm{OR}=2,06$; IC95\%:1,17-3,62); com 0,1uM, 56\% (OR=1,76; IC95\%:1,01-3,1); e com 0,01uM, morte de 35\% (OR=0,71; IC95\%:0,4-1,26).Teste com MTS: foi observado que a testosterona apresenta uma tendência para inibir a proliferação das células de glioblastoma. Teste com anexina V-Iodato de propídio: foi observado que a testosterona promove morte celular de forma dose-dependente. Em relação ao DMSO, a testosterona a 10uM apresentou 4 vezes mais células inviáveis (IC95\%:2-8,1); a $1 \mathrm{uM}, 3$ vezes (IC95\%: 1,48-6); a 0,1uM, 3 vezes (IC95\%: 1,52-6,2); e a 0,01uM, 1,9 vezes (IC95\%: 0,9-3,9). Considerando que cirurgia exclusiva não costuma ser suficiente como forma de tratamento do glioblastoma, a testosterona poderá se tornar uma opção de tratamento dos pacientes. Assim, a testosterona apresentou resultados anti-neoplásicos promissores na pesquisa. CONCLUSÃO: Foi observado que doses crescentes de testosterona inibem a proliferação e promovem a morte celular de células de glioblastoma.

Palavras-chave: testosterona; glioblastoma; proliferação de células; morte celular.

\section{CIÊNCIAS SOCIAIS E HUMANAS}

\section{CSH-01 CUIDADOS FUNDAMENTAIS COM A PESSOA IDOSA APÓS UM ACIDENTE VASCULAR ENCEFÁLICO}

Isadora Maria de Oliveira Santos, Ramon Félix Martins Fernandes, Bruno Afonso Crenitte Sanches, Carmen Silvia Molleis Galego Miziara, Ivan Dieb Miziara

\section{Email: isadora1252@gmail.com}

INTRODUÇÃO: O acidente vascular encefálico (AVE) é resultante de súbita perda de função cerebral causado pela insuficiência do suprimento sanguíneo, com maior incidência e prevalência em pessoas acima dos 60 anos e, potencialmente capaz de comprometer a capacidade funcional. Os cuidados assistenciais após este evento visam, sobretudo, a reabilitação funcional do paciente, sendo que a família e os cuidadores exercem papel fundamental através de supervisão de responsabilidades e de provisão direta dos cuidados. OBJETIVO: Expor a importância das assistências familiar e do cuidador no processo de reabilitação da pessoa idosa pós-AVE; e descrever as políticas sociais e governamentais brasileiras adotadas em defesa da pessoa idosa, sobretudo em relação àquelas em condição de vulnerabilidade. MÉTODO: Trata-se de um estudo transversal descritivo por revisão de literatura nas bases de dados PUBMED e SCIELO, além de livros e sites governamentais brasileiros. RESULTADO: Aproximadamente 50\% dos sobreviventes de AVE apresentam incapacidades permanentes que requerem assistência. O prognóstico está vinculado à adequação do tratamento após o AVE, incluindo as ações preventivas de novo evento, e a terapia de reabilitação, o mais precoce possível. Quanto a reabilitação, destaca-se a importância do paciente ser incentivado a readquirir sua autonomia e sua participação social com auxílio de familiares e de profissionais de saúde. O desenvolvimento do bem-estar psicológico está associado a um maior nível de assistência oferecido pelos cuidadores $(0.06 ; \mathrm{p}<0.001)$, sendo que o melhor seguimento foi a saúde física $(0,21 ; \mathrm{P}<0,001)$. O processo de reabilitação é cíclico e envolve: avaliação, identificação e quantificação das necessidades do paciente; estabelecimento de metas; e a reavaliação do progresso em relação às metas acordadas. O Estatuto do Idoso determina que: É obrigação da família, da comunidade, da sociedade e do Poder Público assegurar ao idoso, com absoluta prioridade, a efetivação do direito à vida, à saúde. Tornar a reabilitação do doente possível é um direito fundamental. CONCLUSÃO: O AVE pode gerar sequelas físicas e psíquicas, comprometendo o desempenho para o autocuidado e para a autonomia da vida. $\mathrm{O}$ viver e conviver de familiares e de cuidadores com a pessoa idosa no processo reabilitação influencia diretamente o prognóstico.

Palavras-chave: acidente vascular encefálico; idoso; reabilitação; assistência integral a saúde.

\section{CSH-02 PERFIL EPIDEMIOLÓGICO DE PACIENTES DO SUS QUE MIGRAM PARA CENTROS DE REFERÊNCIA A FIM DE OBTEREM TRATAMENTO ONCOLÓGICO}

Beatriz de Camargo Preto Piscopo, Heloísa Duarte de Andrade Tavares, Igor Luiz Argani, Elberth José dos Santos, Karoline Passarela, Marília Arrais Garcia

Email: bia.pispico@gmail.com

INTRODUÇÃO: Atualmente, observa-se que as disparidades estruturais entre diferentes regiões no Brasil no sistema público de saúde têm ocasionado um fenômeno de migração de pacientes para grandes centros em busca de melhores condições de tratamento de suas doenças, inclusive tratamento oncológico. Além do desconforto e transtornos gerados ao paciente, existe uma concentração dos atendimentos em grandes centros, gerando sobrecarga dos serviços de referência. Apesar da relevância e do impacto econômico e social dessa situação, não há dados na literatura que abordem esse tema. OBJETIVO: Avaliar o fluxo migratório e fatores associados em um serviço de referência em oncologia. MÉTODO: Trata-se de um estudo transversal, realizado no serviço de oncologia do Hospital de Ensino Padre Anchieta, em São Bernardo do Campo. Foram incluídos pacientes consecutivos em tratamento oncológico, que aceitaram participar do estudo e assinaram o TCLE. Os pacientes foram entrevistados, e os dados obtidos por questionários foram tabulados e submetidos a análise estatística. RESULTADO: Na análise parcial dos dados coletados no período de março a maio de 2016, foram incluídos 103 pacientes, $59,2 \%$ eram do sexo feminino e tinham idade média de 60,25 anos, variando de 20 a 89 anos. Antes de iniciar o tratamento, $75,7 \%$ dos pacientes já moravam em São Bernardo do Campo, $12,6 \%$ residiam em cidades do ABC paulista conveniada a São Bernardo e $11,7 \%$ veio de outras localidades, sendo $58 \%$ desses de fora do Estado São Paulo. A busca pelo tratamento foi o que motivou a maioria dos pacientes a procurar o serviço fora de sua cidade de origem, onde não teriam tido acesso ao tratamento oncológico. Os dados aqui coletados revelam que um número expressivo dos pacientes atendidos na região do Grande $\mathrm{ABC}$ são imigrantes vindos em busca de tratamento oncológico. A amostragem atual ainda é pequena para conclusões definitivas ou para análises de correlações com eventuais fatores associados. Dados mais acurados serão gerados a medida que a amostra for expandida. CONCLUSÃO: A análise preliminar dos dados aponta para um fluxo migratório de pacientes para o serviço de referência em busca de tratamento oncológico, fato que demonstra a necessidade de discussão do tema para reestruturação de políticas de saúde pública.

Palavras-chave: migração; câncer; saúde pública. 


\section{CSH-03 SÍNDROME DE MUNCHAUSEN POR PROCURAÇÃO: CONDUTA MÉDICA E PERFIL PSICOLÓGICO DO AGRESSOR}

Bruna Zapata Zilio Barros, Ramon Félix Martins Fernandes, Brian Vicente, Stéphanie Kim Azevedo de Almeida, Nicole Saliba Chamelian, Cinthia Emy Endo Amemiya, Victor Morgado Corrêa Pinto, Jessica Lopes de Souza, Carmen Silvia Molleis Galego Miziara, Ivan Dieb Miziara, Fabiana Iglessias de Carvalho

\section{Email: brunazzbarros@gmail.com}

INTRODUÇÃO: A Síndrome de Munchausen por procuração (SMP) foi descrita por Meadow em 1971, e pode ser definida como uma forma rara de abuso infantil na qual um perpetrador/cuidador simula, fabrica ou provoca sinais e sintomas de doenças na criança. Dessa maneira, a vítima é submetida a repetidas internações, procedimentos e tratamentos médicos desnecessários. Forma de violência infantil, desconhecida por muitos médicos e outros profissionais da saúde, subnotificada e pode acarretar graves sequelas psicológicas e físicas, inclusive com desfecho fatal. OBJETIVO: Expor a importância do atendimento clínico minucioso como forma de diagnóstico de possível caso de maus tratos contra a criança, incluindo o perfil psiquiátrico do agressor. MÉTODO: A partir de um relato de caso (lactente que foi reiteradamente intoxicado por medicamentos antiepilépticos administrados pela mãe), fez-se um levantamento bibliográfico em bases de dados de livre acesso (PubMed, SCIELO, LILACS) acerca do tema Síndrome de Munchausen por procuração. RESULTADO: Pela $5^{\circ}$ edição do DSM a terminologia atual para a SMP é: transtorno factício imposto a outro. A identificação precoce desta condição é imprescindível para a determinação do prognóstico, incluindo não apenas a assistência à criança, mas também à agressora. A literatura mostra que crianças submetidas a esta forma de abuso têm maior risco de morbimortalidade, com sequelas psicológicas irreparáveis, incluindo comportamento autodestrutivo futuro, e danos físicos potencialmente fatais. Estudos mostram que esta é a forma mais mortal de abuso, com taxa de mortalidade de $5 \%$ a $10 \%$, caso o diagnóstico não seja estabelecido precocemente. Entretanto, a ausência de vestígios, embora na presença de indícios, muitas vezes coloca em dúvida a conduta médica, havendo assim a necessidade de excluir outras causas e a vítima é exposta a estresses físico e mental. Meadow (2008) estabeleceu sinais de alarme, não de certeza, e para o diagnóstico da SMP, pela grande variabilidade de manifestações clínicas. Um sinal importante é a discrepância entre os sinais e os sintomas, geralmente recidivantes, e o estabelecimento de um diagnóstico sindrômico. CONCLUSÃO: A falta do olhar integral para o paciente e para o ambiente em que a vítima vive, incluindo o relacionamento familiar, faz com que o profissional da saúde se perca nas queixas factícias da mãe.

Palavras-chave: Síndrome de Munchausen; Munchausen por procuração; violência infantil.

\section{CSH-04 SÍNDROME DE MUNCHAUSEN POR PROCURAÇÃO - DILEMAS ÉTICOS E ASPECTOS LEGAIS}

Nicole Saliba Chamelian, Bruna Zapata Zilio Barros, Stéphanie Kim Azevedo de Almeida, Ramon Félix Martins Fernandes, Brian Vicente, Jessica Lopes de Souza, Cinthia Emy Endo Amemiya, Victor Morgado Corrêa Pinto, Carmen Silva Molleis Galego Miziara, Ivan Dieb Miziara, Fabiana Iglessias de Carvalho

\section{Email: nicole.salibach@gmail.com}

INTRODUÇÃO: A Síndrome de Munchausen por Procuração (SMP) foi descrita por Meadow em 19771, e incluída no DSM-III desde 1980. Congregam pacientes simuladores ou indutores de doenças em terceiros, podendo ser definida como uma forma de abuso infantil na qual o perpetrador (geralmente a mãe) produz ou simula sinais e sintomas factícios na criança. Frente à suspeita da síndrome muitas vezes o médico não sabe como proceder pela dificuldade de confirmar o diagnóstico e pelo receio gerado ante as consequências da notificação compulsória. OBJETIVO: Apresentar a conduta médica quanto à notificação de casos suspeitos ou confirmados da SMP e alertar os profissionais de saúde para possíveis dilemas éticos relacionados com esse tipo de abuso infantil. MÉTODO: Levantamento bibliográfico em bases de dados de livre acesso (PubMed, SCIELO e LILACS) e sites médicos oficiais acerca do tema Síndrome de Munchausen por procuração. Compilou-se por subdivisão do tema: ética médica perante a quebra de sigilo (notificação compulsória). RESULTADO: A SMP é uma forma grave de abuso infantil e, geralmente, passa despercebida pelos médicos por desconhecimento, o que incorre em demora no diagnóstico. Casos suspeitos ou confirmados devem ser notificados ao Conselho Tutelar, tendo obrigatoriedade desde a implementação do Estatuto da Criança e do Adolescente em 1990 e, desde 2001, às Secretarias de Saúde Estaduais para controle epidemiológico. O manejo desses casos deve ser feito por uma equipe interdisciplinar, envolvendo pediatras, psicólogos, assistentes sociais e advogados. Assim, com o propósito de proteger o menor incapaz por vezes esbarra-se em implicações morais na intervenção devido aos efeitos que promovem na dinâmica familiar. Nesse trabalho serão analisados os problemas à luz de algumas teorias éticas (consequencialismo, utilitarismo e deontologia). CONCLUSÃO: Síndrome de notificação compulsória, a SMP prescinde acima de tudo de tratamento psiquiátrico da mãe e acompanhamento multiprofissional do paciente. $\mathrm{O}$ médico deve ter o cuidado de intervir consciente de seus deveres éticos a fim de possibilitar a beneficência desse paciente, que vai além de apenas notificar a violência infantil, pensando também nas consequências dessa intervenção para a criança e familiares.

Palavras-chave: Síndrome de Munchausen; Ética Médica; Notificação de Doenças.

\section{CIRÚRGICO}

\section{CIR-01 APENDICECTOMIA VIDEOLAPAROSCÓPICA: EXPERIÊNCIA NO HOSPITAL DE ENSINO DA FACULDADE DE MEDICINA DO ABC}

Alexandra Messa Cirlinas, Bianca Mendes Carnevalli, Gabriela Maria Mendes Silva, Jussara Oliveira Silva, Murilo Furtado Mendonça Casati, Mariana de Sousa Prado Geraldo, Thaiane Fagundes Vieira, Ricardo Moreno, Mauricio Campanelli

\section{Email: acirlinas@gmail.com}

INTRODUÇÃO: A apendicite aguda é uma doença frequente, sobretudo em jovens. A cirurgia videolaparoscópica (VL) mostrou-se segura e eficaz no seu tratamento. OBJETIVO: Analisar de forma retrospectiva os dados clínicos e demográficos dos pacientes submetidos à apendicectomia VL, correlacionando-os com dados intra e pós-operatórios. MÉTODOS: Estudou-se Apendicectomias VL realizadas no Hospital de Ensino da Faculdade de Medicina do ABC, em São Bernardo do Campo-SP, entre fevereiro de 2013 e junho de 2015. Coletou-se dados pré-operatórios como idade, sexo, comorbidades, dias de história e hipótese diagnóstica; informações intra-operatórias como invaginação do coto, uso de grampeador, grau da apendicite aguda, conversão para via laparotômica; e dados pós-operatórios como tempo de internação, complicações e resultado anatomopatológico da peça cirúrgica. RESULTADOS: A idade média dos 75 pacientes foi de 28,25 anos (1280 anos), sendo 32 do sexo masculino (43\%). Dois pacientes eram hipertensos, 3 diabéticos e 6 obesos; 6 eram tabagistas e apenas 1 etilista grave; 3 eram pneumopatas graves. A média de dias de dor até admissão no serviço foi de 2,87 dias (1-15 dias).Trinta e cinco pacientes foram submetidos à Videolaparoscopia Diagnóstica com achado intraoperatório de apendicite aguda,os outros 40 pacientes possuíam Apendicite Aguda como diagnóstico pré-operatório. Onze pacientes (14,6\%) encontravam-se em grau 1 de apendicite aguda; $41(54,6 \%)$ em grau 2;12 (16\%) em grau $3 ; 4(5,3 \%)$ em grau 4A;2 (2,6\%) em grau 4B; $1(1,3 \%)$ m grau $4 \mathrm{C} ;$ e $4(5,3 \%)$ em grau 5. Optou-se por conversão para via laparotômica em 4 casos, dos quais 1 encontrava-se em grau 4C e 3 em grau 5, dos quais em 1 realizou-se Ileotiflectomia. O tempo médio de internação pós-operatória foi de 1,74 dias (1-9 dias). Nenhum paciente apresentou complicação pós-operatória grave ou foi reoperado. Dois pacientes apresentaram infecção da ferida operatória, e ambos tiveram conversão para via laparotômica. Três pacientes evoluíram com ileo prolongado no pós-operatório, dos quais 2 tiveram conversão para via laparotômica. Nenhum dos pacientes recebeu diagnóstico anatomopatológico de neoplasia. CONCLUSÃO: $\mathrm{O}$ acesso videolaparoscópico é seguro e eficaz no tratamento da apendicite aguda, mesmo em casos graves, apresentando aparentes taxas inferiores de complicações pós-operatórias.

Palavras-chave: Apendicite; Cirurgia videolaparoscópica.

\section{CIR-02 ANÁLISE DETALHADA DO FLUXO DE INFUSÃO E DE DRENAGEM DOS MATERIAIS UTILIZADOS PARA IRRIGAÇÃO VESICAL NO MANEJO CLÍNICO DO PACIENTE COM HEMATÚRIA MACROSCÓPICA}

Natasha Kouvaleski Saviano Moran, Felipe Ko Chen, Arie Carneiro, Gustavo Caserta Lemos

\section{Email: natasha_smoran@ @otmail.com}

INTRODUÇÃO: A irrigação vesical continua (IVC) é um dos pilares do manejo clínico do paciente com hematúria macroscópica severa. O conhecimento das propriedades dos equipamentos utilizados é de fundamental importância para escolha correta do material que permita um fluxo de infusão e de drenagem adequados para cada situação clínica. Na literatura não há nenhum estudo que compare, de forma objetiva, os modelos de sonda vesical de 3 vias (SV), bem como situações que possam interferir no seu desempenho. OBJETIVO: Comparar o fluxo de infusão e drenagem nos diferentes modelos e tamanhos de SV, bem como avaliar fatores relacionados a piora ou melhora do desempenho. MÉTODO: Utilizamos os 3 modelos [Rusch Latex (X), Rusch Siliconada (Y) Coloplast (Z)] com 3 tamanhos [20, 22 e 24 French (f)] de SV utilizados na instituição. A análise de fluxo de infusão foi realizada em 4 situações diferentes levando em consideração a altura da SV $(0,90 \mathrm{~m}$ e $0,65 \mathrm{~m})$ e a altura do suporte do soro (AS) $(1,98 \mathrm{~m}$ e $1,80 \mathrm{~m})$. A análise da drenagem foi realizada em duas alturas diferentes $(0,90 \mathrm{~m}$ e $0,65 \mathrm{~m})$. A aferição do fluxo foi realizada utilizando um aparelho de fluxometria (Dynamed). As medidas foram realizadas com o cuff vazio, insuflado com $10 \mathrm{ml}, 20 \mathrm{ml} \mathrm{e} 40 \mathrm{ml}$ de agua destilada. RESULTADO: O fluxo de infusão foi similar entre os tamanhos nos modelos $\mathrm{X}$ $(77 \mathrm{ml} / \mathrm{min})$ e $\mathrm{Z}(137 \mathrm{ml} / \mathrm{s})$. A diferença de altura entre a SV e a AS influenciou no fluxo de forma mais significativa que a altura isolada. O Volume injetado no cuff não interferiu nos fluxos de infusão e de drenagem. $\mathrm{O}$ modelo $\mathrm{Z}$ foi superior 
em todos os tamanhos tanto no fluxo de irrigação como no de drenagem. A SV Z tamanho 20 possui um fluxo $45 \%$ maior que a SV X $24 \mathrm{f}$ e $56 \%$ superior que a SV Y 24f. A altura da SV não alterou o fluxo de drenagem. O fluxo de drenagem aumenta com o maior calibre da sonda em todos modelos. A drenagem da SV Z tamanho 20 é similar à SV X 24f e inferior à SV Y 24f e SV Y 22f. CONCLUSÃO: O modelo de SV é o principal fator determinante no fluxo de irrigação e drenagem. O tamanho da SV não influencia o fluxo de irrigação. Quanto maior o calibre da sonda, melhor a drenagem. A diferença entre a altura da SVD e a AS é determinante para o fluxo de irrigação, porém não para a drenagem. $\mathrm{O}$ volume do cuff não interfere nos fluxos de irrigação e de drenagem.

Palavras-chave: Irrigação vesical contínua; sonda vesical; fluxo de infusão; drenagem.

\section{CIR-03 CARCINOMA COLORRETAL: HIPEREXPRESSÃO DA PROTEÍNA PRL-3 NO PROCESSO DE CARCINOGENESE}

Tamyris Kaled El Hayek, Leandro Luongo de Matos

\section{Email: tamyhayek@hotmail.com}

INTRODUÇÃO: O câncer colorretal é a terceira neoplasia maligna com maior ocorrência no mundo, sendo a quinta no Brasil, onde se apresenta como a quarta causa de morte por câncer. A maior porcentagem das mortes ocorre devido ao processo metastático. A proteína PRL (fosfatase do fígado em regeneração) é da família das tirosinasfosfatases (PRL-1, PRL-1, PRL-3). A PRL-3 desempenha importante papel na regulação dos processos celulares, como crescimento e controle do ciclo celular. É ainda um marcador importante no diagnóstico e prognóstico do carcinoma colorretal relacionando à capacidade de destruição das paredes dos vasos, motilidade celular, infiltração das células tumorais e agressividade, processos diretamente relacionados ao desenvolvimento de metástases. OBJETIVO: Estabelecer a relação entre a proteína PRL-3 e o processo de carcinogênese do carcinoma colorretal. MÉTODO: Foram selecionadas amostras de carcinoma colorretal de pacientes consecutivos submetidos a colectomia em uma única instituição em um período de quatro anos, bem como linfonodos metastáticos e mucosa colônica normal adjacente. Lâminas histológicas desses espécimes foram submetidas à técnica de imunohistoquímica para PRL-3 e sua expressão foi digitalmente quantificada. RESULTADO: Foram incluídos no estudo 106 pacientes com adenocarcinoma de cólon e reto, sendo que destes 34 (32,1\%) apresentavam metástases linfonodais e em 40 indivíduos foi possível a análise da margem de mucosa sadia. Foi observada uma hiperexpressão de PRL-3 no tecido tumoral quando comparado à mucosa normal $(\mathrm{p}=0,005$ ANOVA; $\mathrm{p}=0,034$ teste auxiliar de Bonferroni) e, da mesma forma, quando este foi comparado à expressão das células tumorais no linfonodo metastático $(\mathrm{p}=0,005$ ANOVA; $\mathrm{p}=0,022$ teste auxiliar de Bonferroni), principalmente quanto à intensidade da imunomarcação. DISCUSSÃO: Conhecendo fatores prognósticos do câncer é hipoteticamente possível um seguimento mais cuidadoso do paciente, além de orientar terapêutica específica para cada caso. A proteína PRL-3 é um importante marcador no câncer colorretal, já que apresenta expressão aumentada em suas células conforme previamente demonstrado no presente estudo e na literatura. CONCLUSÃO: Os resultados demonstram a importância da proteína PRL-3 como marcador tumoral do carcinoma colorretal e também o seu provável papel na carcinogênese desta doença.

Palavras-chave: câncer colorretal; proteína tirosina fosfatase; biomarcador molecular

\section{CIR-04 CRACK: MUDANÇA NO PARADIGMA NAS CAUSAS DE ABDOME AGUDO PERFURATIVO}

Bárbara Cristina Jardim Miranda, Cauê Fedrigo Loyola Batista, Pedro Augusto Soffner Cardoso, Danielle Yumi Akaishi, Flávia Yumi Ataka, José Henrique Miranda Borducchi, Sandra Di Felice Boratto, Afonso Oetting Júnior

\section{Email: barbaracjmiranda@gmail.com}

INTRODUÇÃO: No Brasil, estima-se que $1 / 5$ da população geral tenha experimentado drogas ilícitas ou controladas pelo menos uma vez na vida. Drogas psicotrópicas são substâncias que agem no sistema nervoso central, mas que podem resultar em complicações agudas e crônicas extra centrais dependendo da predisposição genética do indivíduo e da dose de consumo da droga. Com relação às complicações gastrointestinais envolvidas com o uso do crack, observa-se isquemia mesentérica com ulceração principalmente de região pré-pilórica e primeira porção do duodeno, além de colite isquêmica, hemorragia maciça e necrose transmural. É provável que a fisiopatologia baseie-se no efeito vasoconstritor da droga, além de sua toxicidade direta sobre a mucosa e o aumento sistêmico da pressão arterial. A melhor abordagem é a laparotomia exploradora, envolvendo vagotomia associada à piloroplastia e antrectomia ou gastrectomia subtotal. OBJETIVO: Correlacionar casos de abdome agudo perfurativo com o uso crônico de crack, avaliando dados epidemiológicos (idade, sexo e raça mais prevalentes, tempo de consumo da droga) e fatores que podem ter influenciado o quadro clínico. MÉTODO: Estudo retrospectivo realizado a partir da análise de prontuários de janeiro de 2015 a janeiro de 2016 de pacientes usuários de crack submetidos ao atendimento médico no Centro Hospitalar Municipal Universitário de Santo André por úlceras gastrointestinais perfuradas. RESULTADO: Espera-se encontrar uma correlação entre uso crônico de crack e abdome agudo perfurativo, com base no mecanismo de ação da droga, estabelecendo prevalência de raça, sexo, idade e tempo de consumo da droga. DISCUSSÃO: A vasculatura mesentérica é ricamente inervada por fibras simpáticas pós-ganglionares, o que aumenta sua suscetibilidade ao efeito vasoconstritor contínuo do crack e ao surgimento de trombose intravascular e isquemia aguda. As ações anticolinérgicas da droga aumentam o tempo de exposição da mucosa à ação do ácido gástrico e a predisposição a formação de úlceras. CONCLUSÃO: Além de constituir um problema de cunho social, conclui-se que o abuso do consumo de crack consiste em um potencial desencadeante de urgências e emergências médicas e que a história e análise de sinais clínicos são de suma relevância para o manejo adequado de pacientes com abdome agudo perfurativo.

Palavras-chave: abdome agudo perfurativo; consumo de crack; úlcera perfurada.

\section{CIR-05 COCAÍNA: UM IMPORTANTE FATOR DESENCADEANTE DA PANCREATITE AGUDA}

Danielle Yumi Akaishi, José Henrique Miranda Borducchi, Bárbara Cristina Jardim Miranda, Pedro Augusto Soffner Cardoso, Flávia Yumi Ataka,

Cauê Fedrigo Loyola Batista, Sandra Di Felici Boratto, Afonso Oetting Junior

\section{Email: danielle.akaishi@gmail.com}

INTRODUÇÃO: A cocaína é um alcaloide usado como droga ilegal obtido das folhas da coca. No Brasil, o uso dessa droga vem crescendo e, consequentemente, as intercorrências advindas de seu uso estão cada vez mais presentes nos serviços de saúde. A cocaína é um inibidor da recaptação de dopamina, norepinefrina e um inibidor da reabsorção de serotonina, tornando-se um potente estimulante do sistema nervoso central. Complicações digestivas são pouco frequente sendo o comprometimento pancreático excepcional e somente poucos casos foram relatados na literatura. A Pancreatite Aguda (PA) é definida como sendo um processo inflamatório agudo do pâncreas com envolvimento variável de outros tecidos regionais ou sistemas orgânicos. $\mathrm{O}$ uso de drogas foi, em menor grau, relacionado com o desenvolvimento da PA sendo que a cocaína vem chamando a atenção de especialistas por estar se tornando cada vez mais frequente no dia-a-dia dos hospitais brasileiros. OBJETIVO: Nosso objetivo é avaliar os pacientes do serviço do Centro Hospitalar do Município de Santo André (CHMSA) que foram admitidos com diagnóstico de pancreatite aguda e a possível relação desse diagnóstico com o uso de cocaína. MÉTODO: Será realizado levantamento dos prontuários de pacientes, admitidos no CHMSA no período de janeiro de 2015 a maio de 2016, com pancreatite aguda. Entre os pacientes com esse diagnóstico, será avaliado quantos faziam o uso de cocaína e qual o grau de correlação entre pancreatite aguda e uso dessa droga. RESULTADO: Espera-se encontrar uma correlação positiva entre pancreatite aguda e uso de cocaína, contando com um número significativo de pacientes usuários da droga que desenvolveram a doença. DISCUSSÃO: Um número significativo de pacientes com pancreatite aguda faz uso de cocaína. Os efeitos da cocaína em curto prazo incluem: aumento da pressão arterial, vasoconstrição, estado de alerta mental, pupilas dilatadas, aumento de energia, aumento da frequência cardíaca e da temperatura e diminuição do apetite. Complicações digestivas são pouco frequentes, sendo isquemia intestinal, perfuração, fibrose retroperitoneal e úlcera gástrica as mais comuns. No entanto, acredita-se que a droga pode provocar, por meio da vasoconstrição, isquemia pancreática que pode, dessa forma, evoluir para uma pancreatite aguda. CONCLUSÃO: O uso de cocaína apresenta correlação positiva com o desenvolvimento de PA.

Palavras-chave: cocaína; comprometimento pancreático; pancreatite aguda; hospitais brasileiros

\section{CIR-06 EVOLUÇÃO DA NEFRECTOMIA PARCIAL ABERTA PARA ROBÓTICA: EXPERIÊNCIA DE UM ÚNICO CIRURGIÃO EM ATINGIR A TRIFECTA}

Felipe Ko Chen, Natasha Koualeski Saviano Moran, Arie Carneiro, Gustavo Caserta Lemos

\section{Email: felipechen0@gmail.com}

INTRODUÇÃO: A nefrectomia parcial (NP) está bem estabelecida e deve ser realizada sempre que factível. A via de acesso depende das características do tumor e da experiência do cirurgião. Estudos recentes demonstraram que a tecnologia robótica permite um encurtamento da curva de aprendizado, assegurando os mesmos resultados funcionais e oncológicos. Para análise do sucesso da cirurgia, três fatores devem ser considerados (TRIFECTA): Tempo de isquemia (relacionado a preservação de função renal), Margem negativa (sucesso oncológico) e ausência de complicações. OBJETIVO: Descrever a curva de aprendizado e a experiência em atingir a TRIFECTA de um único cirurgião, na transição da direta da NP aberta para robótica MÉTODO: Estudo retrospectivo de dados coletados prospectivamente de pacientes submetidos à NP robótica por um único cirurgião (GCL) no período de 2009 a abril de 2015. Para análise da curva de aprendizado a amostra foi divida cronologicamente em 3 grupos (G1: 29 primeiros casos, G2: 28 casos e G3: últimos 29 casos). A trifecta foi definida como: tempo de isquemia menor que 25 minutos, margem negativa e ausência de complicações severas (Clavien maior que 2). RESULTADOS: A idade média dos pacientes foi de 54 anos, o tamanho tumoral médio foi de $32 \mathrm{~mm}(\mathrm{DP}=17)$ e a cirurgia foi realizada com isquemia zero em $36 \%$ dos casos, as características demográficas dos pacientes foram semelhantes entre os grupos. Em 52\% dos casos apresentavam nefrometria (R.E.N.A.L.) de moderada complexidade e $4 \%$ de alta complexidade. $16,3 \%$ apresentaram complicações, no entanto apenas $3 \%$ dos casos complicações significativas (Clavien 3 ). 
O tempo de isquemia médio foi de 14,6 minutos com diminuição significativa do G1 para G2 $(20,2$ vs 12,9; $\mathrm{p}<0.05)$. A recuperação da função renal basal ocorreu em 94\% dos pacientes após 3 meses de cirurgia. Um caso apresentou margem positiva A TRIFECTA foi alcançada em $77.9 \%$ dos casos com melhora significativa entre o G1 e o $\mathrm{G} 3(64,1 \%$ vs $89,7 \%$; $\mathrm{p}=0.03)$. Em análise multivariada a nefrometria representou o único fator significativo relacionado com a TRIFECTA. CONCLUSÃO: A transição direta para NP aberta para robótica é segura. Desde o inicio apresenta resultados oncológicos e funcionais satisfatórios, mesmo para cirurgião sem experiência previa com cirurgia laparoscópica. A nefrometria é o principal fator preditivo de sucesso na NP.

Palavras-chave: nefrectomia parcial robótica; TRIFECTA; nefrectomia parcial aberta; nefrometria.

\section{CIR-07 HERNIOPLASTIA INCISIONAL VIDEOLAPAROSCOPICA: EXPERIÊNCIA NO HOSPITAL DE ENSINO DA FACULDADE DE MEDICINA DO ABC}

Carolina Yone Tamashiro, Renata Gomes Castello, Yan Cachoni Sen, Paulo Roberto Zamfolini Zachêu, Lívia Yadoya Vasconcelos, Beatriz Gregorio Soares, Mauricio Campanelli Costas, Ricardo Moreno

Email: carol_yone@ hotmail.com

INTRODUÇÃO: Hérnia Incisional (HI) é uma complicação frequente em pós-operatórios de cirurgias laparotômicas. Sua correção, em geral, é feita com uso de próteses, seja pela técnica aberta seja por via videolaparoscópica (VL). OBJETIVO Mostrar a experiência do Hospital de Ensino da Faculdade de Medicina do ABC (FMABC) no tratamento das HI através da via laparoscópica. MÉTODO: Foram estudadas as Hernioplastias VL realizadas no Hospital de Ensino da FMABC, no período de julho de 2008 a julho de 2013. Avaliaram-se dados dos pacientes como idade, sexo, comorbidades e Índice de Massa Cospórea (IMC); achados intraoperatórios como dimensões do anel herniário e da tela, bem como sua forma de fixação, além do tempo cirúrgico e complicações intra e pós-operatórias. RESULTADO: Dos 67 pacientes submetidos à Hernioplastia Incisional VL, 42 (62,7\%) eram mulheres. A idade média foi de 53,83 anos. O IMC médio foi de $29,88 \mathrm{~kg} / \mathrm{m} 2$. 30 pacientes eram hipertensos, 15 diabéticos, 6 possuíam hipotireoidismo. 54 pacientes foram submetidos à Hernioplastia Incisional VL pura e 7 à técnica híbrida. A média do maior diâmetro do anel herniário foi $10,48 \mathrm{~cm}$ e a área média do anel foi de $79,04 \mathrm{~cm} 2$. A área média da tela foi de $274,5 \mathrm{~cm} 2$. O tempo operatório médio foi de 156,36 minutos. O tempo médio de internação foi de 4,03 dias. De todos os pacientes, apenas em 6 casos a cirurgia foi convertida para uso de prótese onlay com tela de polipropileno. Houve também um caso de lesão de intestino delgado, corrigida com enterorrafia. Não houve casos de complicações pós-operatórias graves. DISCUSSÃO: A taxa de infecção após o reparo videolaparoscopico é menor que a do reparo convencional. No trabalho realizado, nenhum paciente desenvolveu complicações infecciosas. Entretanto, na cirurgia laparoscópica, a incidência de lesões intestinais descrita é de até 3,5\%, discretamente superior ao reparo convencional, sendo que dos 67 pacientes estudados, houve apenas 1 caso de lesão do intestino $(1,49 \%)$. O tempo de permanência hospitalar após a correção laparoscópica é menor do que após operação aberta, no estudo realizado o tempo de internação também foi menor, com uma média de 4,03 dias. CONCLUSÃO: $\mathrm{O}$ acesso videolaparoscópico para correção de HI é seguro, eficaz e com baixas taxas de complicações intra e pós-operatórias, sendo uma excelente opção, inclusive em pacientes obesos. Palavras-chave: Hernioplastia; incisional; videolaparoscopia.

\section{CIR-08 HERNIOPLASTIA INGUINAL VIDEOLAPAROSCOPOICA: EXPERIÊNCIA NO HOSPITAL DE ENSINO DA FACULDADE DE MEDICINA DO ABC}

Renata Gomes Castello, Carolina Yone Tamashiro, Yan Cachoni Sen, Paulo Roberto Zamfolini Zacheu, Livia Yadoya Vasconcelos, Beatriz Gregio Soares, Mauricio Campanelli Costas, Ricardo Moreno

\section{Email: renatagomescastello@gmail.com}

INTRODUÇÃO: Hérnia Inguinal (HI) é o tipo de hérnia abdominal mais frequente e sua correção cirúrgica pode ser feita via anterior ou posterior, sendo esta através da via videolaparoscópica (VL), seja pela técnica TAPP ou TEP. OBJETIVOS: Mostrar a experiência do Hospital de Ensino da Faculdade de Medicina do ABC na correção da HI através da via VL. MÉTODOS: Foram estudadas as Hernioplastias Inguinais VL realizadas no período de março de 2013 a junho de 2015 no Hospital de Ensino da Faculdade de Medicina do ABC, em São Bernardo do Campo-SP. Foram avaliados os dados demográficos como idade, sexo e comorbidades, dados intraoperatórios como diâmetro do anel, fixação da tela, fechamento do peritôneo, tempo operatório e complicações intra e pós-operatórios. RESULTADOS E DISCUSSAO: Dos 112 pacientes submetidos à Hernioplastia Inguinal VL, 98 (87,5\%) eram do sexo masculino. A idade média foi de 59,28 anos (17-83 anos), 41 eram hipertensos, 15 diabéticos, 14 obesos, 17 tabagistas, 14 etilistas graves, 1 pneumopata grave e outras comorbidades apareceram menor prevalência. Em 36 casos a hérnia era recidivada. Em todos os casos, utilizou-se a técnica TAPP. Em 96 casos $(78,7 \%)$ a hérnia era unilateral, dos quais 82 eram homens, 12 obesos. Em 65 pacientes (58\%) a hérnia era à direita; em 31 casos, recidivada. A média do diâmetro do anel herniário foi de $2,89 \mathrm{~cm}$. Em 3 pacientes foi preciso conversão para via anterior por restrição ventilatória. A dimensão média latero-lateral da tela foi de $15,04 \mathrm{~cm}$, crânio-caudal de $11,95 \mathrm{~cm}$ e a área $80, \mathrm{~cm}^{2}$ A tela foi fixada em 90 pacientes $(93,75 \%)$, dos quais 05 foram com cola e $85 \mathrm{com}$ grampeador. O peritôneo foi fechado em todos os pacientes: 85 com pontos e $8 \mathrm{com}$ grampeador (destes, em 2 pacientes utilizaram-se 4 grampos; em 1 paciente, 5 grampos; em 4 pacientes, 6 grampos; e em um, 7 grampos). O tempo médio de internação foi de 1,19 dias. Em 14 pacientes a hérnia era bilateral, todos do sexo masculino. Em 5 casos a hérnia era recidivada. O diâmetro médio do anel à direita foi de $3,25 \mathrm{~cm}$ e à esquerda, 3,62 cm. Em 6 casos utilizou-se tela única, com dimensões de $36 \times 26 \mathrm{~cm}$. Nos demais, a área média da tela à direita foi de $156 \mathrm{~cm}^{2}$ e à esquerda de $183,25 \mathrm{~cm}^{2}$. A tela foi fixada em 11 pacientes (todos com pontos). CONCLUSÃO: $\mathrm{O}$ acesso VL para correção de hérnia inguinal é seguro e eficaz, sendo excelente escolha para hérnias recidivadas.

Palavras-chave: Hernioplastia; Hérnia Inguinal; Videolaparoscopisa.

\section{CIR-09 INCIDÊNCIA E TRATAMENTO DE QUILOTÓRAX EM PACIENTES PEDIÁTRICOS SUBMETIDOS A CIRURGIA CORRETIVA DE CARDIOPATIAS CONGÊNITAS}

Nicolle Martin Christofe, Danielle Yumi Akaishi, Cristiane Félix Ximenes Pessotti, leda Biscegli Jatene

\section{Email: nicollemchristofe@ hotmail.com}

INTRODUÇÃO: Quilotórax é o extravasamento de linfa na cavidade pleural e sua incidência é de $0,25 \%$ a $5,3 \%$ em crianças submetidas a cirurgia cardíaca pediátrica. Essa complicação pode ocorrer por lesão direta do ducto torácico ou de forma indireta, por aumento na pressão venosa em leito de veia cava superior. OBJETIVO: Avaliar a incidência do quilotórax, associado a cada intervenção cirúrgica e relacionar os tipos de tratamento empregados com a resolução obtida. MÉTODO: Estudo retrospectivo através de levantamento de prontuários de pacientes submetidos à cirurgia cardíaca em serviço de referência, de 2004 a 2014. A análise estatística teve variáveis qualitativas apresentadas por frequência absoluta e frequência relativa, $e$ variáveis quantitativas por mediana e percentis 25 e 75 , pois as variáveis não apresentaram distribuição normal (teste Shapiro-wilk, $\mathrm{p}<0,05$ ). Para analisar associação entre o tipo de tratamento e resultado obtido foi utilizado o teste de Qui-quadrado. O nível de confiança adotado foi de 95\%. RESULTADO: A incidência foi de 2,1\%, sendo $0,9 \%$ nas cirurgias intra-cardíacas, $1,7 \%$ na correção de persistência de canal arterial e na correção de coartação de aorta, $8,3 \%$ na cirurgia de Glenn, 11,8\% na cirurgia Cavopulmonar total e 3\% nas demais cirurgias. Entre os tratamentos habitualmente realizados, o jejum associado à nutrição parenteral total resolveu $66 \%$ dos casos em até 7 dias e $79 \%$ em até 14 dias. A dieta hipogordurosa teve taxa de não resolutividade e encaminhamento para cirurgia em $40 \%$ dos casos. Jejum associado a sandostatina, levou a resoluções em mais de 15 dias em $47 \%$ dos casos. DISCUSSÃO: O quilotorax tem alta morbimortalidade, sendo fundamental diagnóstico e tratamentos precoces. As opções de tratamento são dieta hipogordurosa, jejum associado à nutrição parenteral total, e mais recentemente, jejum associado a sandostatina. Tratamentos cirúrgicos são empregados apenas nos casos de falha Terapeutica. CONCLUSÃO: De acordo com os resultados obtidos, a incidência de quilotórax tem destaque nas cirurgias de Glenn e Cavopulmonar total e o tratamento com jejum e nutrição parenteral total leva a resoluções mais precoces, enquanto tratamento com uso de sandostatina (após uma semana de jejum e NPT) resolveu-se em mais de 15 dias.

Palavras-chave: Quilotorax; cirurgia cardíaca pediátrica; ducto torácico; cardiopatias congênitas.

\section{CLÍNICO}

\section{CLI-01 ATE QUE PONTO O GÊNERO INFLUI NA MORTALIDADE POR DOENCSA CARDIOVASCULAR? COMPARAÇÃO DA INCIDÊNCIA E MORTALIDADE POR DOENÇA CARDIOVASCULAR E CÂNCER DE MAMA EM MULHERES DO ABC PAULISTA}

Bruno Luis Martins, Bianca Cristina Romão da Cunha, Camilla Vilela Giacovone, Gabrielle Gomes de Souza, Guilherme de Almeida Magalhães Gomes, Israel Kanaan Blaas, Karen Yuri Ohki Kawakami, Luisa Rebelo Ayoub, Antônio Carlos Palandri Chagas, Luciano Pessoa Cavalcante, João Fernando Ferreira

\section{Email: brunomvp10@ hotmail.com}

INTRODUÇÃO: Um dos principais propósitos das faculdades de Medicina é prover dados científicos que suportem o planejamento e a execução de ações de Saúde Pública na sua região. Exemplo bem sucedido é o projeto Coração de Estudante, que objetiva a Promoção de Saúde em crianças e adolescentes do ABC Paulista; e se baseia em dados providos por uma escola médica da região, conjugando, com sucesso, ações de Saúde Pública executadas pelas respectivas agências municipais de saúde, e alcançando resultados reconhecidamente importantes na prevenção e mesmo terapêutica dirigida para um determinado grupo populacional. OBJETIVO: Descrever e comparar as taxas de mortalidade por Doença Cardiovascular (DCV) e por Câncer de Mama (CA MAMA) nas mulheres do ABC Paulista, de acordo com os dados do DATASUS. MÉTODO: Estudo Observacional. Baseado em dados 
estatísticos do DATASUS, foram comparadas as taxas de incidência e mortalidade específica por DCV e CA MAMA entre 2008 e 2012. As taxas de mortalidade foram ajustadas por gênero e conforme as faixas etárias. RESULTADO: As taxas de mortalidade (por 100.000 habitantes em determinada população especificada) nas mulheres de região do ABC Paulista foram: 31,3 para CA MAMA e 362,2 para DCV $(\mathrm{p}<0,05)$. Houve diferenças significativas nas taxas de incidência e mortalidade, quando discriminados os dados por município. Após o ajuste por gênero e idade, foi observado que as mulheres apresentaram menor incidência, no entanto maior mortalidade, por doenca cardiovascular, quando comparadas aos indivíduos do sexo masculino. Além disso, comparada com a mortalidade por CA MAMA; a DCV evidenciou taxas crescentes de incidência e mortalidade durante os anos estudados. CONCLUSÃO: Nesse estudo observacional, baseado nos dados do DATASUS, foram encontradas taxas crescentes de mortalidade por Doença Cardiovascular entre mulheres. Comparando-se com a incidência e mortalidade por Câncer de Mama, percebe-se a relevante contribuição da Doença Cardiovascular na mortalidade feminina na região estudada. Considerando isso, pode-se ressaltar a necessidade de ações de Saúde Pública específicas (preventivas e/ou terapêuticas) dirigidas para a população do sexo feminino, com potencial de redução de mortalidade específica nesse grupo.

Palavras-chave: doença cardiovascular; infarto agudo do miocárdio; cancer de mama.

\section{CLI-02 AVALIAÇÃO DO METABOLISMO OXIDATIVO DOS FAGÓCITOS: NBT OU DIHIDROROTADINA?}

Aline Gisele Pena Boanova, Anete Sevciovic Grumach,

Rosemeire Navickas Constantino-Silva

\section{Email: alinegpb@gmail.com}

INTRODUÇÃO: A ativação do metabolismo oxidativo produzindo superóxido e peróxido de hidrogênio é fundamental para a eliminação de bactérias e fungos que produzem catalase (peroxidase). Este princípio pode ser avaliado por duas técnicas: o teste do Nitro Blue Tetrazolium (NBT) e o teste da Dihidrorodamina (DHR). Estes exames permitem o diagnóstico do defeito que caracteriza a Doença Granulomatosa Crônica (DGC) e de portadores da doença. OBJETIVO: Comparar a aplicação dos dois testes de diagnóstico para DGC. MÉTODO: Pacientes com suspeita de distúrbios de fagócitos e indivíduos sadios foram avaliados utilizando-se as duas técnicas: teste do NBT e o ensaio de DHR. O teste do NBT avalia a presença do corante intracelular com mudança para cor azulada após a geração de ânions superóxido; a leitura é feita por microscopia comum de um mínimo de 200 células. O ensaio de DHR utiliza uma substância fluorescente gerada com a ativação do metabolismo oxidativo; a leitura é feita por citometria de fluxo. RESULTADO: Ambos ensaios foram realizados em 67 indivíduos: indivíduos sadios $(n=28)$ e pacientes com suspeita de defeitos do metabolismo oxidativo $(n=39)$. Foram identificados três pacientes com Doença Granulomatosa Crônica (DGC) e igual número de portadoras de DGC, além de três indivíduos com atividade reduzida. Nos portadores heterozigotos para o gene mutado no cromossomo X, duas curvas diferentes são vistas na citometria, representando uma população de células normais e outra com característica de DGC, sem redução da DHR. As medianas para o teste do NBT e DHR em indivíduos sadios foram respectivamente: $2,5 \%$ e $1,83 \%$ sem estímulo, e 99\% e 93,5\% para as células estimuladas. DISCUSSÃO: O ensaio do NBT permitiu o diagnóstico de pacientes com Doença Granulomatosa Crônica, porém avalia cerca de 200 células e necessita ser realizado imediatamente após a coleta. O ensaio de DHR permitiu a deteç̧ão de subpopulações normais de até $0,1 \%$ com pequeno volume de sangue; o número de células avaliado é muito superior (10.000 células) CONCLUSÃO: Considerando-se a objetividade da avaliação, o ensaio de DHR permite melhor e mais rápida avaliação que o teste do NBT.

Palavras-chave: NBT; Dihidrorodamina; Doença Granulomatosa Crônica; metabolismo oxidativo.

\section{CLI-03 COMPARAÇÃO ENTRE INCIDÊNCIA E LOCALIZAÇÃO DA DOR NO OMBRO ENTRE SURFISTAS DE ALTA PERFORMANCE (COMPETIDORES DO WORLD QUALIFYING SERIES) E SURFISTAS DE MENOR PERFORMANCE DE COMPETIÇÕES NACIONAIS}

Nicolle Martin Christofe, Bianca Nicolela Susanna, Julia Pitombo Vella, Guilherme Henrique Vieira Lima

\section{Email: nicollemchristofe@ hotmail.com}

INTRODUÇÃO: O surfe é um esporte que cresceu muito em popularidade nas ultimas décadas, especialmente no Brasil. Com isso, também aumentaram as lesões decorrentes desse esporte. Percebe-se, durante a prática médica, que a queixa de dor nos ombros é freqüente e sua incidência entre os surfistas chega a $20 \%$ de todas as lesões musculoesqueléticas relacionadas ao surfe. OBJETIVO: O objetivo primário deste estudo é comparar a incidência e a localização da dor no ombro de surfistas de alta performance (competidores de uma etapa do campeonato mundial da elite do surfe WQS) e surfistas de menor performance de competições nacionais, correlacionando a fatores que possam influenciar o resultado, como: faixa etária, tempo de prática do esporte, profissionalismo, tempo de profissionalismo, frequência da prática, acompanhamento técnico, treinamento físico e interferência do uso da roupa de neoprene. $\mathrm{O}$ objetivo secundário é identificar as principais causas que expliquem as diferenças encontradas. MÉTODO: Comparação entre avaliação de surfistas realizada durante o campeonato WQS de surfe e campeonatos nacionais de 2016, através de aplicação de protocolo desenvolvido. Os dados serão submetidos à análise estatística, relacionando incidência e localização da dor com os fatores que possam influenciar no resultado. RESULTADO: Espera-se encontrar relevância nos resultados obtidos, identificando possíveis diferenças entre a dor no ombro entre surfistas de maior e menor performance e as principais causas. DISCUSSÃO: Dado o aumento da prática de surfe nas últimas décadas, tanto a nível profissional quanto amador, e o consequente aumento da incidência de lesões, torna-se importante estudar as principais características dessas lesões e suas causas, afim de futuramente desenvolver métodos preventivos eficazes para cada grupo de treinamento.

Palavras-chave: ombro; lesões no surfe; dor no ombro; surfistas.

\section{CLI-04 EFEITO DAS MUTAÇÕES HFE E POSSÍVEIS CAUSAS SECUNDÁRIAS SOBRE OS NÍVEIS DE FERRITINA, CONCENTRAÇÃO DE FERRO HEPÁTICO (LIC) E SATURAÇÃO DE TRANSFERRINA EM PACIENTES PORTADORES DE HEMOCROMATOSE}

José Henrique Miranda Borducchi, Carolina Nicolela Susanna, Igor Luiz Argani, Mirella Regina Cimino Scaff, Davimar Miranda Maciel Borducchi, Vitor Augusto Queiroz Mauad

Email: jhmborducchi@gmail.com

INTRODUÇÃO: Hemocromatose é o termo dado para a manifestação clínica da lesão tissular secundária ao acúmulo de ferro. Definem-se em primárias e secundárias (adquiridas). A Hemocromatose Hereditária $(\mathrm{HH})$ é a principal causa primária, geralmente associada a mutações no locus HFE, no cromossomo 6, que codifica a proteína transmembrana HFE. Dessas mutações, C282Y e H63D são mais prevalentes, em especial em povos do noroeste europeu. Dentre as secundárias, transfusões sanguíneas de repetição, hemoglobinopatias, distúrbios hematopoieticos crônicos e doenças hepáticas merecem atenção. OBJETIVO: Avaliar o efeito das mutações HFE e possíveis causas secundárias sobre o acúmulo tecidual de ferro nesses pacientes. MÉTODO: Foram avaliados 166 pacientes com sobrecarga de ferro do ambulatório de hematologia da Central Clinic de 2008 a janeiro de 2016. Foram pesquisados as mutações do locus HFE, causas secundárias, LIC e perfil ferrico. A análise estatística foi realizada com técnicas de correlação e, em sequência, regressão multilinear para avaliar o impacto individual das variáveis estudadas sobre os níveis de ferritina e concentrações hepáticas de ferro (LIC). RESULTADO: Foram 166 pacientes, 137 homens e 29 mulheres, relação 5:1. Média de idade 50,2 anos (15-84), mediana 51. Indivíduos Wt/Wt contabilizaram 85 pacientes (51\%). Dentre as mutações, H63D/Wt foi a mais prevalente com 48 indivíduos (29\%). As correlações simples não retornaram significantes. Na regressão multilinear obtivemos: genótipos C282Y/C282Y e C282Y/H63F (somados 33, 20\%), presença de hemoglobinopatias e etilismo, além dos níveis ferricos, com impacto significativo sobre LIC $(\mathrm{p}<0.05)$. DISCUSSÃO: Em nosso estudo a hemocromatose secundária representou $51 \%$ dos pacientes. Dentre as mutações, C282Y/C282Y e C282Y/ H63F foram de especial importância para o desenvolvimento de acúmulos ferricos teciduais e estiveram presentes em $20 \%$ dos pacientes. Hemoglobinopatias, ainda que representassem pequena amostra (7 pacientes) tiveram impacto isolado no LIC. O etilismo teve impacto isolado significativo sobre LIC. CONCLUSÃO: Pacientes $\mathrm{HH}$ com HFE C282Y/C282Y e C282Y/H63F e portadores de hemoglobinopatias parecem ter maior tendência ao acúmulo hepático de ferro, independente dos níveis ferricos, e merecem atenção especial. $\mathrm{O}$ etilismo deve ser ativamente combatido nesses pacientes. O impacto evolutivo pende melhor.

Palavras-chave: hemocromatose; sobrecarga de ferro; mutações; ferritina.

\section{CLI-05 ESTUDO DE MARCADORES PRECOCES DE LESÃO RENAL EM DIABÉTICOS TIPO 2}

Marcella Serai, Marcelo Rodrigues Bacc

Email: ma_serai@ hotmail.com

INTRODUÇÃO: O diabetes tipo 2 (DM2) é uma doença crônica de alta prevalência. Ela é caracterizada pelo defeito na secreção e ação da insulina no organismo e ocorre principalmente nos pacientes de meia idade. A DM2 está fortemente associada a outras doenças crônicas muito prevalentes na população mundial como a doença renal em estágio avançado (doença renal crônica), doenças cardiovasculares e a obesidade. OBJETIVO: O objetivo da pesquisa é avaliar se um acompanhamento frequente ao médico com várias coletas de exames laboratoriais contribui para um melhor controle glicêmico e renal em paciente com DM2. MÉTODO: Trata-se de um estudo longitudinal retrospectivo com a formação de dois grupos para comparação de parâmetros laboratoriais entre o período de 2013 a 2016. Os critérios de inclusão são pacientes com diabetes mellitus tipo 2 com idade maior de 21 anos. Os critérios de exclusão são pacientes em hemodiálise, em uso crônico de AINEs, pacientes hospitalizados, pacientes com doenças autoimunes, infeccõos crônicas ou HIV. As variáveis de interesse são creatinina sérica, microalbuminúria e hemoglobina glicada. RESULTADO: O estudo apresenta 85 pacientes, sendo 44 pacientes do sexo feminino e 41 do sexo masculino. Dos 85 pacientes do período analisado, $65,88 \%$ apresentaram apenas uma dosagem de creatinina, $18,82 \%$ apresentam de 1 
a 3 dosagens de creatinina e 15,29\% apresentam mais de 3 dosagens de creatinina. A média de creatinina e hemoglobina glicada dos pacientes com mais do que uma coleta foi de, respectivamente, $1,04 \mathrm{mg} / \mathrm{dL}(+/-0,55)$ e $8,35 \%(+/-4,45)$. Já os com coletas múltiplas apresentaram discreta variação tendo o próprio paciente como controle de si mesmo nos diversos momentos analisados. CONCLUSÃO: Quantas vezes um paciente com doenças crônicas deve retornar ao longo do ano de modo que sua enfermidade fique compensada? O número de vezes realmente importa? Ao analisarmos os dados desta série retrospectiva observamos que a grande maioria dos pacientes que tiveram múltiplas consultas e coletas para avaliar o controle glicêmico não se beneficiou em termos de melhora de função renal ou nível glicêmico. Além disso, não houve diferença significativa quando comparados com pacientes que tiveram apenas um atendimento no mesmo período.

Palavras-chave: Diabetes; Doença renal.

\section{CLI-06 PERCEPÇÃO DO PACIENTE ONCOLÓGICO E DE SEU ACOMPANHANTE SOBRE CUIDADOS PALIATIVOS}

Marília Arrais Garcia, Mariana Carvalho Gouveia, Danielle Yumi Akaishi, Clarisse Kaori Fujishige, Daniel de Iracema Gomes Cubero

\section{Email: marilia.arrais@ hotmail.com}

INTRODUÇÃO: Os Cuidados paliativos são uma área de atuação da medicina que visa melhorar a qualidade de vida de pessoas portadoras de doenças incuráveis. Apesar de sua importância no tratamento integral de pacientes oncológicos, os Cuidados Paliativos ainda são pouco difundidos em nosso meio. OBJETIVOS Avaliar o entendimento de pacientes oncológicos e de seus acompanhantes acerca dos cuidados paliativos e elaborar cartilha educativa. MÉTODOS: A primeira fase do projeto consiste no diagnóstico do conhecimento da população a respeito dos cuidados paliativos. Para isto, elaborou-se questionário a ser aplicado por entrevistador sobre o tema. Na segunda parte do projeto, a partir dos resultados dos questionários, será elaborada e divulgada uma cartilha educativa sobre os cuidados paliativos, a fim de difundir informação sobre o tema. Por fim, os questionários serão reaplicados com o objetivo de avaliar a contribuição da cartilha para o conhecimento desta população. RESULTADO: Neste trabalho apresentamos a primeira fase do projeto. No período de Março a Abril de 2016 foram entrevistadas 194 pessoas, sendo 116 delas mulheres e 78 homens, com idade mediana de 56 anos, a maioria com nível de escolaridade Ensino Fundamental Incompleto. Neste grupo, para a pergunta "Você sabe o que são cuidados paliativos", 13,91\% responderam "sim"; 9,79\% responderam "tenho uma leve ideia" e 76,28\% responderam "não". Daquelas que responderam "sim" e "tenho uma leve ideia" (23,71\%), 6,52\% acreditavam que os cuidados paliativos serviam apenas para pacientes com câncer $19,56 \%$ julgavam que os cuidados tinham como objetivo a cura da doença e $73,91 \%$ acreditavam que aumentava o tempo de vida. DISCUSSÃO: Este trabalho mostra o conhecimento que a população de um ambulatório de Oncologia tem acerca dos cuidados paliativos. CONCLUSÃO: Percebemos que ainda há muito que ser feito para ampliar os conhecimentos sobre o tema.

Palavras-chave: cuidados paliativos; oncologia; conhecimento; cuidador

\section{CLI-07 QUAL O IMPACTO DAS EXTUBACÕES NOTURNAS/FINAIS DE SEMANA VERSUS EXTUBAÇÕES DIURNAS/DIAS DE SEMANA NO DESFECHO DE CRIANÇAS CRITICAMENTE ENFERMAS?}

Thais Suelotto Machado Fonseca, Carolina Bistacco Moreira,

Marcelo Cunio Machado Fonseca, Paulo Sérgio Lucas da Silva

\section{Email: thais.smfonseca@gmail.com}

INTRODUÇÃO: Vários estudos sugerem piores desfechos quando pacientes criticamente doente necessitam de cuidados médicos durante a noite ou em finais de semana, no entanto, se crianças devem ou não ser extubadas apenas durante o dia e dia de semana ainda não foi estudado. OBJETIVO: Comparar os desfechos e complicações de extubações realizadas durante o dia e dia de semana (grupo 1) versus extubações realizadas durante a noite e/ou finais de semana (grupo 2). MÉTODO: Estudo retrospectivo de 5 anos de duração em uma unidade de cuidados intensivos pediátricos (UCIP). Foram selecionados todos os pacientes $<16$ anos que receberam ventilação mecânica $(\mathrm{VM})>24$ horas.O desfecho primário foi o tempo decorrido para a primeira extubação planejada. RESULTADO: Do total de 480 pacientes, 346 (72\%) eram do grupo 1 e 134 (28\%) do grupo 2. Pacientes do grupo 1 tiveram uma maior mediana de tempo de intubação até a primeira extubação planejada ( 6 vs 5 dias,p=0.007), assim como uma maior mediana de tempo total de ventilação mecânica ( 7 vs 6 dias,p=0.01) e de permanência em UCIP (13 vs 11 dias, $\mathrm{p}=0.02$ ) comparado aos pacientes do grupo 2 . Curva de Kaplan-Meier mostrou que pacientes do grupo 1 tinham uma maior probabilidade de permanecerem mais tempo intubados até a primeira extubação (log-rank test: $\mathrm{p}=0.006$; hazard ratio: 5.05). O efeito do tempo de extubação permaneceu inalterado após ajuste de covariáveis clinicas. Não houve diferenças nas taxas de complicações (reintubação, pneumonia associada à ventilação mecânica e mortalidade). DISCUSSÃO: Duas hipóteses foram levantadas para explicar os resultados. Na primeira hipótese, os pacientes do grupo 2 foram mais apropriadamente identificados como candidatos para extubação, enquanto na segunda, os pacientes candidatos para extubação noturna e/ou em finais de semana foram adiados para extubações no período diurno e dias de semana, assim, tiveram seus períodos de desmame prolongados desnecessariamente, aumentando o tempo de VM e indicando baixa aderência aos protocolos da instituição. CONCLUSÃO: Pacientes do grupo 2 tiveram um desfecho mais favorável e taxas de complicações similares comparado aos pacientes do grupo 1. Esses resultados sugerem que não há motivos para se retardar extubações quando preenchido seus critérios. Estudos adicionais são necessários para confirmar esses achados.

Palavras-chave: crianças; extubação; desfechos; terapia intensiva pediátrica.

\section{CLI-08 URTICÁRIA CRÔNICA E COMORBIDADES RELACIONADAS}

Renata Costa Junqueira, Bruna De Martino Martella, Juliana Altieri Vasconcelos, Juliana Milhomem Tamanini, Renata Costa Junqueira, Carlos D` Apparecida Santos Machado Filho, Roberta Fachini Jardim Criado

\section{Email: renatinhajunqueira@ hotmail.com}

INTRODUÇÃO: A urticária crônica (UC), afecção cutânea inflamatória que acomete cerca de 15 a 30\% da população geral, apresenta características como a presença de anticorpos e de citocinas pró inflamatórias. A produção dessas substâncias mediadoras permite possíveis associações entre UC e outras comorbidades, de também elevada prevalência na população, com achados laboratoriais semelhantes como doenças autoimunes e Síndrome Metabólica. OBJETIVO: Avaliar a associação entre UC e doenças sistêmicas (síndrome metabólica, artropatias, doença vascular periférica, do trato gastro-intestinal). MÉTODO: Estudo transversal, descritivo, de base clínica. O levantamento de dados ocorreu pela análise de prontuários de 95 pacientes do Ambulatório de Urticária of Departamento de Dermatologia da Faculdade de Medicina do ABC (FMABC), que estiveram em tratamento ambulatorial rotineiro de abril de 2014 a abril de 2015, mediante assinatura de um Termo de Consentimento Livre e Esclarecido - aprovado pelo Comitê de Ética em pesquisa da FMABC e Plataforma Brasil - pelo paciente durante suas consultas de rotina no Ambulatório de Urticária. Análise estatística: Para analisar a associação das doenças foi utilizado o teste estatístico Qui-quadrado, considerando sexo feminino e masculino e a doença. Considerou-se relevância estatística as relações com p abaixo de $0,05(\mathrm{p}<0,05)$; o nível de significância adotado foi de $95 \%$. O programa utilizado foi o Stata 11.0. RESULTADOS: Artropatias foram contatadas em aproximadamente $55 \%$ das mulheres do estudo e $17 \%$ dos homens $(\mathrm{p}=0,001 / \mathrm{p}<0,05)$. Houve significância estatística na relação entre doença vascular e urticária crônica $(\mathrm{p}=0,022 / \mathrm{p}<0,05)$. Não foi encontrada associação relevante estatisticamente para se afirmar que haja confiança na associação entre diabetes mellitus e UC ( $\mathrm{p}=0,801 / \mathrm{p}>0,05)$. Não se obteve relevância na relação com doenças do trato gastrointestinal $(\mathrm{p}=0,437 / \mathrm{p}>0,05)$.

Palavras-chave: urticaria; comorbidades; gastropatias; artropatias.

\section{EPIDEMIOLÓGICO}

\section{EPI-01 A ATIVIDADE PROFISSIONAL NO ATENDIMENTO DA PARADA CARDIORRESPIRATÓRIA EM AMBIENTE EXTRA-HOSPITALAR}

Juliana Seidler Canonaco, Isabela Corralo Ramos, Caroline Awoki Ferrandez, Gabriella Erine Moretti dos Santos, Jhony Vaz Marques, Adriana de Oliveira Camboim, Antônio Carlos Palandri Chagas, João Fernando Monteiro Ferreira, Miguel Moretti

Email: julianacanonaco@ hotmail.com

INTRODUCÃO: A redução da morbimortalidade em vítimas de parada cardiorrespiratória (PCR) depende da eficácia do atendimento. Se iniciado cedo, as chances de sucesso da ressuscitação cardiopulmonar (RCP) aumentam. Por isso, determinadas etapas devem ser iniciadas antes do atendimento hospitalar por testemunhas no local. Estudos sugerem população desinformada e não capacitada OBJETIVO: Registrar através de um questionário sobre PCR/RCP o quanto a população está preparada para essa situação e apontar as possíveis diferenças de atitude entre profissionais da área da saúde (PAS) e leigos (PL). MÉTODO: Trata-se de pesquisa aplicada, através de um questionário do tipo aberto e fechado, quanti-qualitativo com perguntas sobre a PCR e os procedimentos de RCP. Estudo transversal por amostra de conveniência, a qual será utilizada como reflexo de uma população, e não probabilística. RESULTADO: Entre Ago. a Out. de 2015 foram aplicados 319 questionários. Desses, 52 eram PAS, os demais (267) foram considerados PL. Disseram já ter presenciado uma PCR: $12,7 \%$ dos PL e 53,8\% dos PAS. O PL presenciou mais em locais públicos e em residências $(85,3 \%)$ e os PAS presenciaram mais em locais de trabalho e públicos (89,3\%). Sobre o reconhecimento da PCR (PAS 63,5\% vs 21 , $3 \%$ PL $p<0,001$ ), os que se sentiram aptos ao atendimento (PAS $57,7 \%$ vs $20,6 \%$ PL $\mathrm{p}<0,001$ ) e os que sabem o que fazer (PAS $67,3 \%$ vs $38,9 \%$ PL $p=0,002$ ) há diferenças significativas entre os grupos. Entre os que disseram que saberiam o que fazer, os PAS chamam menos ajuda que os PL, mas adotam atitudes mais ativas como realizar compressão torácica e ventilação, mesmo sem significância estatística $(\mathrm{p}=0,49)$. Com relação ao pedido de ajuda (PAS $37,1 \%$ vs $43,3 \%$ PL), ambos os grupos não sabem qual serviço deve ser chamado (PAS $53,8 \%$ vs $44,4 \%$ PL). CONCLUSÃO $\mathrm{Na}$ amostra analisada, mesmo que o PAS diga que sente-se apto ao atendimento e que sabe o que fazer, esses números ainda são baixos e praticamente iguais a da 
população leiga. Esses dados combinados com os de outros estudos reforçam a necessidade de treinamento e capacitação de todas as pessoas, não só de determinadas áreas profissionais

Palavras-chave: parada cardiorrespiratória; capacitação; ressuscitação.

\section{EPI-02 ADERÊNCIA AO TRATAMENTO EM PACIENTES BRASILEIROS COM ANGIOEDEMA HEREDITÁRIO (AEH): VALIDAÇÃO E APLICAÇÃO DE UM QUESTIONÁRIO}

\section{Anderson Abdon Barbosa, Anete Sevciovic Grumach}

\section{Email: andersonabdon@gmail.com}

INTRODUÇÃO: Angioedema hereditário (AEH) é uma doença autossômica dominante que afeta aproximadamente 1 a cada 50.000 indivíduos. Ela é caracterizada por episódios súbitos e paroxísticos de edema em tecidos subcutâneos e de mucosa que podem pôr em risco a vida do paciente. Estudos prévios sobre a aderência ao tratamento em pacientes com AEH nos EUA e Europa sugerem uma melhora na abordagem do AEH. Não há dados semelhantes sobre a abordagem do AEH nos pacientes sul-americanos. OBJETIVO: Desenvolvimento e aplicação um questionário para avaliar a aderência ao tratamento de pacientes com $\mathrm{AEH}$ no Brasil. MÉTODO: A pesquisa foi desenvolvida a partir de um questionário para avaliar as variáveis que influenciam o diagnóstico e tratamento dos pacientes brasileiros com AEH. O questionário foi validado após avaliação por 18 especialistas brasileiros na área. A associação brasileira de pacientes com AEH enviou por email um endereço eletrônico para o questionário para os pacientes registrados em todo país, após aceitação de termo de consentimento. RESULTADO: 90 pacientes responderam ao questionário (67 mulheres; 23 homens), 83\% ( $\mathrm{n}=73)$ dos pacientes afirmam ter outros membros da família com o diagnóstico e 71,1\% $(n=64)$ dos pacientes relatam casos de morte na família devido à inchaço na garganta ou asfixia. Concomitantemente, cerca de $64 \%(n=53)$ afirmam não terem necessitado de atendimento de emergência nos últimos 6 meses. Cerca de 79\% $(n=71)$ afirmam ter um medo constante de perder a vida devido ao seu diagnóstico. Apesar do risco que AEH traz 60\% $(n=54)$ dos pacientes afirmam ter membros da família com AEH sem tratamento para a doença. A aderência ao tratamento em pacientes com $\mathrm{AEH}$ parece estar não ser dependente somente de como os pacientes afirmam estar comprometidos (48\% deles afirmam ser muito comprometidos com o tratamento) ou satisfeitos ( $49 \%$ afirmam estar muito satisfeitos com o tratamento) com o seu tratamento. CONCLUSÃO: Momentos críticos parecem estimular a aderência ao tratamento em boa parte dos pacientes com AEH. Os resultados mostram que os pacientes com $\mathrm{AEH}$ têm uma ideia da gravidade do seu diagnóstico, mas eles não refletem no quão importante o comprometimento com o tratamento pode diminuir o medo constante de risco de vida trazido pelas crises de edema da doença.

Palavras-chave: Angioedema hereditário; aderência ao tratamento.

\section{EPI - 03 ASSOCIAÇÃO ENTRE INDICADORES DE ADIPOSIDADE E MATURACCÃO SEXUAL EM CRIANÇAS E ADOLESCENTES BRASILEIROS}

Livia Akemi Ramos Takahashi, Francisco Winter dos Santos Figueiredo, Fernando Adami

\section{Email: liviaart@ hotmail.com}

INTRODUÇÃO: A obesidade é um fator de risco para o desenvolvimento de doenças crônicas, que causam grande mortalidade no mundo. Uma forma de se medir o grau de obesidade, é através de indicadores de adiposidade. Durante a maturação sexual, esses indicadores começam a se sobressair, de forma a permitir questionar se um processo fisiológico e natural (como a maturação sexual) pode dar origem a um risco de mortalidade (como a obesidade). OBJETIVO: Analisar a influência do status de maturação sexual sobre os indicadores de adiposidade corporal em crianças e adolescentes com idade entre 7 e 14 anos de Florianópolis, SC, Brasil. MÉTODO: O estudo foi realizado com base em um banco de dados coletado em 2007 na cidade de Florianópolis, Santa Catarina, Brasil, com meninos e meninas de 7 a 14 anos de idade. Maturação sexual foi avaliada segundo critérios de Tanner e indicadores de adiposidade avaliados por adipômetro e cirtometria. As variáveis quantitativas foram descritas por medidas de tendência central e de dispersão de acordo com a normalidade dos dados, que será avaliada pelo teste de Shapiro-Wilk. As variáveis qualitativas foram descritas por frequência absoluta e relativa, e analisadas pelo teste de Qui-quadrado. O nível de significância adotado foi de $95 \%$. As análises foram realizadas no Stata 11.0. RESULTADOS: A prevalência de excesso de peso atual, com respectivo intervalo de confiança de $95 \%$, foi de $34,9(31,3-38,6 \%)$ e de 25,0 $(21,9-32,7 \%)$ em meninos e meninas, respectivamente $(\mathrm{p}<0,001)$. Observamos que, nos meninos, não há tendência de diferença nos indicadores de adiposidade em cada faixa etária segundo status de maturação sexual. Somente em algumas faixas etárias houve diferença nos valores de adiposidade: 11 a $11,5(\mathrm{p}=0,012)$ e 12,5 a 13 anos $(\mathrm{p}=0,035)$ para dobra do tríceps; 12,5 a 13 anos $(\mathrm{p}=0,053)$ para dobra da panturrilha; 11,5 a 12 anos $(\mathrm{p}=0,059)$ para circunferência da cintura; 11 a 11,5 anos $(\mathrm{p}=0,035)$ para somatório das dobras. A literatura é rica em estudos sobre fatores de risco para o aumento de indicadores de adiposidade, sendo que em alguns aparece uma relação entre a maturação sexual precoce e a obesidade semelhante ao encontrado neste. CONCLUSÃO: Há uma associação entre a maturação sexual precoce e o elevado índice de adiposidade, que aceita a hipótese de que a maturação sexual precoce influencia no desenvolvimento de obesidade.

Palavra-chave: adiposidade; maturação sexual; obesidade.

\section{EPI - 04 AVALIAÇÃO DE HIPOTIREOIDISMO SUBCLÍNICO ENTRE PACIENTES DA ENDOCRINOLOGIA PEDIÁTRICA}

Gabrielle Gomes de Souza, Renata Gomes Castello, Carolina Yone Tamashiro, Marina Martinelli Sonnenfeld, Vanessa Akemi Imaizumi, Karina Michelani de Oliveira

Email: gabigomes0810@gmail.com

INTRODUÇÃO: O hipotireoidismo subclínico (HS) cursa com TSH elevado, T4 livre normal e pouca sintomatologia, dificultando seu diagnóstico. Como exames complementares, podem ser usados o ultrassom (USG) de tireoide e a pesquisa de autoanticorpos. Quando a doença evolui para o hipotireoidismo franco, o quadro é grave, principalmente em neonatos. O HS por vezes apresenta sinais clássicos da doença franca: baixa estatura, bócio, ganho de peso e alopécia. O tratamento é indicado em função do TSH e deve ser acompanhado com atenção. OBJETIVO: Avaliar epidemiologia, clínica e tempo de compensação de TSH de pacientes com HS. MÉTODO: Estudo transversal e retrospectivo de análise de prontuários da Endocrinologia Pediátrica da FMABC. Foram pesquisados: idade, sexo, queixa inicial, TSH e T4 livre, USG, autoanticorpos tireoidianos, IMC, histórico familiar, bócio, doenças e sintomas associados e tempo para compensação de TSH. Foram excluídos pacientes com hipotireoidismo congênito assim como menores de 3 meses e maiores de 18 anos. RESULTADO: Foram consideradas 96 crianças $(53,1 \%$ meninas), com idade média de 9,82 anos. A maior parte veio encaminhada da Neurologia e da Hebiatria por alteração em exames. A média de TSH foi de 10,8902 $\mathrm{mU} / \mathrm{L}$ e a de T4 livre 2,159 mg/dl. A USG de tireoide foi em sua maioria normal. No histórico familiar, um ou mais parentes tinham hipotireoidismo em $36 \%$ dos casos. Um terço das crianças estava acima do peso e $38 \%$ tinham dislipidemia e cefaleia. A prevalência de bócio foi de $17 \%$ e a de autoanticorpos $50 \%$. A compensação de TSH na maioria ocorreu em 6 meses. Era esperada maior participação feminina. Questionou-se o porquê de especialidades solicitarem TSH e T4 livre em suas rotinas. A média de hormônios tireoidianos cima de $10 \mathrm{mU} / \mathrm{L}$ foi favorável a alguns autores que incentivam a introdução do tratamento medicamentoso desses pacientes. A USG normal gerou a dúvida se o HS em questão não seria, na verdade, um distúrbio puberal auto resolutivo, sugerindo a necessidade de mais pesquisas de diagnósticos diferenciais entre tais pacientes. Bócio e autoanticorpos estavam dentro do esperado e o tempo de compensação de TSH foi abaixo do esperado, indicando eficácia no tratamento. CONCLUSÃO: O HS é uma doença relevante, que merece maior atenção quando o TSH supera $10 \mathrm{mU} / \mathrm{L}$, devendo sempre serem considerados possíveis diagnósticos diferenciais.

Palavra-chave: Hipotireoidismo Subclínico; Pediatria; Endocrinologia

\section{EPI-05 CÂNCER GÁSTRICO - REVISÃO DE 40 ANOS: ESTUDO CLINICO-HISTOLÓGICO DE 1838 CASOS NA REGIÃO DO GRANDE ABC PAULISTA - SÃO PAULO, BRASIL}

Bernardo Corrêa, Gabriel Calazans, Leandro Mifune, Guilherme Leite, Caio Carrete Mazzei, Raphael Federicci Haddad, Matheus Masuda, Ethel Chehter, Ana Maria Mader

\section{Email: bernardobc@hotmail.com}

INTRODUCÃO: O câncer gástrico (CG) é o quinto tipo de tumor maligno mais comum e é a segunda principal causa de morte relacionada com câncer no mundo. Porém, a epidemiologia do CG não é muito conhecida no Brasil, especialmente na região do $\mathrm{ABC}$, apesar da sua importância como um centro econômico e industrial. OBJETIVOS: Em pacientes operados por CG na região do $\mathrm{ABC}$ (estado de São Paulo, Brasil): 1. Conhecer perfil da população, 2. Verificar possíveis padrões de mudança ao longo das décadas e no grupo por faixa etária, e 3. Conhecer as principais características anatomopatológicas dessas neoplasias. MÉTODOS: Análise retrospectiva entre 1974 e 2014 baseada na revisão de 1.838 laudos anatomopatológicos de diagnósticos de casos de CG confirmados pelo Departamento de Patologia da Faculdade de Medicina do ABC. Investigamos as características morfológicas: tipo de neoplasia (segundo classificação de Lauren), região gástrica, características e estádio da neoplasia; dividimos o trabalho em dois grupos: de acordo com a idade (maior e menor do que 60 anos) e de acordo com as 4 décadas. RESULTADOS: Ao longo das 4 décadas, houve uma predominância do CG no sexo masculino $(68,8 \%)$ acima da $5^{\text {a }}$ década de vida $(77,3 \%)$, sem outras diferenças epidemiológicas. A neoplasia mais frequente foi o adenocarcinoma $(94,3 \%)$ e o tipo, o difuso $(50,7 \%)$. A principal localização é o antro (47,3\%), sendo a classificação de Borrman III mais prevalente $(61,8 \%)$. Comparando os pacientes em relação à idade (maior e menor do que 60 anos), percebemos que a neoplasia mais frequente em ambos é o adenocarcinoma, já o tipo mais frequente naqueles abaixo de 60 anos foi o difuso, e no outro grupo, o intestinal. Os resultados foram semelhantes em relação a região do tumor e a classificação de Borrman, sendo o antro gástrico e Borrman III mais prevalentes nesses grupos. CONCLUSÃO: Os resultados sugerem que a região do $\mathrm{ABC}$ tem dados epidemiológicos similares aos da literatura dos países desenvolvidos, devido ao alto grau de desenvolvimento. Contudo, o grande número de casos em estágio avançado e a alta incidência na região não cárdica são sinais de 
subdesenvolvimento. Portanto, há características de ambos os lados do desenvolvimento, sendo necessário criar uma nova abordagem dessa doença com o objetivo de antecipar o diagnóstico e obter um tratamento mais eficaz e menos agressivo.

Palavras-chave: câncer gástrico; de gênero; patologia; epidemiologia.

\section{EPI-06 CARACTERIZAÇÃO DA VARIABILIDADE DA FREQUÊNCIA CARDÍACA EM MULHERES QUE VIVEM COM AIDS E SÍNDROME LIPODISTRÓFICA}

Karine Risério Rodrigues, Daniel Yvamoto Fujihara, Luiz Carlos de Abreu, Fernando Rocha Oliveira

\section{Email: karine_riserio@ hotmail.com}

INTRODUCÃ̃: Atualmente estima-se que 718 mil indivíduos vivam com HIV e AIDS no Brasil. Uma das comorbidades associadas ao uso de HAART em pacientes com HIV é a síndrome lipodistrófica (SL), diretamente relacionada ao maior risco de coronariopatias. OBJETIVO: Descrever a modulação autonômica cardíaca em mulheres que vivem com AIDS e lipodistrofia. MÉTODO: Trata-se de um estudo transversal em mulheres que vivem com AIDS e SL e são acompanhadas pelo serviço de referência do Programa Municipal de DST/AIDS da Prefeitura de São Bernardo do Campo (Ambulatório de Lipodistrofia). Após avaliação inicial com dados antropométricos e, a partir dos índices lineares de variabilidade da frequência cardíaca (VFC) nos domínios do tempo (RMSSD e SDNN) e da frequência (LF HF e LF/HF), foi analisada a modulação autonômica cardíaca dessas pacientes. RESULTADO: Na amostra composta por 28 mulheres, sendo 17 do grupo com AIDS e SL e 11 do grupo com AIDS e sem SL, foi encontrada associação estatisticamente significativa para as seguintes variáveis: colesterol total, LDL e triglicérides, sendo que os valores médios de colesterol total, LDL e triglicérides foram mais altos no grupo de mulheres com SL do que no grupo de mulheres sem SL (213 vs $180 \mathrm{mg} / \mathrm{dl}, 127$ vs $100 \mathrm{mg} / \mathrm{dl}, 213$ vs $132 \mathrm{mg} / \mathrm{dl}$ e $101 \mathrm{vs} 93 \mathrm{mg} / \mathrm{dl}$, respectivamente). Os índices do domínio da frequência de alta frequência (HF) e de baixa frequência (LF) não apresentaram resultados com significância entre os grupos. A análise do perfil lipídico das pacientes com HIV com SL e das pacientes com HIV e sem SL, ambas em uso de HAART, deve levar em consideração os fatores genéticos e o tempo de uso de HAART na determinação do desenvolvimento da SL. Apesar da SL apresentar importante influência na determinação da modulação autonômica cardíaca, a análise dos índices do domínio da frequência de (HF e LF) não revelou resultados com sig nificância estatística entre os grupos com SL e sem SL. A restrição estatística desse estudo deve-se em grande parte à amostragem pequena, o que dificulta a discussão dos dados encontrados. CONCLUSÃO: O estudo não verificou significância estatística durante a análise dos índices do domínio da frequência entre os grupos com e sem SL. O fato da amostra ser pequena e restrita a um centro de referência limita a descrição da modulação autonômica cardíaca do grupo em estudo.

Palavras-chave: AIDS; Lipodistrofia; Variabilidade da Frequência Cardíaca.

\section{EPI-07 CARCINOMATOSE PERITONEAL. ANALISE DOS PACIENTES ASSISTIDOS NO CENTRO HOSPITALAR DO MUNICÍPIO DE SANTO ANDRÉ/SP}

Raiff Yusser Saad Rached, Ramon Félix Martins Fernandes, Livia Akemi Ramos Takahashi, Nicolas Augusto Cabral Ribeiro, Lívia Alexandre Martins, Paulo Roberto Giovannetti Massabki, Sandra Di Felice Boratto, Afonso Oetting Junior, Carlos Eduardo Rodante Corsi

\section{Email: raiff_rached@ hotmail.com}

INTRODUÇÃO: Carcinomatose peritoneal é descrito como uma condição na qual o câncer possui caráter agressivo e é resultado da propagação da metástase no peritônio, geralmente de cânceres de ovário e colorretal. Além disso, trata-se de uma doença rara e que geralmente é uma complicação de um tumor primário. O diagnóstico é baseado, primeiramente, na avaliação clínica, na avaliação de exames de imagem e, por último na avaliação do achado cirúrgico com citologia do líquido peritoneal e anátomo-patológico de material biopsiado. A evolução da doença e o seu tratamento podem variar de acordo com o gênero, idade e o tipo de tumor primário. OBJETIVO: Identificar qual é o perfil epidemiológico de pacientes diagnosticado com carcinomatose peritoneal que foram submetidos a cirurgia curativa no ano de 2016, no Centro Hospitalar do Município de Santo André-SP. MÉTODO: Trata-se de um estudo transversal no Centro Hospitalar do Município de Santo André-SP no ano de 2016 na qual foram analisados os prontuários dos pacientes diagnosticados com carcinomatose peritoneal pelo serviço de patologia clínica e foram submetidos a cirurgia diagnóstica no próprio Hospital para determinação da epidemiologia regional dessa doença. Para análise descritiva dos resultados foi utilizado o programa estatístico Stata 11.0. RESULTADO: Diante dos dados obtidos, viabiliza-se a correlação entre as variáveis epidemiológicas, como gênero, faixa etária, comorbidades, de modo a esclarecer qual é a melhor conduta e quais grupos se encontram em maior risco. Além disso, saber qual é a causa que acomete os pacientes internados nessa instituição pode ser parâmetro para direcionar políticas de saúde, visando amenizar a conjuntura dos pacientes acometidos. Por mais que seja inexorável o desenvolvimento de carcinomatose peritoneal, conseguinte ao agravamento do quadro clínico do paciente, é possível diminuir a severidade do prognóstico, através do estudo de perfis epidemiológicos e do desenvolvimento de métodos paliativos. CONCLUSÃO: A análise das características dos pacientes com carcinomatose assistidos no Centro Hospitalar pode ser utilizado para produzir conhecimento que promova a saúde individual através de medidas de alcance coletivo na região do Grande $\mathrm{ABC}$.

Palavras-chave: carcinomatose; cirurgia; peritônio; assistência integral a saúde.

\section{EPI-08 CONJUNTIVITE ALÉRGICA EM ÁREAS INDÚSTRIAS NO BRASIL-UM ESTUDO EPIDEMIOLÓGICO}

Priscila Fernandez Contreiro, Aline Rodrigues Loreto, Ana Saito Junqueira Aguiar, Rafael Cunha de Almeida, Lourdes Conceição Martins, Maria Angela Zacarelli-Marino

Email: priscila_contreiro@ hotmail.com

INTRODUÇÃO: Doenças dos olhos são comuns incluindo as conjuntivites. A conjuntivite Alérgica (CA) caracteriza-se pela inflamação dos olhos resultante de reações alérgicas a substâncias como esporos de mofo, cloro de piscina e também poluentes atmosféricos. OBJETIVO: Investigar conjuntivite alérgica em indivíduos que vivem nas proximidades de grandes áreas industriais que fabricam derivados de petróleo no estado de São Paulo, Brasil. MÉTODO: Entre 2003 e 2005, 2.004 indivíduos, de 8 a 72 anos de idade, foram avaliados através de um questionário; CA foi baseada nos seus relatos de sinais e sintomas. As respostas CA foram consideradas positivas quando informaram que o diagnóstico havia sido feito por um oftalmologista. Foram selecionados aqueles que se apresentaram com CA e que estavam tratando. Os indivíduos foram divididos em 2 grupos. Grupo A: 1.002 moradores que vivem perto de áreas industriais que fabricam derivados de petróleo (Região 1), e Grupo B: 1.002 os que vivem em áreas distantes da Região 1, com indústrias predominantemente de aço (Região 2). RESULTADO: Em ambas as regiões, entre um total geral de 2.004 habitantes, $405(20,21 \%)$ residentes tinham CA. Nas regiões 1 e 2 , houve uma diferença altamente significativa no número de residentes com CA $(\mathrm{p}<0,001)$, com 284 $(28,34 \%)$ residentes da região 1 e $121(12,07 \%)$ residentes na Região 2 . Em adultos, observou-se uma diferença significativa entre a Região 1, com $205(29,16 \%)$ residentes e região 2 com $98(12,56 \%)$ residentes com CA $(\mathrm{p}<0,001)$. Em crianças e adolescentes, foi observada uma diferença significativa entre a Região 1, com 79 $(26,42 \%)$ residentes e Região 2 com $23(10,36 \%)$ residentes com CA ( $p<0,001)$. Analisando a literatura, verificamos a relação dos poluentes atmosféricos com o aparecimento da conjuntivite alérgica. No Estado de Pernambuco, foi realizado um estudo dos impactos ambientais pela implantação da refinaria de petróleo, e que os gases liberados no processo causam irritação ocular. Correlacionando com os dados apresentados no trabalho. CONCLUSÃO: Nossos resultados mostraram uma diferença significativa na taxa de CA em residentes que vivem nas proximidades de grandes áreas industriais de que fabricam derivados petróleo (Região 1), em comparação com os residentes que vivem nas proximidades das áreas industriais de aço (Região 2), e abre o campo para novas áreas de pesquisa Palavras-chave: conjuntivite alérgica; poluentes; poluentes industriais.

\section{EPI - 09 CORRELAÇÃO ENTRE ÍNDICE DE DESENVOLVIMENTO HUMANO POR MUNICÍPIO E MORTALIDADE POR ACIDENTE VASCULAR ENCEFÁLICO NAS CAPITAIS BRASILEIRAS}

Diego Monteiro de Melo Lucena, Sidnei José Galego, Marina Raphe Matar, Fernando Mayo Soares, Ramon Felix Fernandes, Luisa Emanuela Biseo Henriques, Henrique Siqueira, Benoit Jean Nemr, João Antônio Correa, Fernando Adami

\section{Email: lucenadiego@ hotmail.com}

INTRODUÇÃO: O Acidente Vascular Cerebral (AVC) é a principal causa de morte no Brasil e a segunda no mundo. A importância epidemiológica dessa mazela pode ser provada pela existência de vários estudos, principalmente nos países desenvolvidos, que apontam associação entre indicadores socioeconômicos, incidência e mortalidade por Acidente Vascular Cerebral, mas nenhum utiliza dados populacionais do Brasil. OBJETIVO: identificar associação entre Índice de Desenvolvimento Humano por Município (IDHM), incidência de internações e mortalidade por Acidente Vascular Cerebral em residentes das capitais brasileiras em 2010. MÉTODO: Foi realizado um estudo ecológico com dados do Índice de Desenvolvimento Humano por Município estratificado por renda, longevidade e educação obtidas do site do Programa das Nações Unidas para Desenvolvimento (PNUD) e de incidência de internações e mortalidade por AVC em residentes do Brasil no ano de 2010, que foram obtidos do site do Departamento de Informações do Sistema Único de Saúde do Brasil (DATASUS). RESULTADO: Os resultados não demonstraram correlação entre mortalidade por AVC e IDHM (Spearman's rho=0,140; $\mathrm{p}=0,484$ ) Além disso, não houve correlação entre mortalidade por AVC e cada subclassificação de IDHM sendo que houve correlação fraca, positiva e não significante para mortalidade por AVC e IDHM para renda (Spearman`s rho $=0,273 ; \mathrm{p}=0,167$ ) e para mortalidade por AVC e IDHM para longevidade (Spearman`s rho $=0,212 ; \mathrm{p}=0,287$ ), além de uma correlação fraca, negativa e não significante (Spearman`s rho=-0,046; $\mathrm{p}=0,817$ ) para mortalidade por AVC e IDHM para educação. Apesar de muitos estudos demonstrarem uma associação indireta entre AVC e condições socioeconômicas, o IDHM não apresentou força de correlação com os indicadores da doença 
podendo este índice não ser adequado para a avaliação epidemiológica da doença ou até mesmo as subclassificações do IDHM apresentarem uma metodologia in suficiente para a análise da influencia na doença. CONCLUSÃO: A mortalidade por AVC nas capitais brasileiras parece não estar associada aos fatores socioeconômicos que compõem o IDHM e suas subclassificações, necessitando estudos que demonstrem um cenário mais claro sobre a interferência de outros fatores socioeconômicos na morbimortalidade dessa doença.

Palavras-chave: Acidente Vascular Cerebral; Epidemiologia; Mortalidade; Economia.

\section{EPI - 10 DERMATITE EM ÁREAS INDUSTRIAIS NO BRASIL: UM ESTUDO EPIDEMIOLÓGICO}

Camilla Vilela Giacovone, Hullie Hottgen Martins, Mileni Emy Takara, Bruna Elena Graciano Falcone, Thalles Zaccarelli Balderi, Lourdes Conceição Martins

\section{Email: camillagiacovone@gmail.com}

INTRODUÇÃO: Afecções de pele são comuns e inclui dermatite atópica, dermatite de contato e alérgicas. Dermatite é um termo genérico usado para descrever inflamação na pele. O diagnóstico dessas patologias cutâneas baseia-se na história clinica de alergias e exposição a poluentes e irritantes. OBJETIVO: Investigar dermatites em indivíduos que moram em áreas próximas a um polo industrial petroquímico no estado de São Paulo, Brasil. MÉTODO: Entre 2003 a 2005, 2004 indivíduos de ambos os sexos, com idade entre 8 e 72 anos, foram avaliados por meio de aplicação de questionários. Considerou-se diagnóstico de dermatite quando o indivíduo entrevistado referiu ter sintomas como eritema, edema, prurido ou lesões cutâneas como pápulas, vesículas ou pústulas previamente diagnosticadas e tratadas por um médico. Os indivíduos foram divididos em 2 grupos. Grupo A: 1002 residentes de áreas próximas ao polo petroquímico (Região 1), e grupo B: 1002 residentes de áreas próximas a polo industrial de manufatura de aço (Região 2), distantes da Região 1 . O nível de significância foi $5 \%(<0.05)$. Este trabalho foi aprovado pelo Comitê de Ética em Pesquisa da Faculdade de Medicina do ABC e registrado sob o número 087/2002. RESULTADO: Nas duas regiões, incluindo o total de 2004 residentes, $153(07,63 \%)$ apresentaram dermatite. Regiões 1 e 2 : houve diferença significativa entre o número de residentes com dermatite $(\mathrm{p}=0,014)$ : 95 (09,48\%)na Região 1 e $58(05,79 \%)$ na Região 2 . Nos adultos e crianças e adolescentes, não observamos diferença significante entre a Região 1: $63(08,96 \%)$ e Região 2: $47(06,02 \%)$ residentes ( $\mathrm{p}=0,90)$; Região 1: $32(10,70 \%)$ e Região 2: $11(04,95 \%)$ residentes com dermatite $(\mathrm{p}=0,27)$, respectivamente. Região 1 é única porque os residentes estão muito próximos de 14 empresas petroquímicas e fatores ambientais podem estar relacionados com o número não usual de casos de dermatites observados nestes residentes próximos destas áreas industriais. CONCLUSÃO: Nossos resultados demonstram uma diferença significativa na taxa de dermatites em residentes de áreas que circundam o polo industrial petroquímico (Região 1) quando comparado a moradores de áreas de polo da indústria do aço (Região 2), o que abre campo para novas áreas de pesquisa.

Palavras-chave: dermatite; poluição atmosférica; industrial; epidemiológico.

\section{EPI-11 ELEVAÇÃO DE HEPCIDINA EM PACIENTES COM SÍNDROME METABÓLICA}

Alexandra Messa Cirlinas, Andrea Perovano Pardini, Carolina Nicolela Susanna, Carolina Yone Tamashiro, Vitor Augusto Queiroz Mauad, Davimar Miranda Borducchi

\section{Email: acirlinas@gmail.com}

INTRODUÇ̃̃O: A síndrome metabólica é um conjunto de fatores de risco para doenças cardiovasculares e alterações no metabolismo glicídico. Dos pacientes com síndrome metabólica 50\% também são diagnosticados com sobrecarga de ferro. Possivelmente o mecanismo seria por meio da ativação da hepcidina pelo estado inflamatório. OBJETIVO: Verificar a incidência de valores de hepcidina elevados em pacientes com síndrome metabólica. MÉTODO: Foi realizada prospectivamente a dosagem de hepcidina, pelo teste de Elisa Elabscience ${ }^{\varpi}$ de 62 pacientes em tratamento por hiperferritinemia e portadores de síndrome metabólica. Foram levantados dados do perfil lipídico e férrico dos mesmos. Ao fim do tabelamento todos os dados necessários foram coletados de apenas 30 pacientes. Fois aplicada análise estatística de correlação pareada pelo coeficiente de Pearson sobre gráfico de dispersão e, posteriormente por regressão linear múltipla. RESULTADO: Na regressão multilinear não houve correlação significante entre fatores individuais e os índices de absorbância do teste de dosagem de hepcidina. Nas análises de correlação pareada glicemia ferritina e HDL tiveram tendência a impacto negativo nos índices de absorbância (valores no teste de Pearson de: $-0,12,-0,19,-0,001$ respectivamente). Por outro lado, LDL e triglicérides tiveram impacto incremental (Pearson 0,16 e 0,15 respectivamente). Ainda assim, $90 \%$ dos pacientes do grupo amostral tinham níveis de hepcidina superiores ao valor de normalidade do teste e $56 \%$ estava a cima do valor de corte máximo utilizado. Devido ao número reduzido de pacientes inclusos podemos apenas constatar uma tendência, compatível com a hipótese de elevação da hepcidina acompanhando a elevação dos marcadores de síndrome metabólica. CONCLUSÃO: Apesar do espaço amostral reduzido, que impossibilitou conclusões significativas, a alta incidência de alterações neste grupo e os processos bioquímicos apontam para uma correlação entre síndrome metabólica e níveis de hepcidina. Os testes de correlação pareada parecem apontar ferritina, HDL e LDL como fatores de maior peso sobre esse índice. Outros trabalhos com a inclusão de grupo controle e expansão do espaço amostral são necessários para melhor avaliar esses achados.

Palavras-chave: Hepcidina; Síndrome Metabólica; Hiperferritinemia.

\section{EPI-12 ESTUDO EPIDEMIOLÓGICO DA HIPERTENSÃO ARTERIAL SISTÊMICA NA XII FEIRA DE SAÚDE DA FACULDADE DE MEDICINA DO ABC NO MUNICÍPIO DE SANTO ANDRÉ-SP 2015}

Italo Coelho da Silva, Ramon Félix Martins Fernandes,

Carolina Doering Neves, Lucca Cirillo Lima, Denise de Oliveira Schoeps, Neusa Falbo Wandalsen, David Feder

\section{Email: italo.coelho.silva@gmail.com}

INTRODUÇ̃̃O: Em 2015, realizou-se a XII Feira de Saúde da FMABC na cidade de Santo André-SP. Durante o evento foi aferidas a pressão arterial dos participantes levando-se em conta aspectos como gênero, tabagismo e IMC. A HAS (hipertensão arterial sistêmica) é uma doença crônica que tem aumentado em razão da mudança de hábitos associados a diversos fatores como tabagismo, alcoolismo, diabetes, sedentarismo. OBJETIVO: Identificar o desenvolvimento da HAS em Santo André e sua relação com fatores como gênero, tabagismo, obesidade e IMC. MÉTODO: Trata-se de um estudo transversal realizado durante XII Feira de saúde na cidade de Santo André em 2015 na qual foram selecionados, ao acaso, 399 pessoas de ambos os sexos e com idade igual ou superior a 18 anos para rastreamento de HAS. Para análise descritiva dos resultados foi utilizado o programa estatístico Stata 11.0. RESULTADO O estudo contou com 399 pessoas, sendo 145 do sexo masculino (36,34\%) e 254 do sexo feminino $(63,66 \%)$. A HAS estava presente em $176(44,33 \%)$ e ausente em 221 $(55,67 \%)$ pacientes. Dos indivíduos com HAS, 115 eram mulheres $(65,34 \%)$ e 61 eram homens (34,66\%). ( $\mathrm{p}=0,4742)$ Do total de pacientes, $334(83,92 \%)$ negaram e 64 $(16,08 \%)$ admitiram serem tabagistas. Dos pacientes tabagistas, $20(31,25 \%)$ tem HAS e $44(68,75 \%)$ não tem HAS ( $\mathrm{p}=0,023)$ Ao avaliar o IMC, os pacientes foram agrupa$\operatorname{dos}^{2}$, notou-se que o grupo considerado pré-obeso era a maioria, com 147 pessoas $(39,20 \%)$. O maior percentual de portador de HAS se encontra no grupo obeso tipo I, $52(57,14 \%)$ dos pacientes com obesidade tipo I tem HAS e 39 (42,86\%) não tem HAS $(\mathrm{p}=0,001)$. A Feira de Saúde busca avaliar a saúde da comunidade, atender, informar conscientizar e sensibilizar a população dos municípios do Grande $\mathrm{ABC}$ quanto à melhoria da qualidade de vida a partir da prevenção, da promoção da importância de ser ativo e do desenvolvimento de práticas saudáveis. Outra questão central é a busca da causa e dos fatores que influenciam a ocorrência de eventos relacionados ao processo saúde-doença. Assim, por meio da análise epidemiológica, pode-se estudar a descrição dos agravos da saúde do paciente e a determinação de suas causas. CONCLUSÃO: O perfil epidemiológico dos pacientes atendidos durante a Feira de saúde pode ser utilizado para produzir conhecimento que promova a saúde individual através de medidas de alcance coletivo.

Palavras-chave: Hipertensão; Fatores de risco; Obesidade.

\section{EPI-13 ESTUDO EPIDEMIOLÓGICO:TALASSEMIA MINOR E SOBRECARGA DE FERRO NO ABC PAULISTA}

Marina Ribeiro Maeji, Fernanda Mello de Oliveira e Silva, Vitor Augusto Queiroz Mauad, Davimar Miranda Maciel Borducchi

\section{Email: mamaeji@ hotmail.com}

INTRODUÇÃO: As anemias talassêmicas são um grupo de doenças hematológicas hereditárias caracterizadas por uma deficiência genética na síntese de uma ou mais cadeias polipeptídicas da hemoglobina (cadeia alfa, cadeia beta ou ambas). Se de um lado do espectro, as talassemias major causam condiçoes altamente complexas, sendo a Alpha Major incompativel com a vida; do outro lado, pacientes com niveis de progução de cadeias de hemoglobina relativamente normais tem uma vida relativamente normal. No entanto, a anomalia leva a um aumento consideravel do turn over eritroide e, por consequencia, interroga-se seu efeito cronico sobre os niveis ferricos e suas consequencias em longo prazo. OBJETIVO: Relacionar os níveis férricos à talassemia minor de pacientes atendidos em serviço privado no Grande ABC. MÉTODO: Foram triados pacientes com CID de talassemia não especificada (56.9). A partir disso foram selecionados os pacientes com valores de Hbs A2 maior ou igual a 3,5 (pacientes com beta talassemia). Foram excluídos todos pacientes com necessidade de suporte transfusional. Foram considerados patologicos niveis de ferritna supertiores a $400 \mathrm{ng} / \mathrm{mL}$ para homens e $300 \mathrm{ng} / \mathrm{mL}$ para mulheres, mesmos niveis utilizados no estudo HIERS, maior estudo populacional sobre o tema. Ao todo foram analisados 117 pacientes. A análise estatistica foi realizada atraves do software Real Statistics ${ }^{\odot}$ pra Microsof Excel. A prevalencia em nosso grupo fo calculada e comparada atraves de Odds Ratio com o observado nos estudos populacionais. RESULTADO: A análise resultou na observação de 76 pacientes do gênero feminino e 41 do masculino. Média de idade ao diagnóstico $=34$ anos, com DP de 17. Desses pacientes, 26 apresentaram hemocromatose (considerando os valores de referência de ferritina acima de $300 \mathrm{ng} / \mathrm{mL}$ para mulheres e acima de $400 \mathrm{ng} / \mathrm{mL}$ para homens), sendo 16 deles do gênero masculino e 10 do gênero feminino. A prevalencia de sobrecarga de ferro, foi significativamente maior que nos estudos populacionais $(22,22 \%$ x 8,7\% - Odds Ratio 2,96 IC 95\% 1,27 - 6,89). A despeito de uma media 
de idade menor, nosso grupo teve niveis ferricos significativamente maior que o esperado. CONCLUSÃO: Nossos resultados permitem inferir que pacientes com Beta talassemia intermedia e minor, mesmo sem necessidade transfusional, podem se beneficiar de triagem ativa dos niveis ferricos.

Palavras-chave: Talassemia, sobrecarga de ferro, ferritina

\section{EPI-14 ESTUDO DA PREVALÊNCIA DE ANEURISMA DE AORTA ABDOMINAL EM INDIVÍDUOS IDOSOS}

Diego Monteiro de Melo Lucena, Sidnei José Galego, Andrea KafejianHaddad, Ramon Félix Fernandes, Luiza Emanuela Biseo Henriques, Stephania Morreale, Giovanna Cardella Vizentini, João Antônio Correa

\section{Email: lucenadiego@ hotmail.com}

INTRODUÇÃO: O Aneurisma de Aorta Abdominal causa aproximadamente 175 mil casos de morte no mundo sendo que a ruptura desse aneurisma representa cerca de $80 \%$ dos casos. Estudos epidemiológicos demonstraram uma frequência que compreende entre $0,5 \%$ e 3,2 \% de AAA em indivíduos com idade superior a 65 anos nos Estados Unidos. OBJETIVO: Determinar a prevalência de aneurisma de aorta abdominal em indivíduos com idade igual ou superior a 60 anos. MÉTODO: Trata-se de um estudo transversal realizado na cidade de São Caetano do Sul em 2015 na qual foram selecionados, ao acaso, 43 pacientes de ambos os sexos e com idade igual ou superior a 60 anos para rastreamento de AAA por meio de medidor de ultrassonografia Samsung mysono U6. Foram analisadas as dimensões ântero-posterior, látero-lateral e longitudinal, sendo considerada a medida do maior diâmetro. Os pacientes analisados foram caracterizados em grupos de acordo com a medida do diâmetro de escolha sendo que os indivíduos do grupo I entre 1 e $2 \mathrm{~cm}$, grupo II entre 2 e $3 \mathrm{~cm}$, grupo III entre 3 e $4 \mathrm{~cm}$ e grupo IV aqueles com diâmetro maior do que $4 \mathrm{~cm}$. Foram considerados aneurismas os casos de diâmetro maior ou igual a $3 \mathrm{~cm}$. Para análise descritiva dos resultados foi utilizado o programa estatístico Stata 11.0. RESULTADO: Nos 43 pacientes estudados, apenas um apresentou dilatação compatível com o grupo III de valor $3.3 \mathrm{~cm}$. O grupo I apresentou 31 pacientes sendo o menor valor encontrado 1,1 $\mathrm{cm}$ e o maior $1,9 \mathrm{~cm}$. O grupo II apresentou 11 pacientes, sendo o valor mínimo e máximo encontrados $2 \mathrm{~cm}$ e 2,4 cm, respectivamente.. Já o grupo IV não apresentou nenhum indivíduo uma vez que nenhum possui diâmetro maior do que $4 \mathrm{~cm}$. Sendo assim, a prevalência de aneurisma de aorta abdominal foi de 1 caso em 43 estudados, ou seja, 2,3\% da amostra, número compatível com estudos prévios de prevalência de AAA. A prevalência encontrada no estudo é semelhante ao encontrado na literatura e serve como um importante instrumento para a prevenção das complicações do AAA principalmente a ruptura deste. CONCLUSÃO: O conhecimento da epidemiologia do aneurisma se mostra importante para determinar o futuro do rastreamento dessa doença e, assim, aprimorar as políticas públicas de saúde na prevenção de suas complicações. Desse modo, esse estudo pode auxiliar reduzindo a morbimortalidade por aneurisma de aorta abdominal.

Palavra-chave: Aneurisma de Aorta Abdominal; Epidemiologia; Ultrassonografia.

\section{EPI-15 FATORES DEMOGRÁFICOS QUE INTERFEREM NO ATENDIMENTO DA PARADA CARDIORRESPIRATÓRIA EM AMBIENTE EXTRA-HOSPITALAR}

Thainá Altarejo Marin, Phillip Hoover, laggo Bernini Costa, Vanessa Lopes Mathia, Giovanna A. N. R. Nogueira, Letícia Mota de Souza, João Fernando Monteiro Ferreira, Antônio Carlos Palandri Chagas, Miguel Moretti

\section{Email: thaina.marin@ hotmail.com}

INTRODUÇÃO: A redução da morbimortalidade da parada cardiorrespiratória (PCR) depende da eficácia do atendimento. O sucesso da ressuscitação cardiopulmonar (RCP) aumenta se iniciada cedo. Estudos mostram uma população desinformada e não capacitada. OBJETIVO: Registrar como os fatores sexo, idade e escolaridade influencia no conhecimento e nas atitudes do socorrista. MÉTODO: Aplicação de um questionário sobre PCR/RCP. Estudo transversal por amostra de conveniência, utilizada como reflexo de uma população, e não probabilística. RESULTADO: 319 questionários entre Ago e Out de 2015. Homens 36\%. Idade média 34,3+14,7 anos. Nível superior $55 \%$ e médio $40 \%$. Homens presenciaram mais eventos $(25,4 \%$ x $14,7 \%$ $\mathrm{p}=0,02)$. Ambos os sexos dizem que sabem reconhecer uma PCR. Homens se sentem mais aptos $(36 \% \times 21,6 \% \mathrm{p}=0,01)$, sabem o que fazer $(51,2 \% \times 38,2 \% \mathrm{p}=0,02)$ e poucos agiriam diferente se fosse algum conhecido $(11,4 \%$ x $24 \% \mathrm{p}=0,01)$. Eles pedem menos ajuda $(27,9 \%$ x $40,4 \%)$ e checam mais os sinais de PCR (27,9\% x 12,5\%). $50 \%$ dos homens e das mulheres sabem o número correto da ajuda. Ninguém com menos de 20a presenciou uma PCR, porém $53 \%$ dos com mais de 60 a já presenciaram ao menos um evento, em diversos locais. Em relação à idade não houve diferença em declarar-se apto ao atendimento da PCR ou saber o que deve ser feito, porém os com mais de 60a ou menos de 20a são capazes de reconhecer mais eventos (40\% x $24 \%$ $\mathrm{p}=0,02)$. Pessoas com mais de $60 \mathrm{a}$ e menos de 30a ligariam para o $192(67 \% \mathrm{x}<50 \%$ $\mathrm{p}=0,02)$. Apesar do reconhecimento da PCR ser maior no nível superior $(45 \%)$, não houve diferença quando se declaram aptos ou que sabem o que deve ser feito. Apesar de mais proativos na RCP (superior e médio), não houve diferença entre os níveis de escolaridade em relação à primeira atitude ou com relação ao número para pedir ajuda (50\% de acerto). CONCLUSÃO: Amostra estudada: homens estão mais bem preparados que as mulheres para PCR. O grau de escolaridade não diferencia $o$ atendimento. Pessoas com mais de 60a e com menos de 20a possuem mais conhecimento que as demais idades. Esses dados aliados a outros estudos reforçam a necessidade de treinar e capacitar as pessoas já no ensino médio ou com menos de 20a e manter treinamento constante.

Palavras-chaves: parada cardiorrespiratória; sexo; escolaridade; idade.

\section{EPI-16 FATORES DE RISCO PARA INFECÇÃO APÓS CIRURGIA DA COLUNA VERTEBRAL}

Matheus Pippa Defino, Guilherme Yukio Kajiya Sakuma, Karyse Helena Crispim Ribeiro Alves, Bernardo Barreto Correa, Caroline Castrucci Ingold, Guilherme Murbach Aliberti, Victor Bignatto Carvalho, Gustavo Ferrareto Pires, Luciano Miller Reis Rodrigues, Leonardo Yukio Asano

\section{Email: matheusdefino@gmail.com}

INTRODUÇÃO: Análise retrospectiva dos casos de infecção após 112 procedimentos cirúrgicos na coluna vertebral. OBJETIVO: Analisar os casos infectados após cirurgia de coluna vertebral para identificar os fatores de risco pré-operatórios e intra-operatórios. MÉTODO: Foram avaliados os prontuários dos pacientes que desenvolveram infecção do sítio cirúrgico durante o ano de 2014 em uma única instituição. Do total de 112 pacientes submetidos a cirurgia na coluna vertebral, cinco pacientes evoluíram com infecção pós-operatória. Os casos de infecção primária da coluna (espondilodiscite e osteomielite) foram excluídos. Características relacionadas ao paciente e a cirurgia foram analisadas. RESULTADO: A taxa de infecção pós-operatória foi de $4,4 \%$. Todas as infecções ocorreram durante o período pós-operatório precoce (menos de 30 dias). Elevado tempo de internação na unidade de terapia intensiva no pós-operatório foi fator de risco identificado. Os agentes mais comuns foram Staphylococcus aureus, Klebsiella pneumoniae e Acinetobacter baumannii. Todos os pacientes infectados foram submetidos a limpeza cirúrgica e debridamento associado a antibioticoterapia endovenosa. CONCLUSÃO: Reconhecer os fatores de risco tanto intrínsecos ao paciente quanto relacionado ao procedimento cirúrgico é fundamental para prevenir infecção pós-operatório.

Palavras-chave: Cirurgia da Coluna Vertebral; Infecção Pós-operatória; Complicações; Fatores de risco.

\section{EPI-17 INCIDÊNCIA DE INTERNAÇÕES DE PACIENTES COM CRITÉRIOS PARA CUIDADOS PALIATIVOS EM HOSPITAL DE NÍVEL TERCIÁRIO}

Raquel Lie Okoshi, Flávia Yumi Ataka, Yuri Louro Bruno de Abreu

\section{Email: lie_okoshi@hotmail.com}

INTRODUCÃO: Cuidado Paliativo (CP), de acordo com a OMS, é o tratamento não curativo, que busca oferecer uma melhor qualidade de vida ao paciente e familiares, tanto físico, quanto psicológico. No Brasil, essa prática é recente e são poucos os locais especializados no serviço. Tendo-se em vista a significativa quantidade de internações prolongadas com tratamento invasivo e pouco eficaz, é de suma importância conhecer o perfil dos pacientes com critério para CP. OBJETIVO: Definir o número de pacientes internados que preenchem os parâmetros para Cuidados Paliativos, além de mostrar ao HEMC a importância do conhecimento dos critérios da Academia Nacional de Cuidados Paliativos (ANCP) para o correto encaminhamento dos pacientes ao serviço. MÉTODO: Análise de prontuários (meta: 1500) de internados nas enfermarias de Oncologia, UTI, Infectologia, Doenças Cardíacas do HEMC. Os dados coletados (identificação, comorbidade, tempo e motivo de internação, tratamento, presença de óbito) serão comparados aos critérios de inclusão aos $\mathrm{CP}$. RESULTADO: Busca-se encontrar número relevante de pacientes dentro dessas enfermarias com características que os incluam-nos CP. São locais cujos pacientes, por vezes, apresentam doenças não responsivas a tratamento curativo e que carecem de atenção especial a fim de respeitar sua qualidade de vida e também a de seus familiares. DISCUSSÃO: Os critérios para CP são pouco conhecidos pelos profissionais da saúde e, com isso, muitos pacientes permanecem na enfermaria recebendo tratamentos incorretos e ineficazes, fato que prejudica seu bem estar e prolongam o sofrimento, tanto do paciente quanto de seus familiares. O devido tratamento busca aliviar a dor e controlar os sintomas de doenças que ameaçam a continuidade da vida, com a ajuda de uma equipe multidisciplinar. Atua também no processo de luto quando a vida chegar ao fim. CONCLUSÃO: Com o envelhecimento populacional, o número de doenças consuptivas e degenerativas vem aumentando e, com isso, cresce o grupo de pacientes que necessitam de CP. O correto conhecimento do perfil epidemiológico daqueles que podem ser inclusos no serviço é essencial para sua melhora da qualidade de vida, bem como para a tranquilidade familiar. Além disso, há benefício para o serviço que atende este grupo, uma vez que com esta competência, ele é capaz de melhor encaminhar seus pacientes e, assim, dinamizar o atendimento.

Palavras-chave: Cuidado Paliativo; internação; hospital terciário.

\section{EPI-18 LEVANTAMENTO EPIDEMIOLÓGICO DOS PACIENTES ATENDIDOS NO AMBULATÓRIO DE URTICÁRIA.}

Débora Terra Cardial, Nathalia de Carvalho Baldavira, Roberta Criado

Email: deboracardial@uol.com.br

INTRODUÇÃO: A Urticária é uma lesão cutânea caracterizada pelo aparecimento de urticas, pruriginosas e de duração efêmera. Podem ser classificadas 
como crônicas ou agudas. Acredita-se que de 15 a $20 \%$ da população apresentará algum episodio de urticária durante a vida, embora os dados epidemiológicos sejam de difícil analise, tendo em vista que muitos casos são subdiagnosticados. O diagnostico é predominantemente clinico e o agente etiológico dificilmente é determinado, além disso, a maioria das urticárias são consideradas espontâneas. OBJETIVO: Avaliação epidemiológica dos pacientes atendidos no ambulatório de Urticária da Faculdade de Medicina do ABC. Estabelecendo uma relação entre os tipos de urticária apresentados, resultados dos exames solicitados, o uso de medicamentos que levam a melhora ou ao agravo das lesões e as dosagens de Dímero D entre os pacientes atendidos. MÉTODO: O estudo terá como base a análise de 336 prontuários dos pacientes atendidos, nos últimos anos, no ambulatório de Urticária da Faculdade de Medicina do $\mathrm{ABC}$, de onde serão retirados os dados para o levantamento epidemiológico. RESULTADO: A análise dos prontuários não foi concluído no presente momento. DISCUSSÃO: Atualmente só existem dois trabalhos de levantamento de dados na área de urticária, sendo o último deles, e portanto de maior relevância, realizado em 1999 pela UNIFESP. Nele, foi encontrado que a urticária crônica foi mais comum em mulheres de meia idade, com predomínio de crises rápidas, com menos de uma hora de duração. A urticária crônica idiopática foi o diagnostico mais comum, seguido pela urticária crônica física. Devido a escassez de trabalhos nessa área e a interferência da urticária no bem estar dos pacientes portadores, acreditamos que com base neste trabalho poderemos levantar dados relevantes para seu diagnostico e tratamento. (Urticária Crônica: estudo clinico e laboratorial de 216 acontecimentos - UNIFESP, 1999). CONCLUSÃO: Trabalho ainda não concluído.

Palavras-chave: urticária; ambulatório; dímero-D.

\section{EPI-19 O PERFIL DO PACIENTE ONCOLÓGICO QUE FAZ USO DA MEDICINA ALTERNATIVA E COMPLEMENTAR}

Camila Ribeiro de Arruda Monteiro, Beatriz de Camargo Preto Piscopo, Guilherme Zaremba, Heloísa Duarte de Andrade Tavares, Igor Luiz Argani, Claudia Vaz de Melo Sette, Auro del Giglio, Daniel de Iracema Gomes Cubero

\section{Email: cml.monteiro@ hotmail.com}

INTRODUÇÃO: Devido ao aumento da sobrevida de pacientes com câncer, um maior número de pacientes passou a sofrer dos sintomas específicos advindos do câncer e com o objetivo de manejar esses sintomas tardios, o uso da medicina complementar e alternativa (MAC) tem se tornado frequente. Apesar disso, pouco se sabe sobre o assunto, o que torna importante trabalho relacionado ao tema OBJETIVO: Identificar a motivação e o perfil do paciente que faz uso da MAC bem como o impacto gerado por tal tratamento. MÉTODO: Estudo transversal, realizado nos serviços de oncologia da FMABC. Pacientes assinaram o TCLE, responderam três questionários validados: EORTC QLQ-C30, HAD e LOT-R; e uma ficha com dados socioeconômicos e clínicos. RESULTADO: Foram inclusos 28 pacientes, dos quais $50 \%$ fazia o uso da MAC, com o seguinte perfil: idade média de 59,7 anos, $85,7 \%$ mulheres, $50 \%$ casados/amasiados e $50 \%$ aposentados. Quanto aos questionários, a análise do $\mathrm{HAD}$, resultou em um valor de ansiedade e depressão

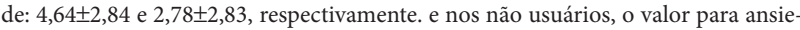
dade foi de 4,71 $\pm 2,55$; e para depressão $3,5 \pm 2,13$. O LOT-R, dos usuários resultou

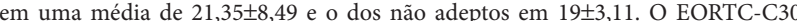
é subdivido em três setores, que avaliam: questões gerais, funcionais e saúde global; A análise da ESG resultou em média de score e dp, entre os usuários igual a $76,19 \pm 19,57$; os não usuários o valor obtido foi de $77,38 \pm 27,62$. Na EF, os pacientes usuários de terapias alternativas, resultou em $80,63 \pm 13,08$, entre os não usuários o resultado foi $83,61 \pm 10,77$. A ES entre os usuários resultou $9,89 \pm 7,78$ e nos não usuários o valor foi $13,55 \pm 15,59$. A MAC é pouco difundida, havendo, a necessidade de maiores estudos quanto à segurança e eficácia de suas diversas modalidades, já que não se sabe os efeitos que podem causar na doença e no tratamento e a maioria dos tipos de MAC é de fácil acesso à população. A comparação entre os grupos dos níveis de ansiedade, depressão, bem como qualidade de vida não foi realizada nesta análise interina em virtude do número reduzido de paciente incluídos, e para não comprometer a análise final do estudo. CONCLUSÃO: A análise parcial demonstra MAC, faz parte da rotina de uma parcela significativa dos pacientes atendidos pelos serviços de oncologia.

Palavras-chave: Medicina Complementar; Neoplasias.

\section{EPI-20 PERFIL DE SENSIBILIZAÇÃO A AEROALÉRGENOS E ALIMENTOS DOS PACIENTES MATRICULADOS EM AMBULATÓRIO DE ALERGIA E IMUNOLOGIA}

Amanda Bosio Quinzani, Sandra Mitie Ueda Palma, Ana Thamilla Fonseca, Neusa Falbo Wandalsen

\section{Email: amanda.bosio@ hotmail.com}

INTRODUÇÃO: Asma, rinite, alergia alimentar, dermatite atópica e urticária são doenças crônicas que afetam parcela significativa da população mundial. Teste cutâneo de hipersensibilidade imediata para inalantes e alimentos é o teste mais comumente empregado, in vivo, para detectar a presença de IgE sérica específica. OBJETIVO: Analisar perfil de sensibilização a aeroalérgenos e alimentos em pacientes com diagnóstico de atopia, submetidos ao teste cutâneo de hipersensibilidade imediata, de ambulatório especializado de Alergia e Imunologia.
MÉTODO: Estudo retrospectivo com dados de prontuários de pacientes menores de 22 anos, ambos os sexos, com diagnóstico de asma, rinite, alergia alimentar, dermatite atópica, urticária crônica, associados ou não a outras doenças atópicas, avaliados em ambulatório especializado, de out/2014 a out/2015. Foram analisados dados referentes ao sexo, idade, positividade aos inalantes e alimentos e o diagnóstico inicial da doença atópica, todos com diagnóstico clínico confirmado por pediatra alergista. RESULTADO: 130 pacientes: $51(39,2 \%)$ são do sexo feminino e $79(60,7 \%)$ do masculino. Os $130(100 \%)$ pacientes realizaram teste cutâneo para inalantes e $30(23 \%)$ realizaram teste cutâneo para alimentos. Os pacientes foram separados por grupos. O nível de significância adotado foi $<0,05$ ou $5 \%$. Houve significância no número total de atendimentos por faixa etária com teste cutâneo para inalantes positivos ao Dematophagoides pteronyssinus $(\mathrm{p}<0,001)$, Dematophagoides farinae $(\mathrm{p}<0,001)$ e Blomia tropicalis $(\mathrm{p}<0,001)$. Não houve significância estatística do sexo com a faixa etária $(\mathrm{p}=206)$ e em relação ao teste cutâneo para alimentos, os resultados não foram significativos estatisticamente. O método escolhido para avaliar a hipersensibilidade imediata foi o teste cutâneo por puntura, devido a facilidade na sua aplicação e leitura, efeitos colaterais mínimos (10) e por ter maior positividade em relação aos testes intradérmicos. É importante reconhecer no nosso meio a positividade dos testes cutâneos e identificar em que idade esses testes tem maior positividade, auxiliando assim no diagnóstico. CONCLUSÃO: Testes cutâneos de hipersensibilidade imediata foram positivos para Dematophagoides pteronyssinus, Dematophagoides farinae e Blomia tropicalis em todas as faixas etárias. Quanto maior a idade maior a sensibilização aos testes cutâneos de hipersensibilidade imediata para estes inalantes.

Palavras-chave: Prick test; sensibilização; atopia; crianças.

\section{EPI - 21 PERFIL CLÍNICO-EPIDEMIOLÓGICO DOS ADOLESCENTES ATENDIDOS NO SERVIÇO DE EMERGÊNCIA}

Stéphanie Kim Azevedo de Almeida, Nicole Saliba Chamelian, Nathalia de Carvalho Baldavira, Giovanna Guimarães Soares, Caroline Ricci Castelan, Maria Aparecida Dix Chehab, Lígia de Fátima Nóbrega Reato, Alexandre Massashi Hirata

Email: stephanie_kaa@hotmail.com

INTRODUÇ̃̃O: A adolescência consiste na transição da infância para a fase adulta e compreende a segunda década de vida (OMS). Nessa fase ocorrem alterações biopsicossociais quando a puberdade marca o início dessas transformações; ocorre o desenvolvimento dos caracteres sexuais secundários e aceleração da velocidade de crescimento. As mudanças psicológicas desse ciclo de vida determinarão a personalidade do indivíduo. Diante de intensas e rápidas transformações há necessidade de um acompanhamento médico e multidisciplinar. Os índices de morbi-mortalidade pediatria têm diminuído devido a diversas estratégias nos diferentes tipos de atenção, mas as unidades precisam se preparar melhor para atender essa faixa etária quando chegam em situação de emergência ou urgência (Assistência à criança e ao adolescente em unidades não-hospitalares de urgência e emergência em um município do interior do Estado de São Paulo: um estudo de avaliação. OBJETIVO: Avaliação clínico-epidemiológica dos pacientes atendidos no UPA Central de Santo André, São Paulo. MÉTODO: Análise quantitativa e qualitativa dos prontuários de adolescentes, atendidos no UPA Central de Santo André nos anos de 2014 e 2015. A partir das informações encontradas serão estabelecidos os dados epidemiológicos, a fim de se estabelecer as principais queixas e intercorrências que levam os adolescentes a busca por atendimento médico. RESULTADO: Análise de dados não foi finalizada. Um estudo realizado no Paraná em 2003 concluiu que os adolescentes procuram um serviço de emergência principalmente por doenças infecciosas e parasitárias $(25,6)$, seguido de doenças do aparelho respiratório $(17,2)$ (Adolescentes atendidos num serviço público de urgência e emergência: perfil de morbidade e mortalidade). Outro estudo, realizado em 2009, demonstra que muitos adolescentes procuram esses serviços por diferentes tipos de trauma e violência (Causas externas em adolescentes: atendimentos em serviços sentinelas de urgência e emergência nas Capitais Brasileiras - 2009). CONCLUSÃO: Pretende-se, com esse trabalho, analisar quais são as principais comorbidades que levam os adolescentes até o serviço de emergência da UPA Central de Santo André, delimitando o perfil do paciente nesse serviço.

Palavras-chave: Perfil de Saúde; Medicina do Adolescente; Serviços Médicos de Emergência.

\section{EPI - 22 PERFIL CLÍNICO-EPIDEMIOLÓGICO DOS ADOLESCENTES NO SERVIÇO AMBULATORIAL}

Nicole Saliba Chamelian, Nathalia de Carvalho Baldavira, Stéphanie Kim Azevedo de Almeida, Giovanna Guimarães Soares, Caroline Ricci Castelan, Maria Aparecida Dix Chehab, Lígia de Fátima Nóbrega Reato, Alexandre Massashi Hirata

Email: nicole.salibach@gmail.com

INTRODUÇÃO: A adolescência consiste na transição da infância para a fase adulta e compreende a segunda década de vida (OMS). Nessa fase ocorrem alterações biopsicossociais e a puberdade marca o início dessas transformações; há o desenvolvimento dos caracteres sexuais secundários e aceleração da velocidade de crescimento. As mudanças psicológicas desse ciclo de vida determinarão a personalidade do indivíduo. Diante de intensas e rápidas transformações há necessidade 
de um acompanhamento médico e multidisciplinar. OBJETIVO: Avaliação clínico-epidemiológica dos pacientes atendidos no ambulatório de Hebiatria da Faculdade de Medicina do ABC, em Santo André. MÉTODO: Avaliação clínico-epidemiológica dos pacientes atendidos no ambulatório de Hebiatria da Faculdade de Medicina do ABC, em Santo André. RESULTADO: Análise de dados não fo finalizada. Um estudo feito na Universidade Estadual do Oeste do Paraná 2013 demonstrou que a maioria dos pacientes adolescentes que procuram um serviço ambulatorial é do sexo feminino (56,3\%). O diagnóstico mais frequente nessas pacientes é consulta de rotina (17,5\%), seguida de IVAS $(7,9 \%)$ e cefaleia/enxaqueca $(5,4 \%)$. Em relação ao sexo masculino, temos os mesmos diagnósticos, mas com frequências relativas distintas, de $19,3 \%, 10,0 \%$ e $4,5 \%$ respectivamente (Perfil dos atendimentos em um ambulatório de medicina do adolescente. Outro estudo, realizado em Pernambuco em 2008, demonstrou que a maioria dos pacientes adolescentes que procuraram um serviço ambulatorial nessa região também são do sexo feminino $(57,43)$. Sendo a maior procura relacionada à questões psicológicas, seguido de consultas de rotina (Centro de Referência em Atenção à Saúde do Adolescente no município de Jaboatão dos Guararapes. CONCLUSÃO: Pretendese, com esse trabalho, analisar quais são as principais comorbidades que levam os adolescentes até o serviço ambulatorial, delimitando o perfil do paciente do Ambulatório de Hebiatria da FMABC.

Palavra-chave: Perfil de Saúde; Medicina do Adolescente; Assistência Ambulatorial.

\section{EPI-23 PERFIL EPIDEMIOLÓGICO DA TROMBOFILIA EM PACIENTES DA REGIÃO DO ABC}

Heloísa Duarte de Andrade Tavares, Mariana Carvalho Gouveia, Ariadine Chaves de Oliveira, Isabella Ghiringhello Paludetti,

Davimar Miranda Maciel Borducchi, Vitor Augusto Queiroz Mauad, Karen Dariane Barbosa de Vasconcelos

\section{Email: heloarty@ hotmail.com}

INTRODUÇÃO: Trombofilia é definida como tendência à trombose decorrente de alteracõoes hereditárias ou adquirida da coagulação ou fibrinólise, levando a estado pró-trombótico. No que diz respeito às formas hereditárias, as mutações mais pesquisadas são as do Fator V (Leyden), Protrombina, Antitrombina III, MTHFR, Proteina C e S. Por outro lado, causas adquiridas estão relacionadas ao uso de anticoncepcional hormonal, imobilização, tabagismo, malignidades, cirurgias, sín drome do anticorpo antifosfolípide, entre outros. O protocolo da American College of Chest Physicians (ACCP) mantém guidelines baseados em evidência de que a pesquisa de mutações específicas e história familiar do paciente não interferem em seguimento e tratamento. Porém, o histórico pessoal e fatores de risco associados são dados relevantes no manejo desses casos. OBJETIVO: $\mathrm{O}$ intuito desse trabalho é avaliar se nos pacientes da região do $\mathrm{ABC}$ esses dados são estatisticamente significativos e compatíveis com o que já foi descrito na literatura. MÉTODOS: Foram analisados 105 prontuários de pacientes com suspeita de trombofilia em clínicas privadas do grande ABC (Central Clinic), que haviam realizado a pesquisa de todas as mutações genéticas preconizadas. RESULTADOS: Foi observado que as alterações genéticas não são estatisticamente significantes em relação a ocorrência de fenômenos trombóticos $(\mathrm{p}=0,668)$, tampouco o histórico familiar $(\mathrm{p}=0,397)$. Já os grupos de risco propostos nos guidelines da ACCP foram altamente significativos $(\mathrm{p}=3 \times 10-26)$, bem como histórico pessoal isolado $(\mathrm{p}=0,010)$. Os dados coletados nesse trabalho corroboram com a literatura, onde fatores genéticos e histórico familiar não são relevantes para seguimento e conduta destes pacientes. Alguns artigos recentes vêm ainda questionar o impacto, potencialmente negativo, dessa pesquisa na aderência e controle desses pacientes, bem como na qualidade de vida. Atualmente, a pesquisa só está recomendada em casos seletos, frente aconselhamento, ciência e interesse do paciente e/ou familiares. CONCLUSÃO: Esse trabalho condiz com o que está descrito na literatura a respeito do manejo da trombofilia. Com número razoável de pacientes, nossos resultados vêm a fortalecer a ideia de que anticoagulação perene como profilaxia secundária não deve ser indicada mediante alteração genética ou história familiar isoladamente.

Palavras-chave: Trombofilia; ACCP.

\section{EPI-24 PERFIL EPIDEMIOLÓGICO E PSICOSSOCIAL DOS CUIDADORES INFORMAIS DE PACIENTES PORTADORES DE DOR CRÔNICA}

Flávia Yumi Ataka, Raquel Lie Okoshi, Yuri Louro Bruno de Abreu

Email: ayflavia@ hotmail.com

INTRODUÇÃO: A dor crônica relaciona-se a muitas doenças e o cuidador informal, geralmente vindo do núcleo familiar, surge responsável por ajudar os pacientes no cotidiano sem, muitas vezes, receber a devida atenção diante da estressante atividade que praticam. A descrição epidemiológica dos cuidadores é feita através de questionários que avaliam a qualidade de vida. Com isso, pode-se intervir futuramente nas esferas social e psicológica OBJETIVO: Descrição epidemiológica e psicossocial dos cuidadores informais dos pacientes com dor crônica do Ambulatório de Controle de Sintomas do HEMC. Possibilitar intervenções no âmbito psicossocial do cuidador MÉTODO: Aplicou-se o questionário sobre Qualidade de Vida WHOQOL-BREF por telefone. Abordam questões sobre qualidade de vida, domínios físico, psicológico, social e meio ambiente. Analisaram-se os dados por meio do software estatístico IBM SPSS 20.0. Cada domínio foi pontuado de 0 a 100 ( $0=$ muito negativo; $100=$ muito satisfatório $)$. Cada faceta dentro do domínio recebeu nota de 1 a 5 (quanto>a pontuação, melhor a qualidade de vida). RESULTADO: Em todos os domínios, os resultados foram positivos para $>=50 \%$ dos cuidadores. As médias obtidas foram: físico $=68,07$; psicológico $=67,04$; relações sociais $=67,42$; meio ambiente $=64,58$. Nas facetas do domínio físico, os extremos foram atividades da vida cotidiana (3.03) e capacidade de trabalho (3.97). No psicológico, autoestima (3.12) e imagem corporal e aparência (4.03). Ainda, 30.3\% deles apresentam sentimentos negativos. No social, tanto relações pessoais quanto suporte social apresentou valores $>3.40$. No meio ambiente, oportunidade de adquirir novas informações e habilidades (2.67), segurança física e proteção (3.91) e cuidados de saúde e sociais (3.91). Os cuidadores, em geral, apresentaram satisfação em suas funções. Algo a ser considerado é o fato deste questionamento envolver lado ético do entrevistado, podendo este se sentir constrangido em demonstrar sua real opinião sobre sua atividade. Os que tiveram resposta negativa em relação ao suporte social são mais propensos à ansiedade e sentimentos negativos, prejudicando a autoestima e dificultando sua tarefa CONCLUSÃO: Urge-se avançar em políticas que diminuam o estresse e a sobrecarga dos cuidadores, além de ser necessária a implantação de programas de suporte social à família, oferecendo orientações relevantes ao cuidado

Palavras-chave: cuidador informal dor crônica qualidade de vida perfil epidemiológico.

\section{EPI-25 PREVALÊNCIA DE DISTÚRBIOS NUTRICIONAIS EM CRIANÇAS DE 3 A 10 ANOS EM INSTITUIÇÃO FILANTRÓPICA DO MUNICÍPIO DE SANTO ANDRÉ}

Amanda Bosio Quinzani, Diego Monteiro de Melo Lucena, Fernanda Ramires Cafeo, Julia Pitombo Vella, Lais Sales Seriacopi, Mariana Carvalho Gouveia, Marta Maria Santos Arcoverde Cavalcanti, Tiago Almeida Meniconi, Denise de Oliveira Shoeps

\section{Email: amanda.bosio@ hotmail.com}

INTRODUÇÃO: A obesidade é um tema de grande relevância, pois tem aumentado sua prevalência em todo mundo, gerando diversas comorbidades ao indivíduo. OBJETIVO: Utilizar os medidores antropométricos (peso, altura, circunferência abdominal) para definir o grupo de risco nutricional nas crianças de 3 a 10 anos da instituição filantrópica Cidade dos Meninos-Santo André. MÉTODO: As crianças foram pesadas e medidas em altura e circunferência abdominal para triagem. Após, os dados foram tabulados para calcular o IMC e o $\mathrm{Z}$ score e definir o grupo de risco nutricional (sobrepeso e obesos). RESULTADO: Foram triadas 391 crianças, sendo 96 classificadas em sobrepeso e 74 em obesas, formando um grupo de risco de 170 crianças, representando $45,7 \%$ da população estudada. Essa porcentagem de excesso de peso é muito superior à máxima do Brasil para mesma faixa etária, 33,8\% (IBGE, 2008-2009). Obesidade é uma doença crônica, multifatorial, em que ocorre sobreposição de fatores genéticos e ambientais, sendo as causas exógenas correspondentes a 95-98\% do total (Obesidade exógena na infância e na adolescência, 2000). No chamado ambiente obesogênico, há uma confluência do estilo de vida contemporâneo, industrialização alimentícia e influência das mídias, grandes responsáveis pelo aumento da prevalência da obesidade nos últimos anos. A obesidade infantil relaciona-se diretamente à fase adulta. Cerca de $50 \%$ das crianças obesas aos 6 meses de idade e $80 \%$ das obesas aos 5 anos permanecerão obesas (Prevalência de sobrepeso e obesidade em crianças e adolescentes das regiões SE e NE, 2002). Esse fato representa um risco à saúde do indivíduo, pois diversas comorbidades decorrem do sobrepeso, tais como diabetes, hipertensão arterial e doença aterosclerótica. Com o intuito de combater o desenvolvimento dessas doenças ou minimizar os seus efeitos, é importante inserir hábitos saudáveis na rotina da criança o quanto antes, já que essa é uma fase de aprendizado, em que novas informações e experiências tendem a ser assimiladas de forma mais eficaz e perpetuadas pela vida. CONCLUSÃO: A população de risco na instituição é significativa, sendo necessárias maiores abordagens sobre o tema nutricional, a fim de que essas crianças mudem seus hábitos de vida, tornando-se jovens e adultos saudáveis.

Palavras-chave: Obesidade infantil; Epidemiologia; Comorbidades da obesidade.

\section{EPI-26 SÍNDROME DA LIPODISTROFIA ASSOCIADA A HIVIAIDS: ANÁLISE DA VARIABILIDADE E PERFIL CLINICO EM HOMENS}

Daniel Yvamoto Fujihara, Karine Risério Rodrigues, Luiz Carlos de Abreu, Fernando Rocha de Oliveira

Email: dy.fujihara@gmail.com

INTRODUÇÃO: O HIV causa uma imunodepressão, além de produzir repercussões cardíacas aumentando a incidência de cardiopatias na infecção por HIV e tem sido relatada como uma das principais causas de morte entre indivíduos HIVpositiva na Europa. A neuropatia autonômica pode ser um indicador precoce de doenças neurológicas relacionadas com envolvimento do HIV, refletida por redução da variabilidade da frequência cardíaca (VFC) apontada como um indicativo de pior prognóstico em doenças cardiovasculares. OBJETIVO: Descrever modulação autonômica cardíaca em homens com HIV/AIDS e lipodistrofia. MÉTODO: O estudo transversal foi realizado com indivíduos do sexo masculino com HIV/AIDS e 
lipodistrofia atendidos no Programa de DST/AIDS da Prefeitura de São Bernardo do Campo (Ambulatório de Lipodistrofia) no período superior a um ano. Antes do procedimento experimental foi realizado um protocolo rigoroso de identificação dos pacientes. O receptor de frequência cardíaca foi realizado por equipamento previamente validado e seus dados foram avaliados no domínio da frequência. RESULTADO: A amostra foi composta por 48 indivíduos sendo 22 do grupo com HIV e 26 com HIV e lipodistrofia. A média de idade dos grupos foram 43.68 (3.02) e 53.69 (2.08) respectivamente. Os resultados encontrados observaram significância estatística para perfil lipídico nas variáveis triglicérides 157.95 (14.36) e 232.5 (17.22) e colesterol total 177,13 (9.05) e 208.5 (8.35). Para os índices da variabilidade da frequência cardíaca não foi observado significância estatística, porém, os índices LF $\left(\mathrm{ms}^{2}\right) 441$ (352.95-850.99) e 289 (189.29-596.34) e HF $\left(\mathrm{ms}^{2}\right) 164$ (80.23217.52) e 67 (48.35-135.04) apresentaram tendência à significância. A lipodistrofia por si só é causa de alteração da VFC mesmo em indivíduos sem HIV/AIDS ou distúrbios metabólicos, entretanto, os mecanismos fisiopatológicos da disfunção autonômica da HIV/AIDS podem ser associados ao efeito neurotrópico do vírus e à terapia anti retro viral que leva a hiperglicemia e ao aumento do colesterol total. CONCLUSÃO: O estudo não verificou significância estatística, mas observou-se uma tendência para o índice HF e LF, além de algumas alterações no perfil lipídico o que pode representar um maior risco cardiovascular para os pacientes com lipodistrofia.

Palavras-chave: HIV; lipodistrofia; variabilidade frequência cardíaca; sistema nervoso autônomo.

\section{EPI-27 TEMPO DE ALEITAMENTO MATERNO E OBESIDADE EM PRÉ- ESCOLARES DE ESCOLA MUNICIPAL DE SÃO CAETANO DO SUL}

Bruna Rago Ricci, Caroline Ricci Castelan, Débora Ribeiros Fernandes, Gabriela Aoki Shimaoka, João Victor dos Santos Teixeira,

Karoline Passarela, Lívia Akemi Ramos Takahashi,

Nicolas Augusto Cabral Ribeiro, Denise de Oliveira Schoeps

Email: bruricci@ hotmail.com

INTRODUÇÃO: A obesidade é um fator de risco para o desenvolvimento de doenças crônicas, que causam grande mortalidade no mundo. Uma das medidas preventivas para tal condição corresponde ao aleitamento materno, o qual fornece o efeito protetor ao desenvolvimento do sobrepeso e obesidade infantil, especialmente quando em longa duração. OBJETIVO: Descrever a frequência de aleitamento materno total e exclusivo e a obesidade infantil, além de associar o menor tempo de aleitamento materno à tal obesidade. MÉTODO: Trata-se de um estudo transversal com 52 pré-escolares da escola municipal de São Caetano. Após autorização da escola e aprovação de responsáveis pelos pré-escolares (termo de consentimento livre esclarecido), foi avaliada a obesidade infantil por medidas antropométricas (peso, estatura e índice de massa corpórea - IMC) em relação às curvas de crescimento da Organização Mundial de Saúde, OMS 2005 - 2006. O tempo de aleitamento materno e o histórico alimentar foram obtidos por questionário padronizado preenchido pelos pais. Teste de comparação de média e mediano foi realizados como análise de dados. RESULTADO: De acordo com a amostra de 52 crianças, obtidas até então, foi encontrado um IMC médio de 16, com desvio padrão de 1,9. Tanto as crianças com aleitamento materno menor ou igual a seis meses, como as crianças com aleitamento materno acima de 6 meses, apresentaram um IMC de 16. No entanto o desvio padrão obtido foi de 2,15 e 1,22, respectivamente. Além disso, é observada uma diferença percentual entre ambas as categorias. $O$ percentual de sobrepeso foi de 35,7 para crianças com aleitamento menor que 6 meses, e 28,57 para as demais, considerando o IMC maior que 17 de acordo com a OMS. DISCUSSÃO: De acordo com a literatura, o aleitamento materno promove uma moderação de processos fisiológicos associados ao ganho de peso, durante a infância, através de diferentes mecanismos. Com base nos dados obtidos, até o presente momento, a amamentação apresenta-se como um fator protetor da obesidade infantil. Tendo esses resultados sido alcançados, com viés de informação dos sujeitos da pesquisa. CONCLUSÃO: Os resultados esperados não fugiram de todas as informações coletadas, referências e revisão de literatura. Em geral, a amamentação inapropriada está associada ao sobrepeso infantil.

Palavras-chave: aleitamento materno; obesidade; antropometria; crianças.

\section{EPI-28 USO DA MEDICINA COMPLEMENTAR POR PACIENTES ONCOLÓGICOS: UMA ANÁLISE SOBRE O CONSUMO DE FITOTERÁPICOS NA POPULAÇÃO ATENDIDA PELO SISTEMA ÚNICO DE SAÚDE}

Camila Ribeiro de Arruda Monteiro, Jean Henri Maselli Schoueri, Maria Leticia Lasca Sales Campos, In Young Noh, Alessandra Lima Nougueira Tolentino, Claudia Vaz de Melo Sette, Auro del Giglio, Daniel de Iracema Gomes Cubero

\section{Email: cml.monteiro@ hotmail.com}

INTRODUÇÃO: No Brasil, os fitoterápicos são amplamente utilizados, em função de fatores como a condição socioeconômica, a condição climática que favorece a flora local e a cultura local. Neste universo, destacam-se os pacientes oncológicos, que buscam a medicina complementar na esperança de obterem a redução de sintomas ou mesmo a cura para suas enfermidades. Neste cenário, é importante estudar a prevalência do uso de fitoterápicos e as razões pelas quais buscam esta alternativa. OBJETIVOS: Estudar epidemiologia dos principais fitoterápicos utilizados pela população oncológica, suas indicações e possíveis interações com tratamento tradicional. MÉTODO: Estudo transversal, realizado nos serviços de oncologia da FMABC. Os pacientes elegíveis assinaram o TCLE, preencheram uma ficha de identificação e um questionário relacionado ao tratamento complementar. RESULTADO: Foram inclusos 59 pacientes consecutivos, dos quais 39 não faziam uso de fitoterápicos e 20 utilizava. A análise do grupo que fazia uso levou ao seguinte perfil: $75 \%$ sexo feminino, média de idade de 57,7 anos; $65 \%$ declarou-se branco e quanto ao grau de escolaridade $85 \%$ possuía ensino médio completo ou maiores níveis de escolaridade. Em relação às repercussões geradas pela doença ou tratamento, $85 \%$ dos pacientes que fazem uso dessa terapia referiu ao menos um sintoma. Quanto a classificação dos fitoterápicos utilizados, $45 \%$ dos pacientes referiu utilizar ervas, $15 \%$ raízes, $5 \%$ sementes e $35 \%$ outros tipos. $85 \%$ relacionam melhora significativa dos sintomas ao uso de fitoterápicos. Observou-se também que $45 \%$ dos pacientes não comunicaram a equipe médica sobre o uso de tal tratamento. Os pacientes relacionam a melhora do seu quadro ao consumo dessas substâncias, e há uma lista de diferentes substâncias utilizadas para diversos fins, o que justifica estudo e a adequação da equipe médica. Vale ressaltar que a amostragem desta análise interina é pequena, por isso os resultados aqui apresentados mostram apenas uma tendência. A expansão da amostra, já em curso, permitirá conclusões mais definitivas. CONCLUSÃO: A análise interina mostrou que os fitoterápicos fazem parte da realidade dos pacientes atendidos pelo SUS, e que eles relacionam o uso de tais substâncias a melhora do quadro. O que mostra a necessidade de estudos mais detalhados sobre o tema para maior adaptação da equipe médica a essa realidade.

Palavras-chave: Fitoterápicos; Medicina complementar; Pacientes oncológicos; SUS.

\section{RELATO DE CASO CIRÚRGICO - RCI}

\section{RCl-01 ANEMIA SEVERA ASSOCIADA A LEIOMIOMATOSE UTERINA - RELATO DE CASO EM PACIENTE JOVEM COM NECESSIDADE DE CONDUTA MUTILANTE}

Cauê Fedrigo Loyola Batista, Bárbara Cristina Jardim de Miranda,

Pedro Augusto Soffner Cardoso, Danielle Yumi Akaishi, Flávia Yumi Ataka, José Henrique Miranda Borducchi, Sandra Di Felice Boratto,

Afonso Oetting Júnior

\section{Email: caue.fedrigo@gmail.com}

INTRODUÇÃO: Os leiomiomas são tumores benignos da musculatura lisa uterina (miométrio), cuja conversão maligna é extremamente rara. Sua incidência é maior em pacientes de raça negra e em idade fértil, sendo relativamente raros em mulheres jovens e em climatério. A maioria dos casos é assintomática, mas nos casos sintomáticos a hipermenorreia é a principal manifestação clínica, podendo estar associada à dor pélvica, aumento de volume abdominal, infertilidade e anemia. Mulheres com miomatose assintomática geralmente não necessitam de tratamento, mas devem ser acompanhadas e realizar exames ginecológicos anualmente. Alguns estudos questionam a eficiência do tratamento clínico da leiomiomatose, devido às altas taxas de recorrência dos tumores quando suspensa a medicação. O manejo cirúrgico depende do desejo reprodutivo da paciente, entre outros condicionantes. A miomectomia consiste no procedimento clássico para a remoção das lesões, mas existem casos que exigem a histerectomia como escolha ou ainda que permitam o uso de técnicas mais conservadoras, como a embolização de artérias uterinas. RELATO DE CASO: JFP, 32 anos, vinha apresentando há aproximadamente um ano hipermenorreia e menorragia acompanhada por cefaleia de forte intensidade, náuseas e astenia. Com relação a antecedentes pessoais, paciente relatou nunca ter tido relações sexuais, nem acompanhamento ginecológico de rotina. $\mathrm{O}$ exame físico detectou massa palpável em hipogástrio, enquanto que exames laboratoriais diagnosticaram anemia com $\mathrm{Hb}$ de $4,0 \mathrm{~g} / \mathrm{dL}$ e $\mathrm{Ht}$ de $13 \%$. A paciente foi submetida à laparotomia exploradora que confirmou a hipótese de leiomiomatose. O procedimento de escolha foi histerectomia total. O útero apresentou-se endurecido e com volume aumentado, com lesão subserosa à esquerda leiomiomas múltiplos intramurais e cervicite crônica inespecífica. Também foi en contrado endometrioma em ovário esquerdo com exérese de líquido achocolatado negativo para células neoplásicas malignas pela citologia oncótica. CONCLUSÃO: Dentre as possíveis complicações oriundas da leimiomatose uterina estão os quadros anêmicos, que variam de intensidade conforme o fluxo e duração do ciclo menstrual. Apesar de a miomectomia ser a conduta clássica para esses casos, a histerectomia pode-se fazer o procedimento de melhor escolha.

Palavras-chave: Leiomioma uterino; Hemorragia uterina; Anemia.

\section{RCl-02 BOLA FÚNGICA EM CISTO BRONCOGÊNICO}

Mariana Jancis Rigolo; Nicolle Martin Christofe; Ariadne Chaves Oliveira; Renata Tiemi Mizuno Watanabe; Leandro Klarge Carlos Cunha; Wladmir Faustino Saporito; Adilson Casemiro Pires;

Email: marianarigolo @ gmail.com

INTRODUÇÃO: Os cistos broncogênicos são lesões congênitas raras e assintomáticas, porém podem produzir sintomas caso ocorra uma infecção secundária. 
Bolas fúngicas são colonizações por fungos saprófitas e que, no parênquima pulmonar, formam cavidades que em geral não possuem infecção ativa, sendo mais comuns em sequelas de tuberculose e sarcoidose pulmonar e também descrita em bronquiectasias saculares entre outras lesões. RELATO DE CASO: Paciente masculino, 24 anos, sem antecedentes patológicos, com tosse produtiva, com secreção purulenta, febre baixa e imagem radiológica de abscessos pulmonares em lóbulo médio e lóbulo inferior direito. Tratado com clindamicina por 28 dias associado a ciprofloxacina nos primeiros 14 dias e gentamicina por mais 10 dias sem melhora radiológica, apesar da regressão sintomática clínica. Realizou-se broncoscopia que não mostrava anormalidades apesar de nível líquido persistente na radiografia de tórax. Nova tomografia mostra lesões praticamente inalteradas, tendo sido optado por tratamento cirúrgico. $\mathrm{O}$ achado cirúrgico foi de lesão cística com comprometimento apenas parcial do lobo sendo optado por sequestrectomia. CONCLUSÃO A Aspergilose pode apresentar características clínico-patológicas diversificadas. A forma invasiva é mais comum em pacientes imunodeprimidos, sendo a segunda infecção fúngica mais relatada entre pacientes submetidos a transplantes de órgãos sólidos ou de medula ou portadores de doenças hematológicas malignas, determinando mortalidade de 40 a 100\%. A comprovação diagnóstica no pulmão pode ser difícil devido à dificuldade de determinar sua presença em secreções respiratórias. A melhor forma de comprovação diagnóstica é a biópsia pulmonar a céu aberto ou a punção aspirativa. A associação entre cisto broncogênico e bola fúngica é pouco descrita na literatura, apesar do comportamento do fungo em infectar cavidades sem infecção prévia ser bastante plausível e explica o diagnóstico do paciente. No caso descrito, o início dos sintomas de infecção piogênica, levanta a possibilidade de ter havido uma infecção primária e logo após uma colonização pelo fungo. O tratamento realizado foi de ressecção do cisto, tendo como achado, a presença do fungo com cura deste paciente mesmo sem o uso de antifúngico no pós-operatório como sugere a literatura.

Palavras-chave: Bola fúngica; Cisto Broncogênico.

\section{RCl-03 CONDUTA CONSERVADORA PARA CASO DE RIM MULTICISTICO - RELATO DE CASO}

Cauê Fedrigo Loyola Batista, Caroline da Freiria Catilho Reche,

Lara Estupina Braghieri, In Young No, Vicente Antônio Gerardi

\section{Email: caue.fedrigo@gmail.com}

INTRODUÇÃO: O rim displásico multicístico é a malformação renal cística congênita mais frequente e a segunda causa de massa abdominal palpável na infância. Podendo ser identificado por meio da ultrassonografia pré-natal, possui incidência estimada de 1:1000 a 1:4300 nascidos vivos. É resultante de uma falha na embriogênese do metanéfron que ocorre precocemente na gestação e resulta na formação de massa cística no parênquima renal. A incidência de seu diagnóstico vem aumentando devido à evolução e uso disseminado da ultrassonografia fetal intrauterina e também devido ao avanço no conhecimento do curso e da fisiopatologia da doença. No passado, a conduta para os pacientes portadores dessa anomalia consistia no tratamento cirúrgico através de nefrectomia a fim de confirmar o diagnóstico, aliviar sintomas e eliminar o risco de hipertensão e malignidade. No entanto, essa técnica vem sendo substituída pelo seguimento clínico e ecográfico das crianças acometidas, já que os estudos demonstram a involução espontânea da doença e sua baixa incidência de complicações. RELATO DE CASO: LFA, masculino, encaminhado ao serviço de Cirurgia Pediátrica devido à ectasia pielocalicial esquerda detectada pela USG morfológica fetal. A USG pós-natal identificou rim esquerdo com formações císticas e paredes finas com presença de conteúdo anecóico, além de acentuada ectasia do sistema pielocalicial direito. DMSA de rim esquerdo revelou ausência de função, enquanto que o DTPA mostrou rim direito vicariante com fluxo e função glomerular preservado, mas com ectasia e resposta parcial ao estímulo diurético. Vale ressaltar que era referida boa diurese e que os valores de ureia e creatinina estavam dentro da normalidade. O paciente continua em acompanhamento conservador. CONCLUSÃO: Apesar de o manejo clássico para casos de rim multicístico ser a nefrectomia, o seguimento clínico vem criando espaço como técnica mais conservadora e com prognóstico satisfatório da evolução do paciente.

Palavras-chave: Rim multicístico; Displasia renal.

\section{RCI-04 CORREÇÃO DE CIFOSE EM PACIENTE COM MIELOMENINGOCELE}

Guilherme de Almeida Magalhães Gomes, Gustavo Ferrareto Pires, Paulo Victor Dias Macedo, Giuliana Annicchin, Marcel Arnaud Sanchez, Gabriel Sartori Calazans, Raphael Federicci Haddad, Bernardo Barreto Correa, Leonardo Yukio Jorge Asano, Luciano Miller Reis Rodrigues

\section{Email: gui921@ hotmail.com}

INTRODUÇÃO: Mielomeningocele é uma patologia que frequentemente evolui com deformidade na coluna vertebral, sendo a cifose uma manifestação grave e comprometedora da qualidade de vida do paciente. Devido a complicações secundárias à cifose como lesões cutâneas no ápice da deformidade e dificuldade de adaptação em cadeiras de rodas, correção cirúrgica da deformidade torna-se necessária, com diversos tipos de técnicas na literatura. RELATO DE CASO: Paciente de 11 anos de idade portadora de cifose da coluna vértebra secundária a mielomeningocele de nível torácico com lesão de pele no ápice da curvatura vertebral foi submetida a correção da deformidade com osteotomia de L1 e L2 através de acesso único posterior e fixação pedicular associado a haste de ancoragem distal no forame sacral. CONCLUSÃO: O tratamento da cifose secundário a mielomeningocele tem como objetivo corrigir e estabilizar a coluna para permitir equilíbrio sentado, diminuir a proeminência óssea e possibilitar um aumento da altura do tronco. A osteotomia vertebral associada a artrodese ampla pode ser um procedimento necessário para alcançar maior grau de correção em paciente com grave comprometimento vertebral.

Palavras-chave: Mielomeningocele; cifose; correção; osteotomia

\section{RCI-05 CISTO DE DISCO, UM CASO RARO DE COMPRESSÃO NEUROLÓGICA EM ADULTOS JOVENS.}

Caroline Castrucci Ingold, Raphael Federicci Haddad, Guilherme de Almeida Magalhães Gomes, Guilherme Murbach Aliberti, Gustavo Ferrareto Pires, Guilherme Yukio Kajiya Sakuma, Gabriel Sartori Calazans, Victor Bignatto Carvalho, Luciano Miller Reis Rodrigues, Leonardo Yukio Jorge Asano

Email: caroline.c.ingold@gmail.com

INTRODUÇÃO: Cistos de disco são lesões intraespinais extradurais expansivas que podem causar graus de compressão neurológica. Na literatura, poucos estudos abordam essa patologia extremamente rara. Dependendo de seu tamanho e de sua localização no canal espinal, a lesão pode causar sintomas que variam de dor na parte inferior das costas, radiculopatia unilateral ou bilateral, que podem ser graves, causando deficiências neurológicas. Por se tratar de uma patologia rara, não existe consenso na escolha de tratamento para aborda-las. Foram descritas diversas opções de abordagens para cistos discais: tratamento conservativo, injeção percutânea radiologicamente guiada, ressecção endoscópica e descompressão microscópica. RELATO DE CASO: Homem, 27 anos de idade tinha uma história de dor lombar Um mês após o início apresentou dor na perna esquerda grave, que se seguiu principalmente do dermatomo de L5. Seu exame físico apresentou teste de perna reta positiva dentro de 10 graus, na esquerda fraqueza de grau 4 para a extensão do pé, e incapacidade de andar nos seus calcanhares, no lado esquerdo. A ressonância magnética (RM) demonstrou uma lesão cística com uma intensidade de sinal fraco na imagem e de alta intensidade de sinal em T1 na imagem ponderada em T2 ao nível da massa cística L4-L5, localizada na face ventral do espaço extradural, deslocando dorsalmente o saco tecal. O disco intervertebral L4-L5 parecia ter degeneração leve. $\mathrm{Na}$ visão axial foi localizado no centro lateralmente para o lado esquerdo no canal medular, comprimindo a raiz transversa de L5. O paciente foi submetido a uma técnica microendoscópica minimamente invasiva. Um laminotomia conservadora foi feita, seguida por um flavectomia parcial. A raiz nervosa L5 foi cuidadosamente retraída e um cisto foi identificado ligado tanto ao saco tecal e o ligamento longitudinal posterior, esse foi rastreado até seu caule, que se comunicava com o disco L4-L5 por um rasgo anular central. O cisto e haste foram retirados na base. O paciente se recuperou completamente após o procedimento. CONCLUSÃO: Desde descrito em 2001 por Chiba et al., o cisto discal foi abordado em várias formas. Do tratamento conservador, punção guiada por tomografia computadorizad, cirurgia endoscópica percutânea e a descompressão microscópica. Devido a raridade da doença não se tem um consenso de abordagem.

Palavras-chave: cisto de disco; compressão neurológica; cirurgia minimamente invasiva.

\section{RCI-06 CISTO DISCAL: UMA CAUSA RARA DE COMPRESSÃO NEUROLÓGICA EM JOVENS}

Gabriel Sartori Calazans, Raphael Federicci Haddad, Guilherme de Almeida Magalhães Gomes, Alexandre Kyoshi Hidaka, Marcel Arnaud Sanchez, Guilherme Yukio Kajiya Sakuma, Karyse Helena Crispim Ribeiro Alves, Luciano Miller Reis Rodrigues, Leonardo Yukio Jorge Asano

\section{Email: gscalazans@gmail.com}

INTRODUÇÃO: Cisto discal é uma patologia rara, mais comum em pacientes do sexo masculino, em sua quarta década de vida. Sua apresentação clínica pode ser confundida com hérnia de disco, com dor nas costas, radiculopatia e déficit neurológico. Porque eles são raros, não há consenso sobre o tratamento. Uma grande variedade de processo tem sido descritas. RELATO DE CASO: A ressonância magnética (RM) demonstrou uma lesão cística a nível L4-L5. A massa cística deslocou o saco dorsa tecal com compressão acentuada da raiz transversa de L5. O paciente foi submetido a uma técnica microendoscópica minimamente invasiva utilizando um afastador tubular. Após o procedimento, o paciente apresentou ausência de dor nas pernas e voltou às suas atividades regulares 3 semanas após a cirurgia. $\mathrm{O}$ exame histopatológico do cisto revela tecido conjuntivo fibroso de espessura intercalado com áreas de inflamação crônica. Finalidade: Para documentar um caso de cisto discal no nível L4-L5 com compressão de L5 raiz nervosa direita tratada com sucesso com um procedimento minimamente invasivo. CONCLUSÃO: Cistos discais são lesões intra-espinhais raras. Eles podem desencadear os sintomas neurológicos graves, e deve ser diferenciada de outras formas de cistos epidurais e tumores. Devido à raridade dos cistos discais, não há consenso sobre o tratamento ideal. Portanto utilizou-se um método menos invasivo da conduta descrito em literatura. 
Palavras-chave: Procedimentos cirúrgicos; minimamente invasivos.

\section{RCl-07 GRANDE PSEUDOCISTO PANCREÁTICO}

Natália Sousa Alves Ferreira, Anderson Abdon Barbosa, Cassia Maria Nascimbem, Ana Caroline Fernandes Fontinele, Ricardo Moreno, Maurício Campanelli Costas

Email: nat.sousaferreira@gmail.com

INTRODUÇÃO: O pseudocisto pancreático se define como uma coleção que contém líquido rico em amilase, formado a partir do pâncreas, sem parede própria. Sua frequência varia de $16-30 \%$ em pancreatites agudas e de $20-40 \%$ em pancreatites crônicas. Sua etiologia está ligada com formas de dano pancreático e sua evolução pode ter solução espontânea ou aparecer como complicações complexas, direcionado a possibilidade de tratamento cirúrgico. RELATO DE CASO: Paciente masculino, 55 anos, etilista grave chega em 2013 ao nosso serviço com pancreatite aguda de origem biliar, resolvida após realização de colecistectomia com exploração radiológica, quando foi detectada estenose de colédoco e deixado com dreno transcístico Posteriormente, paciente apresentou exame de imagem compatível com tumoração em cabeça de pâncreas. Durante ato operatório para cirurgia de Whipple foi observada irressecabilidade da lesão com realização de biópsias. Paciente evoluiu bem nos anos seguintes, até chegar no nosso serviço em janeiro de $2016 \mathrm{com}$ intensa dor abdominal, anorexia e perda ponderal. Na TC observou-se enorme pseudocisto pancreático hipertensivo. CONCLUSÃO: O pseudocisto pancreático representa cerca de $75 \%$ das lesões císticas do pâncreas. Na presença de pseudocistos pancreáticos estes podem ser assintomáticos e ter resolução espontânea ou até ter resoluções abdominais catastróficas, incluindo sangramento, ruptura e infecção em quadros agudos. A conexão desse caso complexo desde o diagnóstico até o pós-operatório será descorrido no trabalho.

Palavras-chave: Pseudocisto pancreático; pancreatite crônica.

\section{RCI-08 HEMANGIOMA HEPÁTICO GIGANTE ASSOCIADO À SÍNDROME DE KASABACH-MERRIT}

Victor Harasawa Uno, Sandra Carina Lopez Calcines, Beatriz de Santana Soares, André Merini Menini, Tamlyn Tieme Matushida, Paulo Victor Dias Macedo, Lívia yadoya Vasconcelos, Ligia Walter Moura, Fernanda Ribeiro Danziere, Franscisco Antonio Sergi, Tércio Genzin

\section{Email: victorharasawauno @ gmail.com}

INTRODUÇÃO: Hemangioma é o tumor hepático (benigno) mais comum. Normalmente, são assintomáticos e não maiores do que $4 \mathrm{~cm}$ de diâmetro. A Sindrome de Kasabach-Merritt é descrita pela presença de hemangioma (hepático ou não) gigante (maior de que $4 \mathrm{~cm}$ de diâmetro) associada à coagulopatia de consumo. A taxa de mortalidade dessa síndrome varia de 10 - 37\% e o tratamento de escolha são cirúrgicos, sempre que o tumor for passível de ressecção. Esse trabalho tem por objetivo relatar o caso clínico de uma paciente portadora de Síndrome de Kasabach-Merritt submetida a tratamento cirúrgico. RELATO DE CASO: M.J.S.C., mulher, 56 anos, portadora de hepatite do tipo B encaminhada ao Hospital Beneficência Portuguesa de São Paulo por quadro de Síndrome de Kasabach-Merritt: hemangioma hepático gigante (com shunt da artéria hepática média) associado à coagulopatia. A paciente foi internada no serviço e submetida a segmentectomia hepática (segmento IVA e VIII). Apresentou ótima evolução no pós-operatório, tendo tido alta hospitalar cinco dias após o procedimento cirúrgico. Após 60 dias da cirurgia, a paciente segue em acompanhamento ambulatorial, assintomática e com exames laboratoriais normais. CONCLUSÃO: Hemangiomas são os tumores hepáticos mais frequentes, sendo, normalmente, diagnosticados durante exames abdominais de rotina. A síndrome de Kasabach-Merritt é uma complicação rara, mais comum em crianças do sexo masculino. O tratamento dessa patologia é difícil, porém, a ressecção do tumor é, na maioria das vezes, curativa, estando indicada sempre que possível.

Palavras-chave: Hemangioma; Síndrome de Kasabach-Merrit.

\section{RCl-09 HÉRNIA DE SPIEGEL: RELATO DE CASO}

Natanael Martins Ribeiro, Guilherme Henrique Fagundes da Silva, Isabela Nacione Pedruzzi, Alexandre Cruz Henriques, Ricardo Moreno

\section{Email: natanael.medicina2017@ hotmail.com}

INTRODUÇÃO: Neste trabalho, os autores ressaltam a raridade da Hérnia de Spiegel (HS), correspondendo a menos de $1 \%$ das hérnias ventrais. Trata-se de um quadro, em geral oligossintomático e de difícil diagnóstico, sendo necessários exames de imagem, nos quais observa-se a integridade da aponeurose do Músculo Oblíquo Externo (MOE). RELATO DE CASO: AAM, sexo masculino, 62 anos, encaminhado ao serviço de Cirurgia Geral devido à abaulamento em quadrante inferior direito do abdômen há cerca de 02 anos, associado a episódios de dor abdominal. O diagnóstico de HS foi confirmado através da Tomografia Computadorizada, cujas imagens confirmaram a integridade da aponeurose do MOE, lateralmente à Linha Semilunar de Spiegel. Submetido à herniorrafia por via laparotômica com colocação de tela de polipropileno. Evoluiu sem complicações e com resultados satisfatórios. No seguimento ambulatorial, o paciente se apresentou assintomático. CONCLUSÃO: Geralmente, a HS aparece na $4^{\circ}$ década de vida sem predileção por sexo e raramente é bilateral. Independentemente de ser do lado direito ou esquerdo, normalmente seu conteúdo é composto por epíplon e alças de intestino delgado. Não são comuns relatos de encarceramento ou estrangulamento. Em geral, é oligossintomática, manifestando-se com vaga dor abdominal e abaulamento. Sua etiologia é incerta, mas os principais fatores predisponentes são aqueles relacionados ao aumento da pressão intrabdominal: obesidade, ascite, tosse crônica, gestações múltiplas, perda súbita de peso, doenças prostáticas. O tratamento é cirúrgico, e raro são os casos de recidiva.

Palavras-chave: hérnia; spiegel; semilunar ventral.

\section{RCl-10 INTERVENÇÃO POR TÉCNICA HÍBRIDA DE ANEURISMA DE ARTÉRIA SUBCLÁVIA ESQUERDA - RELATO DE CASO}

Luisa Emanuela Biseo Henriques, Diego Monteiro De Melo Lucena, Ramon Félix Martins Fernandes, Paulo Roberto Zamfolini Zachêu, João Antônio Corrêa, Marina Raphe Matar, Andrea Paula Kafejian Haddad, Stephania Morreale, Sidnei José Galego

Email: luisa_henriques@ hotmail.com

INTRODUÇÃO: Os aneurismas da artéria subclávia (AAS) são raros em relação a aneurismas periféricos. Os AAS podem ser assintomáticos, apresentando apenas massa pulsátil na região supraclavicular, porém tem potencial risco de ruptura, embolização distal e trombose. Procedimentos híbridos que combinam simultaneamente procedimentos cirúrgicos abertos e endovasculares surgiram como uma opção terapêutica para esse aneurisma. RELATO DE CASO: Paciente APS, do sexo masculino, 51 anos, foi diagnosticado com AAS esquerda com grande diâmetro, sem colo. Paciente portador de Hipertensão Arterial Sistêmica, Diabetes Mellitus tipo 2 e com história prévia de IAM com introdução de 2 stents há 3 anos.Paciente chegou ao nosso serviço com dor torácica ao repouso de forte intensidade com 4 horas de duração. O ECG na admissão não apresentou alterações isquêmicas agudas. Durante investigação clínica, foi diagnosticado AAS esquerda na tomografia computadorizada de tórax. Observou-se uma dilatação aneurismática da porção posterior da croça da aorta descendente e uma dilatação da emergência da artéria subclávia esquerda, sem sinais de dissecção. Foi realizado tratamento híbrido endovascular visando o isolamento do aneurisma da artéria subclávia esquerda com planejamento inicial de endoprótese com segmento descoberto na emergência de artéria carótida esquerda. Após o implante dessas endoprótese houve migração do dispositivo para o interior do aneurisma. Optou-se por técnica de resgate com colocação de segundo dispositivo com stent descoberto na emergência do tronco braquiocefálico. Anteriormente da abertura do dispositivo, realizou-se enxerto PTFE anelado heparinizado extra-anatômico carótido D-carotídeo E, e derivação extra anatômica carotídeo E-subclávio E com colocação de dispositivo híbrido. No pós operatório imediato, o paciente apresentava pulsos palpáveis. Paciente recebeu alta hospitalar sem anormalidades ou intercorrências, fazendo uso de antiagregante plaquetário. Após trinta dias de pós operatório, o paciente evoluiu com perda de força de membro inferior esquerdo. Realizou-se ressonância magnética com imagem de infarto lobular parietal direito, que evoluiu sem sequelas. CONCLUSÃO: Neste caso, a abordagem endovascular do AAS associada à técnica cirúrgica aberta, tornou-se uma boa opção no tratamento dessa lesão complexa intratorácicas, com bons resultados.

Palavras-chave: Artéria Subclávia; Procedimento Endovascular; Endoprótese.

\section{RCI-11 INTUSSUSCEPCCÃO INTESTINAL POR RARO PÓLIPO FIBROIDE INFLAMATÓRIO: RELATO DE CASO}

Raphael Federicci Haddad, Ligia Walter Moura, Lívia Yadoya Vasconcelos, Paulo Victor Dias Macedo, Tamlyn Tieme Matushita, André Marini Menini, Beatriz de Santana Soares, Sandra C. Lopez Calcines, Tércio Genzini, Fernanda Ribeiro Danziere, Francisco Antonio Sergi Filho

Email: raphael_haddad@outlook.com

INTRODUÇÃO: Intussuscepção ocorre quando uma porção proximal do intestino invagina-se para uma mais distal a si. É relativamente rara em adultos, compondo apenas $1 \%$ dos pacientes com obstruções intestinais. As causas mais comuns são tumorais, sendo $80 \%$ destas associadas ao intestino delgado (benignos). Lipomas e tumores estromais gastrointestinais (GIST) são os mais prevalentes na população adulta, e os pólipos fibróides inflamatórios (IFP) raramente causam intussuscepção ileal. RELATO DE CASO: A. M. P. 71 anos, sexo feminino, admitida no pronto atendimentocom dor abdominal, náuseas,vômitos e parada de eliminação de flatos e fezes há 24 horas. Ao exame físico, apresentava distensão abdominal,hipertimpanismo e ruídos hidroaéreos diminuídos. Iniciadas medidas na admissão hospitalar, como hidratação e pro-cinéticos intestinais, evacuou em moderada quantidade e melhorou clinicamente após 12 horas. Solicitou-se uma colonoscopia, que identificou um pólipo em cólon sigmoide, sem outras alterações. Então, fez-se uma tomografia computadorizada de abdome, que evidenciou intussuscepção íleo-ileal em quadrante inferior direito do abdome. No quinto dia de internação hospitalar ainda apresentava distensão abdominal e pouca evacuação, sendo submetida a uma videolaparoscopia diagnóstica. Esta identificou importante dilatação de todo o intestino fino até $40 \mathrm{~cm}$ da válvula íleo-cecal, encontrando o ponto de intussuscepção. Exteriorizou-se, então, o ponto de obstrução por uma 
pequena incisão mediana infraumbilical, de $5 \mathrm{~cm} \mathrm{e}$, manualmente,desfez-se a invaginação e identificou-se lesão ovalada de $5 \times 5 \mathrm{~cm}$ no interior de alça ileal. Procedeu-se com enterectomia segmentar da parte intussuscepta, já isquêmica, com margens distantando mais de $5 \mathrm{~cm}$ da tumoração,anastomose látero-lateral mecânica e antibiótico terapia.À patologia,o perfil imunohistoquímico da lesão,associado ao quadro histológico,era compatível com IFP. Recebeu alta no terceiro dia de pós operatório com antibióticos por mais 4 dias e dieta leve. CONCLUSÃO: $\mathrm{O}$ caso está de acordo com a literatura: paciente do sexo feminino, entre a quinta e sétima décadas de vida, com queixas de suboclusão intestinal, em topografia ileal, e apresenta uma rara causa de intussuscepção intestinal. A paciente segue em acompanhamento ambulatorial com a equipe cirúrgica sem complicações no intra e no pós-operatório até o momento.

Palavras-chave: intussuscepção intestinal, suboclusão intestinal, pólipo fibroide inflamatório.

\section{RCl-12 LINFEDEMA, O QUE É E POR QUE SABER TRATAR?}

Luisa Emanuela Biseo Henriques, Diego Monteiro De Melo Lucena, Ramon Félix Martins Fernandes, Stephania Morreale, Cintia Sayuri Hoshii Suguiyama, Paulo Roberto Zamfolini Zachêu, João Antônio Corrêa, Sidnei José Galego, Marina Raphe Matar, Andrea Paula Kafejian Haddad

\section{Email: luisa_henriques@hotmail.com}

INTRODUCÃ̃: Linfedema é uma doença crônica caracterizada pelo acúmulo de líquido intersticial de alta concentração proteica, decorrente de insuficiência da drenagem linfática por anormalidades congênitas ou adquiridas. No Brasil, a incidência do linfedema é pouco conhecida. Este caso é de uma paciente com linfedema primário precoce com agravamento do quadro no decorrer dos anos. RELATO DE CASO: MNS, 44 anos, feminino, branca. Paciente foi encaminhada ao ambulatório de Cirurgia Vascular do Hospital de Ensino Padre Anchieta - Disciplina de Cirurgia Vascular da Faculdade de Medicina do ABC. Na primeira consulta há 16 anos, a queixa era de edema indolor, espontâneo e progressivo em membro inferior esquerdo há quatro anos. Negava trauma, cirurgia prévia no membro, quadro semelhante na família, hipertensão arterial sistêmica, Diabetes Mellitus. Quando interrogada, referiu quadros sugestivos de erisipela no membro inferior esquerdo com piora do edema. Ao exame físico de entrada, apresentava edema bilateral dos membros inferiores, porém mais acentuado à esquerda, com deformidade deste, tendo sido feita a hipótese de linfedema dos membros inferiores: de grau II à direita e de grau III (Elefantíase) à esquerda pela classificação de Mollew. Notava-se micose interdigital em ambos os pés. O diagnóstico clínico foi confirmado por linfocintilografia com Tc-99. Resolvemos apresentar este estudo devido à paciente ter evoluído com a progressão da doença também no membro inferior direito para o grau III (Elefantíase). Como isso ocorreu? Para responder esta pergunta decidimos apresentar este estudo por meio de levantamento de prontuário. CONCLUSÃO: Em muitos pacientes, a manifestação clínica do linfedema é observada apenas em uma extremidade e, na investigação linfocintilográfica, há alterações bilaterais, fato que alerta e auxilia no tratamento preventivo de alterações do membro aparentemente normal ao exame físico. Na literatura médica há evidências de que a profilaxia antimicrobiana pode reduzir os episódios de recidiva da erisipela. Embora a doença não tenha cura, há tratamentos que melhoram a qualidade de vida dos pacientes e previne uma evolução do quadro com deformidade do membro como ocorreu neste estudo, por isso a importância do conhecimento desta enfermidade e de seu tratamento.

Palavras-chave: Linfedema; Sistema Linfático; Cintilografia; Extremidade Inferior.

\section{RCl-13 PERSISTÊNCIA DA ARTÉRIA CIÁTICA ASSINTOMÁTICA - RELATO DE CASO}

Luisa Emanuela Biseo Henriques, Diego Monteiro De Melo Lucena, Ramon Félix Martins Fernandes, Stephania Morreale, Cintia Sayuri Hoshii Suguiyama, Gustavo Bertollini Lamy, João Antônio Corrêa, Sidnei José Galego, Marina Raphe Matar, Andrea Paula Kafejian Haddad

\section{Email: luisa_henriques@ hotmail.com}

INTRODUÇÃO: Persistência da Artéria Ciática (PSA) é uma anomalia rara com incidência de $0,03 \%$ a $0,06 \%$, que consiste na persistência da artéria ciática, a qual deveria regredir no terceiro mês da embriogênese dando lugar ao segmento proximal da artéria glútea inferior. A maioria dos casos de PAC é diagnosticada quando ocorre uma complicação como isquemia, sintomas de compressão ou rotura da dilatação aneurismática. RELATO DE CASO: A. A. A, 63 anos, feminino, branca, passou em consulta no ambulatório da Faculdade de Medicina do ABC com queixa de edema em membros inferiores há 1 mês. Negava qualquer tipo de dor nos membros inferiores ou lesões tróficas, Diabetes Mellitus e tabagismo. Paciente referia hipertensão arterial. No exame físico apresentava edema $+/ 4$ e todos os pulsos normais $(4+/ 4)$ nos membros inferiores, porém as artérias poplíteas apresentavam-se hiperpulsáteis bilateralmente. Foi solicitado Doppler venoso e arterial dos membros inferiores, o venoso para investigação do edema e o arterial para afastar doença aneurismática da artéria poplítea devido a hiperpulsatilidade. O Doppler venoso não mostrou maiores alterações. O Doppler arterial do membro inferior direito era normal; no do membro inferior esquerdo notava-se artéria femoral "superficial" pérvia em terço proximal e médio e em terço distal não era visualizada (provável hipoplasia), além de apresentar também calibre reduzido em relação à artéria femoral do membro contralateral. A artéria poplítea apresentava-se pérvia ectasiada medindo $0,83 \mathrm{~cm}$, com paredes lisas, regulares e fluxo proveniente de provável artéria ciática persistente, com continuidade para face posterior e ascendente na coxa (trajeto não habitual). $\mathrm{Na}$ coxa posterior a artéria mede $0,93 \mathrm{~cm}$ e, por isso, foi feita a hipótese diagnóstica de PAC. Foi solicitado exame de Doppler arterial colorido de artéria aorta e artérias ilíacas para confirmar e complementar o diagnóstico além de avaliar a artéria ciática em todo o trajeto. CONCLUSÃO: PAC é uma anomalia rara, com alta incidência de complicações, como formação de aneurisma e isquemia. A formação de aneurisma ocorre em aproximadamente $46 \%$ dos casos. Estas complicações podem levar a uma amputação em $8 \%$ dos casos. A maioria das PAC assintomáticas não é detectada, só sendo diagnosticada quando já existem complicações associadas.

Palavras-chave: Artéria Ciática; Aneurisma; Congênito; Isquemia.

\section{RCl-14 RECONSTITUIÇÃO DA FUNÇÃO DE PINÇA APÓS AMPUTAÇÃO TRAUMÁTICA DE POLEGAR}

Isabela Pereira Blanco, Rodrigo Mattner Gaspar, Pedro Soffner Cardoso, Gustavo Ferraneto Pires, Othon Moritoshi Shiroma, Luiz Felipe Fernandes, Márcio Aurélio Aita, Douglas Hideki Ikeuti

Email: isa.blanco@ hotmail.com

INTRODUÇÃO: O trauma da mão, mais incidente na população economicamente ativa, representa uma lesão que frequentemente deixa sequelas funcionais significativas. A amputação parcial do polegar consiste em uma lesão traumática comum nesta população. Para esse tipo de trauma, no qual se destacam as múltiplas fraturas, ruptura de ligamentos, tendões e nervos, nem sempre o tratamento adequado previne e minimiza as complicações. Devem-se buscar métodos alternativos para o salvamento, principalmente do polegar, visando à retomada da função primordial da pinça. RELATO DE CASO: R.A.L., 23 anos, sexo masculino, canhoto, auxiliar de serviços de engenharia civil, procurou o serviço de emergência do Hospital Municipal de Santo André vítima de acidente de trabalho com serra circular $\left(\right.$ Makita $\left.^{\varpi}\right)$, dia 24/02/16. Apresentava amputação total do polegar esquerdo, com o coto distal armazenado de forma correta. A princípio tentou-se o reimplante, porém evoluiu com necrose de partes moles. Optou-se pela limpeza cirúrgica da região acometida e buscou-se a cobertura das falanges proximal e distal com um retalho chinês. Com uma semana de pós-operatório, houve necrose parcial e exposição da falange distal, realizando sua retirada e a cobertura da região dorsal com retalho de Kitte e da região lateral com enxerto de pele. No mesmo ato operatório, manteve-se o fio Kirchner em falange proximal e primeiro metacarpo, com o intuito de alongamento deste por meio de uma haste e fixador externo. Nesta técnica, realiza-se osteotomia do primeiro metacarpo e, em seguida, alongamento ósseo gradativo com auxílio do fixador. Pretende-se, após o alongamento e a remoção do fixador externo, fazer o acompanhamento ambulatorial e a realização futura de comissuroplastia para aumentar a amplitude de pinça da mão dominante do paciente. CONCLUSÃO: A reconstituição do movimento de pinça é de extrema importância para realização de atividades diárias, como escrever, digitar, manusear talheres, entre outras habilidades manuais, devendo ser prioridade quando se trata de trauma da mão. É necessário o uso de ferramentas específicas, como a microcirurgia e a reconstrução óssea com fixadores externos. O tratamento é longo, com múltiplos procedimentos e curativos, e requer uma abordagem multidisciplinar com a participação da família do paciente, enfermeira, cirurgião de mão, terapeuta ocupacional e psicóloga.

Palavras-chave: Retalho chinês; amputação traumática; pinça bimanual; alongamento metacarpal.

\section{RCl-15 RECONSTRUÇ̃̃O DE LESÕES DISTAIS DA MÃO USANDO RETALHO ADIPOFASCIAL.}

Natalia Rebeque Modolo, Henrique Batissoco de Siqueira, Othon Moritoshi Shiroma, Gustavo Ferraneto Pires, Isabela Pereira Blanco, Luiz Sorrente, Luiz Felipe Fernandes Longuino, Rafael Saleme

\section{Email: modolo89@gmail.com}

INTRODUÇÃO: Lesões complexas envolvendo as superfícies extensoras e flexoras da mão são uma ocorrência comum. O resultado dessas lesões é muitas vezes a destruição dos tecidos incluindo pele, tendões cápsula articularp eriósteo e osso. O atendimento primário dessas lesões é dirigido para controlar a infecção fornecendo cobertura de tecidos moles. Reconstrução de tecidos moles da mão posa como desafio. Opcõoes terapêuticas são inúmeras. Cada método, no entanto, tem desvantagens significativas limitando a sua aplicaçãoo clínica. RELATO DE CASO: L R J 35 anos masculino vítima de acidente de motocicleta versus caçamba de lixo. Apresentava trauma do quarto quirodáctilo tendo como lesão associadas avulsão da loja extensora deste dedo. Porém, não apresentava lesão óssea ou articular. Na urgência foi submetido á limpeza e sutura primária do ferimento cortocontuso que evoluiu com necrose de pele e subcutâneo. Foi proposta pelo grupo da mão uma reabordagem cirúrgica para desbridamento do tecido desvitalizado e cobertura das estruturas nobres expostas através de retalho adipofascial. A técnica cirúrgica consistiuem: $\mathrm{O}$ tamanho do defeito é medido assim também o retalho adipofascial necessário para sua cobertura. A pele sobrejacente ao retalho é incisada cuidadosamente até a camada dérmica. A pele da região doadora é dissecada sem o componete adiposo e mantida segura lateralmente pelo uso de ganchos. O retalho adipofascial então é dissecado livre dos músculos subjacentes. A dissecação do retalho para cerca de 1 a $1,5 \mathrm{~cm}$ antes que a 
borda do defeito seja alcançada. O retalho é dobrado em cima de sua base fixa e voltado para alcançar a extremidade oposta do defeito. Enxerto de pele total ou parcial é colocado sobre o retalho para cobertura. A pele da região doadora é reaproximada. Uma atadura metálica é aplicada sobre um bolo de gaze sobre a pele transplantada e a mão é imobilizada por uma tala. CONCLUSÃO: Retalhos adipofasciais locais para cobertura de tecidos moles em mãos oferecem várias vantagens que incluem a simplicidade e a rapidez do procedimento, um único ato cirúrgico, e não há necessidade de desepitelização. Proporciona um retalho delgado e de boa flexibilidade, e mínima deformidade do local doador. Comprado a outros retalhos é consideravelmente de mais fácil transposição. Menos enxerto de pele é necessário Os nervos sensitivos cutâneo são preservados com dissecação meticulosa, enquanto que ao executar um retalho tradicional é sacrificado para habilitar o retalho alcançar o defeito. Porque a mão executa uma função mecânica ímpar, uma boa cobertura de tecido mole é imperativa. $\mathrm{O}$ retalho ideal para cobrir defeitos de tecidos moles da mão deve fornecer gordura suficiente para cobrir estruturas nóbres e ser esteticamente interessante. $\mathrm{O}$ retalho adipofascial preenche esses critérios.

Palavras-chave: retalho adipofascial; reconstrução em mão.

\section{RCl-16 RECONSTRUÇÃO DE LIGAMENTOS INTRÍNSECOS E EXTRÍNSECOS DO PUNHO APÓS TRAUMA DE ALTA ENERGIA: UM RELATO DE CASO.}

Paulo Victor Dias Macedo, Rodrigo Mattner Gaspar, Marcel Arnaud Sanchez, Natália Rebeque Modolo, Pedro Augusto Soffner Cardoso, Márcio Aurélio Aita, Luis Felipe Fernandes Longuino, Douglas Hideki Ikeuti

\section{Email: paulomacedo.fmabc@gmail.com}

INTRODUÇÃO: Os traumatismos do punho e da mão correspondem a 43,6\% da incidência geral de traumatismos dos ossos do carpo como um todo, sendo lesões graves por destruirem a cápsula, os ligamentos e, principalmente, a circulação desses. O resultado esperado para os pacientes é que tenham um punho com déficit de movimentos e presença de necrose óssea e insuficiência ligamentar. Desta forma, torna-se necessário o tratamento adequado a fim de minimizar todas as possíveis complicações, visando preservar ao máximo as funções do membro acometido. RELATO DE CASO: L.L.O, masculino, 25 anos,encaminhado ao setor de emergência do Hospital Estadual Mario Covas, vítima de acidente de moto,em colisão auto $\mathrm{x}$ moto, em alta velocidade. Ao exame físico, notou-se luxação completa dos ossos do carpo em relação aos do antebraço, sendo encaminhado imediatamente ao centro cirúrgico. O punho foi abordado por um acesso dorso-radial. O tendão do músculo braquioradial foi dissecado e utilizado para o enxerto na reconstrução do ligamento radioscafocapitato, mantendo a inserção no estilóide radial. O coto proximal do tendão foi passado por 3 túneis: $\mathrm{O}$ primeiro iniciou na face radial do rádio,direção oblíqua,terminando no centro da articulação da fossa escafoídea do rádio. O segundo foi no escafóide, sentido de dorsal para palmar e o terceiro, no capitato, de palmar para dorsal. O coto do enxerto foi suturado ao eixo dorsal do terceiro metacarpo com uma âncora e com tendese no extensor radial curto do carpo. O carpo foi realinhado e estabilizado (após a tensão adequada dada ao neo-ligamento). Para proteger a reconstrução ligamentar, estabilizamos o punho com fixador externo transarticular, com dois pinos de Schantz no rádio e dois no terceiro metacarpal $\mathrm{O}$ enxerto de tendão foi fixado na face volar do escafóide e no dorso da diáfise do terceiro metacarpo com âncoras de sutura. O punho ficou imobilizado por oito semanas e depois o fixador externo e os pinos foram removidos sob anestesia local. Até agora, evoluiu sem comorbidades no intra e pós-operatório. CONCLUSÃO: As reconstruções dos ligamentos e das articulações carpais devem ser reconstruídas de forma a recuperar a capacidade funcional da mão, para atividades diárias e laborais. A cirurgia foi bem sucedida, e o paciente manter-se-á inserido no mercado de trabalho e na sociedade. Hoje, segue em acompanhamento ambulatorial com a equipe de cirurgia da mão e com a fisioterapia.

Palavras-chave: luxação; ossos do carpo; articulações do carpo.

\section{RCl-17 RELATO DE CASO: CARCINOMA GIGANTE DE ADRENAL ASSOCIADO A INVASÃO DE VEIA CAVA}

André Marini Menini, Beatriz de Santana Soares, Paulo Victor Dias Macedo, Tamlyn Tieme Matushita, Ligia Walter Moura, Livia Yadoya Vasconcelos, Raphael Federicci Haddad, Sandra Carina Lopez Calcines, Fernanda Ribeiro Danziere, Francisco Antonio Sergi Filho, Tercio Genzini

\section{Email: andre_menini@hotmail.com}

INTRODUÇÃO: O carcinoma de adrenal é considerado o segundo tipo de câncer endócrino mais agressivo, é mais comum na primeira e na quinta décadas de vida e afeta mais mulheres do que homens, em uma proporção de 1,5:1. Esse tumor tem uma incidência de 1 caso em 1,7 milhões ( $0,02 \%$ de todos os tumores) e, aproximadamente, $60 \%$ deles cursam com elevação da produção hormonal (geralmente cortisol). Tumores adrenais maiores do que $6 \mathrm{~cm}$ geralmente são carcinomas que, em mais de $70 \%$ dos casos, já estão disseminados no momento do diagnóstico. O objetivo deste pôster é relatar um carcinoma gigante de glândula adrenal com invasão de veia cava. RELATO DE CASO: R.B.S., mulher, 53 anos encaminhada ao Hospital Beneficência Portuguesa de São Paulo com diagnóstico de tumor de adrenal. A paciente estava tentando controlar a pressão arterial por 7 meses porém, sem sucesso. Além disso, ela tinha ganhado $15 \mathrm{~kg}$ neste mesmo período. Realizou
TC que mostrou massa adrenal direita com invasão de veia cava retrohepática, se estendendo até o átrio direito. Após discussão multidisciplinar na reunião do setor de Oncologia, a paciente foi submetida a uma ressecção atrial direita (com retirada da metástase) e plastia da válvula tricúspide, depois disso, foi submetida adrenalectomia com nefrectomia direita e cavoplastia abdominal com colocação de prótese Dracon. A paciente permaneceu no hospital por 24 dias e depois retornou a sua cidade de origem para realizar o acompanhamento oncológico. CONCLUSÃO O carcinoma da glândula suprarrenal se estende, primeiramente, para as estruturas circunvizinhas, tais como: rins, veia cava superior e inferior e, algumas vezes, para o átrio direito. Os fatores de mau prognóstico são: estágio avançado, ressecção cirúrgica incompleta, alto grau, idade avançada e tamanho maior que $10 \mathrm{~cm}$. O tratamento cirúrgico é a primeira escolha, mesmo em casos de estágios avançados. Se não tratado, o prognóstico é ruim, com menos de 35\% de sobrevida em 5 anos. Palavras-chave: carcinoma; adrenal; veia cava; adrenalectomia.

\section{RCI-18 RELATO DE CASO - PAPEL DA BIOPSIA GONADAL NO MANEJO DE PACIENTE COM SÍNDROME DE TURNER}

Cauê Fedrigo Loyola Batista, Bárbara Cristina Jardim Miranda, Julia Fernanda Pellegrim, Vicente Antônio Gerardi Filho

\section{Email: caue.fedrigo@gmail.com}

INTRODUÇÃO: A Síndrome de Turner é baseada na ausência parcial ou completa de um dos cromossomos sexuais, sendo que $50 \%$ dos indivíduos afetados possui cariótipo 45,X0. Estudos apontam que histologia e anatomia das gônadas de pacientes com distúrbios de cromossomos sexuais são bastante complexas: a maior parte das portadoras da ST possui gônadas disgenéticas, compostas apenas por estroma ovariano e tecido conjuntivo cicatricial. Durante muito tempo a gonadetectomia foi recomendada para pacientes com distúrbios de desenvolvimento sexual. Porém, por tratar-se de um procedimento radical e irreversível, é importante considerar técnicas mais conservadoras, como a laparoscopia associada à biópsia gonadal. Sugere-se que a biópsia gonadal seja uma técnica útil para estudo histológico detecção de células pré-neoplásicas em casos de diagnóstico duvidoso, principalmente quando relacionada com FISH e PCR. Hoje em dia, está bem estabelecida a relação entre a presença do cromossomo $\mathrm{Y}$ em gônadas disgenéticas e o risco aumentado de tumores gonadais, em especial quando se leva em conta a expressão dos genes OCT4, TSPY e SRY. Visa-se, portanto, a prevenção precoce de modificações causadas pela expressão desses genes, bem como do possível desenvolvimento de tumores. RELATO DE CASO: JVS, feminino, 10 anos, chegou ao serviço de Cirurgia Pediátrica encaminhada pela equipe de Endocrinologia com o quadro de obesidade (40 kg), baixa estatura (1,23 m), idade óssea compatível com 10 anos, hipertelorismo mamário e desenvolvimento puberal M1P2. Teste de cariótipo e amplificação do gene TSPY revelaram mosaicismo 45,X(26)/46,X + MAR(24) presença de fragmentos $\mathrm{Y}$, respectivamente. A USG pélvica mostrou útero com dimensões reduzidas sem evidências tumorais no miométrio; os ovários não foram visualizados. A RNM de sela turca não apresentou alterações. $\mathrm{O}$ manejo cirúrgico se deu quando a paciente tinha 12 anos e consistiu em ooforectomia bilateral que identificou ovários em fita. Ao AP, os ovários apresentaram tecido escasso de estroma, com abundante fibrose e congestão vascular; as tubas uterinas apresentaram-se congestas. CONCLUSÃO: A biópsia gonadal assume papel de destaque no manejo de pacientes com ST, pois constitui ferramenta importante na detecção de fragmentos do cromossomo Y em gônadas disgenéticas e possibilita a adoção de medidas precoces de prevenção contra tumores gonadais.

Palavras-chave: Síndrome de Turner; Biópsia gonadal; Gônada disgenética.

\section{RCl-19 TRATAMENTO DE TRAUMA RENAL POR EMBOLIZAÇÃO PERCUTÂNEA}

Paulo Roberto Zamfolini Zachêu, Ramon Félix Martins Fernandes, Diego Monteiro de Melo Lucena, Luisa Emanuela Biseo Henriques, Enrico Gonelli Gennari, Cintia Sayuri Hoshii Suguiyama, Gian Carlo Vassoler, Gustavo Bertollini Lamy, Marina Raphe Matar, Sidnei José Galego, João Antônio Correa

\section{Email: paulozacheu@ hotmail.com}

INTRODUÇ̃̃O: O trauma renal ocorre em $8 \%$ a $10 \%$ dos pacientes traumatizados, sendo $85 \%$ a $90 \%$ causados por trauma contuso. A embolização percutânea de artérias segmentares do rim é considerada procedimento minimamente invasivo e faz parte do algoritmo de tratamento de hemorragias causadas por trauma renal ou distúrbios de coagulação. RELATO DE CASO: Paciente GSB, masculino, 27 anos, branco, deu entrada no Pronto-Socorro após ter sofrido um trauma contuso em flanco esquerdo causada por um acidente de trânsito há 20 dias. Apresentava na admissão hematoma em hipocôndrio esquerdo, hematúria significativa $4+\backslash 4+$ e intensa dor na região. Ao exame físico apresentava-se descorado $2+/ 4+$, estável hemodinamicamente, Pulso $=110 \mathrm{bpm}, \mathrm{PA}=110 \times 70 \mathrm{mmHg}$, dor em flanco esquerdo intenso à palpação, descompressão brusca negativa. Realizados exames laboratoriais: hemoglobina de $11 \mathrm{mg} / \mathrm{dl}$ e hematócrito de 34\%. Realizada tomografia computadorizada (TC) de abdome, que evidenciou imagem hiperecogênica em loja renal esquerda sem extravasamento de contraste, com limites menores de $1 \mathrm{~cm}$ sugeriu-se trauma renal tipo II, hematoma perirrenal não-expansivo confinado ao retroperitônio renal com profundidade $<1 \mathrm{~cm}$ do córtex renal, sem extravasamento urinário. O paciente permaneceu estável hemodinamicamente e foi dada alta 
para o paciente. No dia seguinte, o paciente procurou o Hospital de Ensino Padre Anchieta com o quadro de hematúria macroscópica. Foi realizada uma arteriografia no paciente que detectou a hemorragia em uma das arteríolas do rim esquerdo. Pautando-se no algoritmo, foi classificado como grau IV, com laceração que se estende pelo córtex renal, medula e sistema coletor. Optou-se por uma embolização com micropartículas pVA (Polivinil Alcool) 500-700 micras com embolização permanente. O paciente, atualmente, se mantém com os níveis pressóricos normais, sem queixas e com retorno de suas atividades profissionais. CONCLUSÃO: A arteriografia com embolização se mostrou fundamental para o tratamento deste paciente e deve sempre ser lembrada pelo cirurgião geral ou do trauma. Trata-se de método pouco invasivo, que pode ser realizado sob anestesia local, com rápida recuperação. No entanto, ainda trata-se de recurso pouco disponível, principalmente em serviços públicos.

Palavras-chave: trauma renal; embolização percutânea; arteriografia;

cirurgia vascular

\section{RCI-20 SÍNDROME DE REGRESSÃO CAUDAL - RELATO DE CASO}

Cauê Fedrigo Loyola Batista, Reynaldo Estevez Júnior, Vicente Antônio Gerardi Filho

\section{Email: caue.fedrigo@gmail.com}

INTRODUÇÃO: A síndrome de regressão caudal (SRC) é uma malformação congênita caracterizada por anormalidades osteomusculares da coluna lombossacral, pelve e membros inferiores, podendo estar relacionada com distúrbios renais, genitourinários, digestivos, cardíacos e pulmonares. A incidência da síndrome é rara, sendo que 16 - 22\% das crianças afetadas são filhas de mães diabéticas. Acredita-se que a etiopatogenia circule ao redor das consequências do diabetes materno, hipoperfusão vascular e predisposição genética. O diagnóstico pré-natal é possível com USG transvaginal de alta resolução ao redor da $9^{\text {a }}$ semana de gestação ou com USG simples a partir da $22^{\mathrm{a}}$. A severidade das alterações e o prognóstico da doença dependem da quantidade de vértebras acometidas. O tratamento deve contar com uma equipe multidisciplinar, envolvendo ortopedistas e urologistas pediátricos disponibilizando atenção especial à função muscular, sensibilidade dos membros inferiores, controle de escoliose e atividade dos órgãos internos. RELATO DE CASO: WSP, 10 anos, masculino, apresentou-se ao serviço de Cirurgia Pediátrica do Hospital Estadual Mário Covas com o quadro de agenesia de membro inferior esquerdo, escoliose tóraco-lombar, pé torto congênito à direita, quadris anquilosados em rotação externa, incontinência vesicointestinal, infecções urinárias de repetição e testículo esquerdo palpável em região inguinal esquerda, sem déficit cognitivo. Após exame físico e radiológico, o paciente foi submetido à correção cirúrgica da escoliose neuromuscular e osteossíntese de fêmur direito, além da or quidopexia esquerda. $\mathrm{Na}$ evolução, desenvolveu orquite à direita e hérnia inguinal esquerda, resolvidas com drenagem de abcesso e exérese de granuloma do testículo direito e herniorrafia inguinal esquerda com tela, respectivamente. CONCLUSÃO Apesar do quadro clínico da Síndrome variar de acordo com o grau de comprometimento vertebral, o paciente relatado apresentou alterações típicas da doença O manejo envolveu equipes de ortopedia e urologia, conforme é preconizado na literatura, e o paciente continua em acompanhamento no HEMC. Atualmente com 16 anos, é hábil o suficiente para lidar com situações cotidianas básicas, mostrando que, apesar de a etiologia primária da doença ser irreversível, o tratamento é importante para garantir melhor qualidade de vida para os portadores da SRC.

Palavras-chave: Regressão caudal; Agenesia sacral.

\section{RCl-21 SUCESSO NO TRATAMENTO DE FERIDAS COMPLEXAS EM MÉDIO-PÉ COM PLÁSTICO ESTÉRIL.}

Pedro Augusto Soffner Cardoso, Paulo Victor Dias, Henrique Batissoco de Siqueira, Othon Moritoshi Shiroma, Isabela Pereira Blanco, Márcio Aurélio Aita, Rafael Saleme, Luiz Felipe Fernandes Longuino

\section{Email: pedro.soffner.cardoso@gmail.com}

INTRODUÇÃO: O trauma tornou-se uma doença muito significativa no cenário hospitalar. Cada vez mais o número de vítimas sobe e, estas, com uma característica preocupante: envolver uma faixa etária que compreende adultos jovens e economicamente ativos. A amputação de um membro em decorrência das lesões sofridas causa um impacto social ainda maior. Ferimentos nas extremidades dos membros, em queda de motocicleta, são extremamente comuns, podendo variar de simples escoriações, até complexas mutilações. RELATO DE CASO: IOS, 19 anos, masculino, sofreu queda de motocicleta no dia 01/03/2016 sendo levado pelo SAMU ao Centro Hospitalar Municipal de Santo André. Fora diagnosticado com fratura diafisária de fêmur esquerdo e fratura exposta de ante-pé e médio-pé direito. No primeiro momento cirúrgico, na urgência, realizou-se tração esquelética em tíbia direta, e amplo desbridamento em pé direito. Nesta fase observou-se perda de tecido cutâneo e do $4^{\circ}$ e $5^{\circ}$ metatarsos. No segundo ato cirúrgico, realizou-se a osteossíntese do fêmur. Para substituir os metatarsos perdidos no acidente, optou-se por colocar no local cimento ósseo guiado por fios Kirschner e realização de curativo com plástico estéril (parte transparente do coletor de urina) em dorso e região plantar do pé, tendo alta hospitalar em $24 \mathrm{~h}$ pós cirurgia. Ambulatorialmente fora realizado curativos seriados semanais e troca do plástico a cada 3 semanas. Realizou-se no último ato cirúrgico enxerto de fíbula para substituir o cimento ósseo, não tendo a necessidade de enxertia de pele. DISCUSSÃO: A utilização do plástico estéril no tratamento de lesões complexas tem mostrado ótimos resultados no tratamento de feridas. Favorece a formação de tecido de granulação e aumento do fluxo sanguíneo na região, que proporcionam uma enxertia local de pele, substituindo, muitas vezes, retalhos complexos. Essa técnica permite uma qualidade de vida melhor ao paciente, uma vez que ele pode deambular e até tomar banho. Além disso, o baixo custo do curativo com o plástico transparente do coletor de urina ( 3 a 4 reais), evita o uso de alternativas muito mais caros (VAC/íntegra). Desse modo, visto sua alta hospitalar rápida e a não necessidade de troca do curativo em ambiente cirúrgico e o baixo valor do curativo, diminui-se o custo de internação do paciente e a oneração do SUS. Palavras-chave: Feridas complexas; curativo com plástico estéril; coletor urina, baixo custo.

\section{RCl-22 VARIEDADE DO ARSENAL TERAPÊUTICO ENDOVASCULAR E MEDIDAS COADJUVANTES PERMITEM AUMENTAR AS CHANCES DE TRATAMENTO DE MEMBROS EM CASOS COMPLEXOS}

Juliana Hegedus Baroni, Ramon Felix Fernandes Martins, Diego Monteiro de Melo Lucena, Luisa Emanuela Biseo Henriques, Enrico Gennari Gonelli, Paulo Roberto Zamfolini Zachêu, Fernanda di Bella Santos, Rafael Furst, Marina Raphe Killing, Sidnei José Gallego,

João Antônio Correa

\section{Email: julianahbaroni@ hotmail.com}

INTRODUÇÃO: Demonstrar que a somatória do arsenal terapêutico, disponível ao cirurgião vascular permite aumentar as chances de tratamento de membro em casos complexos. RELATO DE CASO: Paciente MFFA, do sexo masculino, 70 anos, ex-tabagista, portador de Hipertensão Arterial Sistêmica (HAS), diabetes mellitus (DM) tipo II e neoplasia prostática localmente avançada em programação de tratamento cirúrgico, com queixa de claudicação limitante de membro inferior direito e lesão trófica interdigital nos $3^{\circ} \mathrm{e} 4^{\circ}$ pododáctilos que evoluiu com dor em repouso. No exame físico o pulso femoral bilateral estava ausente, com lesão trófica entre o $3^{\circ}$ e $4^{\circ}$ pododáctilos com necrose. Ao estudo angiográfico através de angiografia digital encontrou-se suboclusão de artéria ilíaca comum direita próxima à bifurcação aórtica e estenose da artéria ilíaca comum esquerda. Em membro inferior direito, foi identificado oclusão da artéria femoral superficial na sua origem com reenchimento de artéria poplítea (TASC D) supragenicular e lesões de artéria de perna com reenchimento parcial do arco plantar. Optou-se por angioplastia de segmento aórtico ilíaco com técnica de Kissing Ballon com utilização de stents auto-expansivos. Tentou-se no mesmo ato por via anterógrada recanalizar a artéria femoral superficial sem sucesso. O paciente evoluiu com melhora parcial do quadro sendo submetido, então, a oxigenoterapia hiperbárica e desbridamento local com amputação de $3^{\circ}$ e $4^{\circ}$ pododáctilos, evoluindo com isquemia de borda da ferida e progressão da área da necrose, englobando $2^{\circ}$ e $5^{\circ}$ pododáctilos. Dada a persistência da isquemia e impossibilidade de recanalização por via anterógrada, optou-se por recanalização de artéria femoral superficial com stent tipo Woven-Stent (SUPERA) de baixa força radial através de punção retrógrada de artéria poplítea ecoguiada. No mesmo ato cirúrgico, o paciente foi submetido à amputação transmetatarsiana com correção de retalho de plantar e, logo após, foi iniciado terapia de pressão negativa com boa evolução. Paciente foi submetido posteriormente, após melhora do quadro, à regularização do coto, evitando-se dessa forma uma amputação maior CONCLUSÃO: A variedade do arsenal terapêutico endovascular se mostrou fundamental para o tratamento e preservação do membro deste paciente. Portanto, o cirurgião vascular deve estar habilitado para estas novas táticas terapêuticas.

Palavras-chave: Procedimento Endovascular; Membros; Woven-Stent; Angioplastia

\section{RELATO DE CASO CLÍNICO}

\section{RCL-01 ABSCESSO HEPÁTICO AMEBIANO: RELATO DE CASO}

Luiz Felipe Avila Carvalho Custodio da Silva, Matheus Polly, Xu Xue Qing, Lina Yamaguchi, Carolina Fuin Zauith, Sandra Boratto

\section{Email: Ifaccsmedabc@gmail.com}

INTRODUÇÃO: O Abscesso hepático amebiano é uma das complicações extraintestinais mais comuns da colite amebiana. Estima-se que $10 \%$ da população mundial esteja infectada pelo protozoário Entamoeba histolytica, o agente etiológico principal da colite amebiana, o que resulta em aproximadamente 50 milhões de casos de amebíase invasiva. Apontam-se 40 milhões de novos casos anualmente que resultam em 100 mil mortes anuais. A prevalência é muito maior em países em desenvolvimento quando comparada com países desenvolvidos, uma vez que aqueles não contam com amplo serviço de saneamento básico, enquanto que a grande maioria da população residente em países desenvolvidos é infectada por conta de viagens a áreas endêmicas de países em desenvolvimento. Menos de $1 \%$ dos casos de infecção por E. histolytica evoluem para a forma de abscesso hepático amebiano. RELATO DE CASO: Primeiro paciente: W. R. O, 45 anos, sexo masculino, deu entrada no pronto socorro do Centro Hospitalar do Município de Santo André com 
hipótese diagnóstica de abdome agudo inflamatório, foi submetido a laparotomia exploratória com ressecção de apendices epiploicos por apendagite epiploica, porem não houve melhora clínica, mantinha leucocitose e a ultrassonografia mostrou abscesso hepático de aproximadamente $7 \mathrm{~cm}$ de diâmetro, confirmado por tomografia computadorizada de abdome. Segunda paciente: J.M.C., 75 anos, feminina, deu entrada do mesmo serviço com hipótese diagnóstica de abdome agudo inflamatório, com história de contato com água de rio no interior de Pernambuco, foi realizada tomografia de abdome, que evidenciou abcesso hepático, cuja etiologia amebiana foi confirmada por exame microscópico de fezes a fresco. Foi iniciado tratamento clínico com antibioticoterapia e antiparasitário para ambos os pacientes, observando-se como resultado a diminuição das lesões, confirmadas por exame radiológico, não sendo, portanto, necessária intervenção cirúrgica em nenhum dos casos. CONCLUSÃO: As condutas adotadas foram conservadoras e consistiram na administração de antiparasitários e antibióticos, não se optando pela drenagem dos abscessos. Condutas estas preconizadas por outros relatos e estudos que mostraram que a punção dos abscessos deve ser reservada para casos particulares e que a adoção única da terapia farmacológica é eficaz na diminuição do tamanho e resolução dos abscessos

Palavras-chave: Abscesso hepático; Amebiano; E. histolytica; Tratamento clínico.

\section{RCL-02 ARTIGO DE REVISÃO: ACOMETIMENTOS} NEUROLÓGICOS NA DEFICIÊNCIA DE CIANOCOBALAMINA

José Henrique Miranda Borducchi, Carolina Nicolela Susanna, Davimar Miranda Maciel Borducchi, Vitor Augusto Queiroz Mauad

\section{Email: jhmborducchi@gmail.com}

INTRODUÇÃO: A vitamina B12 é necessária para o desenvolvimento e mielinização do SNC, assim como para a manutenção de sua função normal. Sua deficiência é bastante comum e ocorre por deficiência dietética; modificações no $\mathrm{pH}$ gástrico; insuficiência na dosagem ou função de proteases pancreáticas; deficiência do fator intrínseco gástrico; deficiências nos receptores ileais para o complexo IF-B12. A apresentação clínica clássica, com anemia megaloblástica e sintomas neurológicos discretos é amplamente reconhecida. Em revisão recente publicada no NEJM, apenas $29 \%$ dos pacientes com deficiência de vitamina B12 apresentava anemia, sendo comum apenas a apresentação neurológica, o que confunde e leva a erros no tratamento do doente. RELATO DE CASO: JDA, 68 anos, natural e procedente da Grande SP, casado, aposentado. Chegou ao serviço queixando-se de perda de força em MMII, acompanhada de perda de sensibilidade, ascendente e progressiva há 4 meses. Evoluiu nos 15 dias anteriores à admissão com fraqueza importante em membros inferiores, perda de equilíbrio, dificuldade de marcha. Em seus antecedentes, referiu dieta a base de carnes e carboidratos, poucas verduras. No exame físico apresentou força G IV em MMII, G V em MMSS, perda da sensibilidade vibratória e simétrica em MMII, Romberg e Lhermitte positivo, marcha dificultosa, deambulava apenas com apoio. Sensibilidade tátil diminuída em MMII, sensibilidade térmica aparentemente preservada. Foi solicitado o hemograma, na entrada em $22 / \mathrm{Fev}$, o qual não apresentou alterações. Dosou-se os níveis séricos de vitamina B12 e ácido folico, os quais estavam diminuídos, nesse ponto, o tratamento com reposição para-enteral foi iniciado. Posteriormente, em 25/Fev dosou-se a homocisteína e ácido metilmalônico, apresentando apenas elevação da primeira. Realizou biópsia gástrica, apresentando diagnóstico de gastrite crônica antral moderada, inativa, com agregados linfóides na lâmina própria e H. Pylori ausente. CONCLUSÃO: $\mathrm{Na}$ anamnese de paciente com deficiência de vitamina B12 pode-se encontrar sintomas de anemia, distúrbios subjacentes que causam má absorção, e sintomas neurológicos. O nosso paciente apresentou-se apenas com alterações neurológicas, e na investigação da etiologia encontrou-se gastrite crônica em antro. Chamamos a atenção para a possibilidade deste espectro clínico da insuficiência de cianocobalamina.

Palavras-chave: vitamina B12; deficiência; anemia; neurológicos

\section{RCL-03 ARTRITE REUMATÓIDE EM PACIENTE COM RETOCOLITE ULCERATIVA INESPECÍFICA}

Pedro Matos, Elaine Shizue Novalo-Goto, Michelle Gomes dos Santos, Sonia Maria Alvarenga Anti Loduca Lima

\section{Email: pedro89mts@gmail.com}

INTRODUÇÃO: A Retocolite Ulcerativa Inespecífica (RCUI) é uma doença inflamatória sistêmica, de etiologia desconhecida e de natureza autoimune. Sua sintomatologia condiz principalmente com diarreia crônica resultante do acometimento do cólon e do reto. Além dos sintomas clássicos, a RCUI também pode apresentar manifestações extra-intestinais como dores articulares, contudo, é rara a associação entre RCUI e Artrite Reumatóide (AR). RELATO DE CASO: MAS, 29 anos, feminino, iniciou acompanhamento no ambulatório de gastroenterologia da FMABC em 2007. Relatava queixa de obstipação intercalada com episódios de diarreia e dor abdominal em cólica. Os resultados da colonoscopia com biópsia foram sugestivos de RCUI e foi iniciado o tratamento com Mesalazina. Em 2010, a paciente, durante o tratamento da RCUI, evoluiu com queixa de dores articulares em mãos, cotovelos, joelhos e pés acompanhadas de edema e calor local associadas a rigidez matinal. Na investigação diagnóstica foi observada elevação das Provas de Atividade Inflamatória e Fator Reumatóide (FR) Positivo em baixos títulos. Feito o diagnóstico de AR e iniciado o uso de anti-malárico associado a baixas doses de glicocorticóide e analgésicos, a paciente evoluiu mantendo de leve a moderada atividade inflamatória articular. Em 2011, foi iniciado tratamento com Adalimulabe com total controle do quadro intestinal, porém sem melhora articular. Em 2013, foi realizada substituição de Adalimulabe por Infliximabe, afim de melhor controle da RCUI e do quadro articular. Na ocasião, exames laboratoriais: FR 16UI Anti-Peptídeo Citrulinado Cíclico (Anti-CCP) 90UI/ml, Fator Anti-Nuclear (FAN) $1 / 160$ padrão nuclear e citoplasmático. A paciente segue em acompanhamento e em sua última consulta, outubro de 2015, após a 2a infusão de Infliximabe encontrava-se com a doença articular em remissão. CONCLUSÃO: A associação entre AR e RCUI é raramente descrita na literatura e ainda não se sabe se há uma patogênese comum as duas doenças. Na literatura, alguns estudos demonstraram que a resposta imune anormal às bactérias intestinais pode ser um fator desencadeante do aparecimento de sinovites e colites por meio da ativação das células T, corroborando assim para uma relação concreta entre a patogenia da AR e RCUI. Entretanto, este ainda é um campo de pesquisa muito vasto e se faz necessário um maior número de pesquisas sobre o tema.

Palavras-chave: Artrite Reumatóide; Retocolite Ulcerativa Inespecífica; relato de caso; auto-imune.

\section{RCL-04 DIAGNÓSTICO DIFERENCIAL DE LESÃO EXPANSIVA CEREBRAL HEMORRÁGICA.}

Kenzo Saito Tomishige, Elberth José dos Santos, In Young Noh e Rodrigo Scabora, Cláudio Campi de Castro, Zélia Maria de Sousa Campos

\section{Email: kenzotomishige@gmail.com}

INTRODUÇÃO: Os métodos de imagem permitem o diagnóstico de formações expansivas do Sistema Nervoso Central. Lesões Hemorrágicas geralmente são hiperatenuantes na Tomografia Computadorizada (TC) e, na Ressonância Nuclear Magnética (RNM), hiperintensas em T1 e hipointensas em T2. No entanto, nem sempre é simples o diagnóstico diferencial entre lesão hemorrágica não neoplásica, neoplasia com componente hemorrágico e metástase de melanoma. RELATO DE CASO: Paciente do sexo masculino, 73 anos, com antecedente pessoal de melanoma em dedos do pé, iniciou quadro de hemiparesia à direita, sem alteração de pares cranianos. A TC de Crânio evidenciou uma lesão lobulada espontaneamente hiperatenuante na região frontal esquerda, associada a extenso edema perilesional e à compressão do ventrículo lateral ipsilateral, levando a um discreto desvio das estruturas da linha média para a direita. Posteriormente, a RNM demonstrou lesão hiperintensa em T1, hipointensa em T2 e com leve realce pós-contraste, e extenso edema perilesional. Em seguida, o exame anatomopatológico revelou uma neoplasia maligna pouco diferenciada, infiltrando tecido cerebral, e com intensa deposição de pigmento acastanhado, compatível com metástase de melanoma. CONCLUSÃO: Os Tumores Cerebrais Metastáticos ocorrem em até $30 \%$ dos pacientes com câncer metastático, e os achados clínicos que podem estar presentes em um processo tumoral no lobo frontal consistem em alterações de personalidade hemiparesia contralateral. O fato de a lesão citada anteriormente ser hiperatenuante na TC, hiperintensa em T1 e hipointensa em T2 na RNM, fez com que se pensasse em lesão hemorrágica como, por exemplo, Hematoma Intraparenquimatoso (HIP) ou uma Metástase Cerebral Hemorrágica. Metástase de Melanoma também entraria no diagnóstico diferencial, já que pode apresentar os mesmos aspectos de imagem. O HIP Cerebral na TC, é traduzido por lesão hiperdensa com ou sem halo hipodenso circunjacente (edema) estendendo-se à Substância Branca nos lobos frontais e temporais, preferencialmente. A metástase de melanoma pode ser observada como uma lesão arredondada com realce anular, circundada por intenso edema perilesional, espontaneamente hiperintensa em T1 e heterogênea, e é um importante diagnóstico diferencial de HIP, uma vez que é a neoplasia com maior taxa de sangramento, e a que possui a maior propensão para se disseminar ao SNC. Palavras-chave: Lesão Expansiva Cerebral; Hematoma Intraparenquimatoso; Metástase de Melanoma; Lesão Hemorrágica.

\section{RCL-05 DIAGNÓSTICO E ACOMPANHAMENTO DA SÍNDROME DE STICKLER: RELATO DE CASO}

Carolina Akyko Uehara, Cristina Nery Carbajo, Luciano Rabello Netto Cirillo, Mariana Gameiro lerardi, Gabriel Castilho Sandoval Barbosa, Thiago Cavenaghi Castanheira, Kenzo Saito Tomishige, Beatriz Jeronymo Pardi, Thalita Cipriano de Sá Ambrosano, Jéssica Agena, Wesley de Paula Duque

\section{Email: caakyko@gmail.com}

INTRODUÇÃO: A Síndrome de Stickler (SS) é uma artro- oftalmopatia hereditária progressiva, causada por distúrbios do colágeno. Foi descrita em 1956 como uma miopia iniciada nas primeiras décadas de vida, que resultava em descolamento de retina (DR) e cegueira. Hoje, a SS é a causa mais comum identificada de DR em crianças. O diagnóstico pode ser confirmado por análise genética. RELATO DE CASO: AF, 7 anos, masculino. Mãe refere que com um ano o filho acompanhava objetos apenas com o olho esquerdo (OE). Aos três anos foi diagnosticado $\mathrm{DR}$ em olho direito (OD). Realizado introflexão e vitrectomia via pars plana em OD. Ao exame físico: AVOD: movimento de mãos AVOE: 20/20 (-18,00 -1,50 180 $)$ Ectoscopia OD: esotropia (ET), reflexo vermelho ausente. OE: sem alteração. Além de todas as patologias oftalmológicas apresenta alterações ortopédicas, baixa estatura, déficit de fala, devido a alterações de face e articulação, e alterações cardíacas. 
A análise com o kit P070-B2(investigação da presença de deleções e duplicações nas regiões subteloméricas de todos os cromossomos humanos) e P064-B3 (investigação da presença de deleções e duplicações nas regiões envolvidas nas principais síndromes de microdeleção) não evidenciou alterações nas regiões pesquisadas. CONCLUSÃO: A Síndrome de Stickler é uma doença autossômica dominante com envolvimento sistêmico e progressivo. É uma síndrome rara, com incidência de 1/7500 nascidos vivos. A criança acima descrita apresenta diversas características da SS podendo levar ao seu diagnóstico clinico, apesar de não ter sido detectado a alteração cromossômica. Nesse caso o paciente não teve acompanhamento precoce com o oftalmologista, o que retardou o diagnóstico e acompanhamento correto. Atualmente apresenta baixo prognóstico visual no olho direito devido a sequela do descolamento de retina. Porém, mesmo com a alta miopia, quando corrigida com lentes apresenta uma visão excelente no olho esquerdo. Crianças diagnosticadas com SS necessitam acompanhamento constante e multidisciplinar, portanto quanto antes for feito o diagnostico melhor será a estrutura de acompanhamento.

Palavras-chave: Síndrome de Stickler; Descolamento de retina; Colágeno; Cegueira.

\section{RCL-06 DIAGNÓSTICO TARDIO DE FC, A IMPORTÂNCIA DA INVESTIGAÇÃO ENTRE IRMÃOS}

Thais Cristina Chiandotti de Souza, Renata Marli Gonçalves Pires, Lara Braghieri, Jessica Zambelli, Marina Martinelli Sonnenfeld, Victor Negrini, Mayara de Cássia Benedito, Maria Fernanda Botelho Hernandez Perez

\section{Email: tchiandotti@gmail.com}

INTRODUÇÃO: Fibrose Cística é uma doença genética autossômica recessiva, que altera o gene Regulador de Condução Transmembrana (CFTR). Sua mutação gera distúrbio no transporte de íons, afetando as secreçoes dos tratos respiratório gastrointestinal e reprodutivo, tornando-as mais viscosas, possibilitando, principalmente, infecções bacterianas crônicas das vias respiratórias, disfunção pancreática exócrina, intestinal e urogenital. Os primeiros sinais e sintomas costumam ocorrer na infância e variam com a mutação do gene. O diagnóstico é realizado pelo exame clínico, triagem neonatal, história familiar, Teste da Concentração de Cloro no Suor e análise das mutações do gene CFTR, que é o mais específico e confiável no diagnóstico. RELATO DE CASO: ACS, 5a, F, parda; com crises de chiado desde os primeiros meses de vida. Mãe referiu crises de IVAS (infecções de vias aéreas superiores) que evoluem para broncoespasmo desde os primeiros meses de vida Refere apetite voraz, coriza nasal, espirros, prurido, obstrução nasal e tosse esporádica, chiado $3 \mathrm{x} /$ ano. Fezes pastosas, sem odor forte e gordura, $3 \mathrm{x} /$ dia. Sono agitado, respiração oral, tosse e roncos. Enurese noturna. Sem intercorrências na gestação $\mathrm{Na}$ consulta, encontra-se eutrófica. Ao exame físico apresenta xerodermia e conchas nasais de mucosa pálida com coriza. Vem a consulta após o nascimento da irmã IVSS em abril de 2016, a qual apresentou alteração no Teste do Pezinho (dosagem da tripsina imuno-reativa - IRT de $145 \mathrm{ng} / \mathrm{ml}$ aos 2 dias de vida e $139.80 \mathrm{ng} / \mathrm{ml}$ aos 21 dias) sendo submetida ao teste do cloro no suor, que também deu positivo, confirmando o diagnóstico de Fibrose Cística. A irmã mais nova estava colonizada com microrganismos multirresistentes em vias aéreas e apresentava diversos outros sintomas típicos da Fibrose Cística. Este fato levantou a hipótese de ACS também possuir a doença. A paciente foi submetida ao teste de cloro no suor que também positivou. CONCLUSÃO: O caso apresentado evidencia o componente genético da doença. As irmãs apresentam a doença, porém em graus diferentes. A suspeita veio da Triagem Neonatal e a confirmação diagnóstica se deu através do Teste da Concentração de Cloro no Suor somada à história clínica. A irmã mais velha somente foi diagnosticada após a irmã mais nova apresentar alteração na triagem neonatal e possui quadro muito mais brando

Palavras-chave: fibrose cística; irmãos; diagnóstico tardio.

\section{RCL-07 DISTONIA RESPONSIVA À LEVODOPA - RELATO DE CASO}

Ariadine Chaves de Oliveira, Margarete de Jesus Carvalho e Débora Pezzolato

\section{Email: ariadinec.oliveira@yahoo.com.b}

INTRODUÇÃO: A distonia é um distúrbio hipercinético do movimento, com contrações involuntárias, intermitentes ou constantes, em que há alterações da postura e da execução dos movimentos. A doença de Segawa é uma forma rara de distúrbio de movimento, caracterizada por manifestações distônicas, que acomete 0,5 a 1 pessoa por milhão no mundo, principalmente mulheres. Em geral, os sintomas se iniciam na primeira década de vida. RELATO DE CASO: AAT, feminino, 7 anos, encaminhada por distrofia muscular progressiva, diagnosticada à eletroneuromiografia. Aos 5 anos começou a ter quedas frequentes e dores em joelhos, com episódios de enrijecimento de membros, além de tremores, sem perda da consciência, evoluindo com progressiva dificuldade de locomoção. Negou uso de medicamento ou histórico familiar. $\mathrm{Na}$ investigação realizaram-se exames laboratoriais, USG de abdome e exame oftalmológico, sem alterações. Ao exame físico a paciente estava consciente, contactuante, com fácies cushingoide, desenvolvimento neuropsicomotor normal. Apresentava pés equinos, hiperlordose e escoliose e postura distônica com hipertonia dos quatro membros, deambulando com auxílio. Os reflexos-ósteo-tendinosos estavam exaltados nos quatro membros, com predomínio em MMII. Havia ainda clônus bilateral em MMII, reflexo cutâneo-plantar em extensão bilateral, dificuldade de manter-se sentada sem apoio e distonia nos pés, principalmente no esquerdo, e por vezes atetose em MMII. Não havia alterações na fala. O tratamento foi iniciado com 1 comprimido ao dia de levodopa + benserazida com melhora imediata da sintomatologia. CONCLUSÃO: Segawa $e$ al. descreveram uma distonia com rápida resposta a pequenas doses de levodopa em que havia melhora completa do quadro, conhecida como Distonia Responsiva à Levodopa (DRD). A fisiopatologia se dá por deficiência enzimática de GTP ciclohidrolase I (autossômica dominante), ou de tirosina hidroxilase (autossômica recessiva) no sistema nigroestriado dopaminérgico. As manifestações iniciais são a postura distônica em MMII com deformidade equino varus em ambos os pés, além de distonia segmentar e tremores em membros superiores. O diagnóstico definitivo ocorre por testes genéticos, mas diagnóstico através do teste terapêutico à levodopa é importante pelo fato de se tratar de uma distonia de fácil tratamento, garantindo que os pacientes recuperem a qualidade de vida.

Palavras-chave: distonia; doença de Segawa; distonia flutuante; levopa.

\section{RCL - 08 FARMACOGENÉTICA NA INFERTILIDADE: USO DO INIBIDOR DE AROMATASE ASSOCIADO COM POLIMORFISMO NO GENE FSHR}

Ramon Félix Martins Fernandes, Renato de Oliveira, Camila Martins Trevisan, Denise Maria Christofolini, Bianca Bianco, Caio Parente Barbosa

Email: ramonffernandes@yahoo.com.br

INTRODUÇÃO: Dentre as principais causas de infertilidade está a endometriose. Neste contexto destaca-se o hormônio folículo-estimulante (FSH) na proliferação folicular do ovário3. Para tanto, o adequado funcionamento do receptor de FSH (FSHR) é fundamental4. Há dois polimorfismos comuns no éxon 10, Ala307Thr e Asn680Ser, que parecem afetar a sensibilidade do ovário ao FSH nos tratamentos de reprodução assistida (TRA). Estas variantes influenciam a resposta folicular de pacientes com endometriose submetida às TRA. RELATO DO CASO: LES, 41 anos, G2A2, IMC30, $86 \mathrm{~m} 2 / \mathrm{kg}$, com endometriose grau III diagnosticada por videolaparoscopia indicada por cisto hemorrágico submetido à ooforoplastia esquerda. No mês anterior (Janeiro 2011) apresentou aborto espontâneo. Foi submetida à salpingooforectomia direita devido gestação ectópica (Julho 2012). Procurou Instituto Ideia Fértil por infertilidade secundária há 4 anos. Na primeira tentativa de TRA (Janeiro 2013) utilizou 9 dias de 200UI/dia FSH recombinante (FSHr), 3 dias de antagonista de GnRH (ant-GnRH) com formação de 2 folículos $>14 \mathrm{~mm}$, punção de 1 oócito e transferência de embrião $8 \mathrm{~A}$. Após resultado negativo, iniciou no ciclo subsequente protocolo com inibidor de aromatase (IA) $5 \mathrm{mg} /$ dia por 5 dias, seguido de 6 dias de FSHr 200UI, 1 dia de Menopur 225 UI e 4 dias de ant-GnRH. Captado 7 oócitos com obtenção de 5 embriões e transferência de dois embriões 8A. Vitrificação dos demais ( 2 cavitando e um blastocisto). O resultado foi gravidez gemelar tópica que evoluiu no nascimento de gêmeos saudáveis com 35 semanas de gestação (masculino com 2185g e feminino com 1875g). CONCLUSÃO: este é o primeiro relato de uma paciente infértil com endometriose e polimorfismo FSHR Asn680Ser submetida aos TRA e com resposta satisfatória quando associado um IA. A busca de protocolos individualizados é uma tendência médica e a correlação de polimorfismos relacionados com a infertilidade com a adequação das opções terapêuticas é um campo que deve ser estimulado em novas pesquisas, reforçando a necessidade de avançarmos na farmacogenética a fim de melhorarmos a taxa de gravidez das pacientes.

Palavras-chave: endometriose; infertilidade; polimorfismo; inibidor de aromatase.

\section{RCL-09 FÍSTULA ARTERIAL CORONARIANA:} APRESENTAÇÃO PECULIAR DE UMA CARDIOPATIA RARA

Bianca Cristina Romão da Cunha, Luisa Rebelo Ayoub, Amanda Vitiello Pereira Brosco, Isabela Hohlenwerger Schettini, Nara Alves Buriti, Caio César Ferreira Fernandes, Antonio Carlos Palandri Chagas

\section{Email: biancacrcunha@gmail.com}

INTRODUÇÃO: Fístula arterial coronariana (FAC) é uma conexão anormal en tre as artérias coronárias e um grande vaso ou câmara cardíaca, resultando em shunt arterio-venoso. Pode ser congênita, com incidência de $0,002 \%$ na população geral, ou ser adquirida, secundária principalmente a trauma torácico. São assintomáticas em metade dos casos e, quando presente, seu sintoma mais comum -a dor precordial -ocorre na quinta década de vida. Apresentam-se também como complicações do infarto agudo do miocárdio, da hipertensão pulmonar ou da endocardite. RELATO DE CASO: Mulher de 79 anos, com diagnóstico de FAC há 8 anos e assintomática com tratamento clínico, apresentou angina típica, iniciada ao esforço, acompanhada de parestesia em membro superior esquerdo, com melhora parcial ao repouso, após aproximadamente 1 hora. Deu entrada no pronto-socorro hemodinamicamente estável e sem sinais de congestão pulmonar ou sopros cardíacos. Eletrocardiograma revelou bradicardia sinusal, bloqueio de ramo esquerdo com alteração secundária da repolarização ventricular e ausência de alterações no segmento ST. Foi medicada para síndrome coronariana aguda. Exames subsidiários de entrada mostraram marcadores de necrose miocárdica positivos e ausência de anemia. Radiografia de tórax sem alterações. Ecocardiograma revelou hipertrofia septal assimétrica com função ventricular esquerda normal, sem alteração segmentar ou sinal de hipertensão pulmonar. Foi submetida à nova coronariografia que confirmou a presença de fístulas entre coronária direita e artéria pulmona 
(AP) e entre AP e descendente anterior, esta com oclusão total em segmento proximal. Tronco de coronária esquerda estava ectasiado. Não havia sinais de doença aterosclerótica. Optado por tratamento clínico com AAS, atenolol, enalapril e sinvastatina. CONCLUSÃO: Não há consenso sobre o manejo ideal das FAC. Em caso de sintomas refratários, evento cárdio-embólico, sinais de hipertensão pulmonar ou insuficiência cardíaca, indica-se tratamento invasivo, preferencialmente percutâneo. Caso contrário, pode-se manter tratamento clínico com antiagregantes plaquetários associado a beta-bloqueadores e bloqueadores de canal de cálcio de forma a reduzir o efeito do roubo de fluxo coronariano. Ressalta-se, com esse caso, a necessidade de se considerar mais o diagnóstico de FAC e a possibilidade de tratamento clínico, inclusive na idade avançada.

Palavras-chave: Fístula arterial coronariana; cardiopatia congênita; infarto agudo do miocárdio; tratamento clínico.

\section{RCL-10 GANGLIONEUROMA COM INVASÃO LOCAL - ABORDAGEM E TRATAMENTO}

Caroline da Freiria Castilho Reche, Tiago Donizeti Bertolacini Silva, Gabrielle Ellert de Almeida, Gabriela Camilo Teixeira, Ana Luiza Giamelaro Hanania, Clarisse Kaori Fujishige, Olívia Archur Antonio de Faria Alvim, Vivian Costa e Silva, Helaine Cristina de Castro, Sergio Augusto Fernandes Perlamagna, Luciana Oliveira Sousa Almeida Cardoso

\section{Email:carol_reche@ hotmail.com}

INTRODUÇÃO: O ganglioneuroma é uma neoplasia bem diferenciada, composta por células ganglionares maduras e células de Schwann, acometendo tecidos do sistema nervoso simpático. Usualmente é assintomático e, quando apresenta sintomas, é devido ao tamanho e à produção de substâncias, tais como catecolaminas. Compromete principalmente crianças e adolescentes, podendo ocorrer em adultos até os 30 anos. O diagnóstico é feito através do estudo histopatológico da lesão. O tratamento é a ressecção completa do tumor, apresentando ótimo prognóstico após sua retirada. RELATO DE CASO: N. A. S, 8 anos, masculino, branco, natural de Minas Gerais e procedente de São Paulo, portador de ECNE grave. Avó referia piora de constipação há 2 meses. Procurou atendimento médico na UBS, quando foi observada massa abdominal, sendo internado para avaliação. Foram realizado exames de imagem que mostraram volumosa formação sólida, de 7,5 x $5,5 \times 3,5 \mathrm{~cm}$, heterogênea, com calcificações puntiformes, localizada em fossa ilíaca esquerda que se estendia caudalmente para a cavidade pélvica, apresentando captação interna de fluxo vascular ao estudo com doppler colorido. Foi realizada biópsia que fez diagnóstico de ganglioneuroma. Por se tratar de um tumor extenso que invadia estruturas adjacentes, irressecável, optou-se por realizar quimioterapia neoadjuvante a qual não foi efetiva. Realizou-se então, ressecção parcial da massa e o paciente segue em acompanhamento ambulatorial. CONCLUSÂO: O ganglioneuroma é uma patologia benigna que faz parte dos diagnósticos diferenciais de massas abdominais, como o neuroblastoma e o nefroblastoma, patologias malignas que necessitam de tratamento mais agressivo. Possui prognóstico bom quando ressecado totalmente, portanto, é de extrema importância que seja diagnosticado precocemente, antes mesmo de causar sintomas, uma vez que, ao aumentar de volume, pode invadir estruturas adjacentes, tornando-se irressecável. Além disso, por não responder ao uso de quimioterápicos, o tratamento após invasão de estruturas vasculares torna-se mais difícil, sendo realizado acompanhamento ambulatorial para avaliação do crescimento tumoral.

Palavras-chave: Ganglioneuroma; neuroblastoma; tumor de Wilms; massa abdominal.

\section{RCL-11 HISTIOCITOSE DE CÉLULAS DE LANGERHANS: RELATO DE CASO E REVISÃO DA LITERATURA}

Bianca Nicolela Susanna, Heloísa Duarte de Andrade Tavares,

Davimar Miranda Borducchi

\section{Emai: binsusanna@gmail.com}

INTRODUÇÃO: As células de Langerhans (CLs) são células dendríticas derivadas da medula óssea e que residem, normalmente, na pele e linfonodos. A histiocitose de Langerhans (HCL) é uma proliferação clonal de CLs, em um ou múltiplos órgãos (unisistêmica ou multisistêmica). Doença rara com predomínio para o sexo masculino (3,7:1), tem pico de incidência entre os primeiros 3 anos de vida, sendo o acometimento ósseo o mais comum.2,3 Apesar da prevalência na infância, a doença pode acometer pacientes em qualquer faixa etária e, em adultos, é mais comum na terceira década, com comprometimento pulmonar relacionado ao tabaco. O diagnóstico definitivo é feito a partir de achados característicos de CLs na histopatologia, pela presença de grânulos de Birbek (GB) na eletromicroscopia ou pela demonstração de CDla na imunohistoquímica (padrão ouro). O tratamento da HCL é controverso e depende da extensão e gravidade da doença no momento do diagnóstico. Nos pacientes com doença multissistêmica e alto risco é recomendado terapia prolongada e intensiva com vimblastina e esteróides. RELATO DE CASO W.S.V, feminino, 32 anos, tabagista, diagnosticada em maio de 2012 com HCL em região pontina e pulmonar. Na época, a biópsia de pulmão apontou focos múltiplos de proliferação celular de histogênese indeterminada e imunohistoquímica positiva para proteína S-100 e CD1a, compatível com HCL. Foi tratada com vimblastina prednisona e classificada como boa respondedora, atingindo RCC. Retornou em
02/2016 com queixa de cefaleia diária que melhorava com analgesia simples. Exame de ressonância magnética de sela túrcica indicou aumento de volume do parênquima hipofisário. Hipótese de adenoma hipofisário foi excluída pelo neuroendócrino e a biópsia contraindicada pela neurocirurgia. Paciente em seguimento trimestral, sem sinais de progressão da doença. CONCLUSÂO: O envolvimento multisistêmico e a resposta ao tratamento são os principais fatores prognósticos na HCL, o acometimento de sítios não habituais e a faixa etária são menos impactantes na sobrevida destes pacientes. No caso relatado, observa-se a evolução favorável a partir do tratamento adequado e da resposta terapêutica satisfatória, apesar da manifestação fora do pico de incidência etária, e do comprometimento pulmonar e de SNC. Palavras-chave: histiocitose de células de Langerhans em adultos; sistema nervoso central; pulmão.

\section{RCL-12 IMUNODEFICIÊNCIA COMUM VARIÁVEL: DIAGNÓSTICO NÃOTÃO RARO}

Karoline Passarela, Bruna Rago Ricci, Ariane Anzai, Sandra Mitie Ueda Palma, Rosemeire Navickas Constantino-Silva, Joanna Araujo Simões, Nyla Thyara Melo Lobão, Anete Sevciovic Grumach

Email: kapassarela@uol.com.br

INTRODUÇÃO: A imunodeficiência comum variável (ICV) corresponde a uma disfunção do sistema imunológico, associada à deficiência de imunoglobulinas séricas, que pode cursar com alterações de linfócitos B e T. Dentre as imunodeficiências primárias (IDP) sintomáticas, a ICV é a de maior prevalência e relevância clínica na população adulta, uma vez que apresenta manifestação heterogênea pode acometer pacientes de ambos os sexos, em qualquer fase da vida, embora seja mais comum em adultos jovens. O tratamento consiste na reposição de imunoglobulinas e o prognóstico depende do diagnóstico precoce. RELATO DE CASO: Paciente do sexo masculino, 46 anos, filho de pais primos em primeiro grau, com história de 4 irmãos falecidos antes de um ano de vida. Queixa de diarreia crônica (duração aproximada de quinze anos) resolvida após tratamento para helmintase (desconhece medicamento utilizado). Relata pneumonia (5X) nos últimos dois anos, duas com complicações: na primeira com atelectasia e na última, com derrame pleural e foi identificado como agente etiológico Pseudomonas aeruginosa após lavado broncoalvelar necessitando de três internações para antibioticoterapia endovenosa. Acrescenta ainda, inúmeros episódios de sinusite, e sintomas como astenia e sudorese fria noturna. Antecedentes pessoais de hipotireoidismo, em uso de Levotiroxina $125 \mathrm{mcg} / \mathrm{dia}$, rinite alérgica e azoospermia. Ao exame físico: observado amígdalas hipotrofiadas e murmúrio vesicular diminuído. Em exames laboratoriais foi detectada hipogamaglobulinemia severa $(\operatorname{IgA}: 31 \mathrm{mg} / \mathrm{dL} ; \mathrm{IgM}:<4 \mathrm{mg} / \mathrm{dL}$; IgG: $<33 \mathrm{mg} / \mathrm{dL}$ ), ausência de alterações no hemograma, ausência de viragem sorológica a antígenos comprovadamente expostos, como sarampo e poliomielite e sorologia para HIV negativa. Após início do tratamento com gamaglobulina endovenosa $566 \mathrm{mg} / \mathrm{kg}$ a cada 4 semanas e antibioticoprofilaxia com Azitromicina 500mg/dia paciente apresentou significativa melhora clínica sem novos episódios infecciosos. CONCLUSÂO: Embora a Imunodeficiência Comum Variável ocorra em 1 de cada 10000 indivíduos, pacientes com quadros infecciosos recorrentes ou de difícil tratamento devem ser avaliados do ponto de vista imunológico. O comprometimento pulmonar deve ser evitado com o diagnóstico mais precoce.

Palavras-chave: Imunodeficiência Comum Variável, Hipogamaglobulinemia, Infecções recorrentes, Diagnóstico

\section{RCL-13 MANIFESTACÕES NEUROLÓGICAS RARAS DA SÍNDROME DE BAGGIO YOSHINARI EM CRIANÇAS: RELATO DE CASOS}

Adriana Cristina Viesti Domingues, Virginia Gelmeti e Serrano, Baggio Yoshinari, Ariadine Chaves de Oliveira, Alessandra Lima Nogueira Tolentino, Guilherme Bes Borba, Celeste Rodovalho Soares, Cecília Salgueiro Alvo, Carmen Silvia Molleis Galego Miziara

Email: adri.vdomingues@gmail.com

INTRODUÇÃO: A Doença Lyme (DL) é uma zoonose causada pela espiroqueta Borrelia burgdoferi através de picada de carrapato do gênero Ixodes e tem por característica principal manifestações clínicas multivariadas, mas com frequente associação do eritema migratório e quadros de artropatias. No Brasil, foram descritos casos semelhantes à $\mathrm{DL}$, mas que o carrapato transmissor pertencia ao gênero Amblyomma e Rhipicephalus, diferente do ocorrido na América do Norte, esta doença recebeu o nome de Síndrome de Baggio-Yoshinari (SBY). Outra peculiaridade da SBY é que a morfologia da espiroqueta é atípica, lembrando a Chlamydias, Micoplasmas e bacteroides, justificando a dificuldade de isolamento em meios de cultivo Barbour Stoenener-Kelly (BSK) modificado. O relato tem por objetivo descrever três crianças com SBY e com manifestações neurológicas atípicas, cujos diagnósticos somente foram possíveis através de anamnese epidemiológica detalhada e de resultados de sorologias específicas. RELATO DE CASO: Caso 1) Transtorno alimentar (Pica), neuropatia óptica inflamatória e meningite linfomonocitária; Caso 2) Quadro recorrente de depressão do nível de consciência, febre e déficit motor sugestivo de polirradiculoneurite; Caso 3) Mialgia, fraqueza muscular sugestivos de polirradiculoneurite. CONCLUSÂO: a SBY, descrita há mais de 30 anos no Brasil, ainda é pouco reconhecida por médicos brasileiros, 
embora sua prevalência estimada seja de $6,2 \%$, com maior expressão no verão e outono. Médicos e estudantes de medicina têm conhecimento apenas da DL clássica, zoonose específica da América do Norte e Eurásia. Por se tratar de doença com manifestações incaracterísticas, o diagnóstico deve ser sempre considerado mesmo na ausência de eritema migrans ou de relato de picada de carrapato. É fundamental que a história epidemiológica seja detalhada quanto a contatos prévios com carrapato, assim como a ocorrência de eritema migratório, principalmente em casos com clínica prolongada e recidivante de febre de origem indeterminada, com manifestações neurológicas e alterações comportamentais. Não se deve considera SBY somente quando houver a manifestação cutânea de caráter migratório, pois os dados de literatura mostram que um termo a metade dos pacientes não descreve esta queixa.

Palavras-chave: Doença de Lyme; Borreia burgdorferi; L.espiroqueta.

\section{RCL-14 PUPILA TONICA DE ADIE PÓS-HERPES ZOSTER EM UM MENINO DE 5 ANOS: UM RELATO DE CASO RARO}

Carolina Nicolela Susanna, Thiago Cavenaghi Castanheira, Kenzo Saito Tomishige, Giulianna Nasi Domingues de Oliveira, Rodrigo Scabora, Mustapha Mohamed Mourad, Sandra Carina Lopez Calcines, Rafael Cunha de Almeida

\section{Email: cacau_susanna@ hotmail.com}

INTRODUÇÃO: A pupila tónica de Adie resulta da desnervação do gânglio ciliar e esfíncter pupilar, que se caracteriza por midríase, má reação à luz com paralisia sectorial do esfíncter da íris, paresia na acomodação e hipersensibilidade a colinérgicos durante a fase aguda. Fases crônicas apresentam resposta pupilar forte e tônica para perto (dissociação luz-perto), enquanto a resposta à luz permanece severamente prejudicada. Cerca de $80 \%$ dos pacientes com síndrome de Adie têm a doença unilateral, bem como queixas visuais: fotofobia, dificuldade de adaptação ao escuro, a visão para perto turva e dores de cabeça. A etiologia é desconhecida, mas a maioria dos casos ocorre por infecção viral. A prevalência da pupila do Adie é de 2 casos por 1000 habitantes. Ocorre mais em pacientes de 20 - 40 anos de idade, preferencialmente mulheres $(70 \%)$. Na faixa etária pediátrica, não há predileção sexual e a condição é rara. RELATO DE CASO: MBJ, 5, masculino, natura e procedente de Santo André. Encaminhado pela infectopediatria ao serviço de oftalmologia da FMABC com queixa de anisocoria e fotofobia após internação no Hospital Municipal por 10 dias devido a herpes zóster. A criança teve varíola aos 3 anos. O exame oftalmológico revelou: olho direito com 20/30 acuidade visual, refração estática plana, reflexo direto $(4+/ 4+)$ e reflexo consensual ausente $(0 /+4)$; olho esquerdo com acuidade visual 20/40, refração estática de 1,00 DE, reflexo direto ausente $(0 /+4)$ e reflexo consensual $(4+/ 4+)$. A criança não foi colaborativa, portanto a dissociação luz-perto não pôde ser avaliada. Após a instilação de pilocarpina diluída $(0,125 \%)$ o olho direito não revelou alterações, enquanto a pupila esquerda contraiu. CONCLUSÂO: O diagnóstico clínico da pupila de Adie pode ser feito através da demonstração de hipersensibilidade da pupila a agentes parassimpaticomiméticos, como pilocarpina $0,125 \%$, que provoca a constrição da pupila tônica. Destaca-se a necessidade de os oftalmologistas conhecerem os diagnósticos diferenciais de anisocoria ( $20 \%$ da população), de modo que um diagnóstico adequado e precoce possa ser alcançado, a fim de evitar tratamentos desnecessários, seguido por seus efeitos adversos. A lesão pós-ganglionar pode ser frequentemente causada por causas infecciosas (como a varíola e herpes zoster), embora raramente presentes em menores de 15 anos de idade.

Palavras-chave: herpes zoster; pupila de Adie; criança; midríase.

\section{RCL-15 RARA ASSOCIAÇÃO DE TRÊS DOENÇAS AUTOIMUNES: UM RELATO DE CASO}

Flávia Yumi Ataka, Tiago Donizeti Bertolacini Silva, Stéphanie Kim Azevedo de Almeida, Maria Carolina Soares, Ramon Félix Martins Fernandes, André Kenzo Mário, Talissa Auad Carvalho, Karine Risso Barbosa, Wilson Roberto Catapani

\section{Email: ayflavia@hotmail.com}

INTRODUÇÃO: A autoimunidade abrange um amplo espectro de doenças específicas de diversos órgãos. Elas são caracterizadas pela inflamação e a produção de uma ampla variedade de autoanticorpos dirigidos contra autoantígenos múltiplos. Embora sua etiologia seja mal compreendida, fatores genéticos, imunológicos, hormonais e ambientais são os principais fatores predisponentes e desencadeantes. Esses fatores podem interagir de diferentes formas e, assim, ocasionar a coexistência de diversas doenças. A relaçao entre doença celíaca (DC) e diabetes mellitus (DM) tipo I já é bem documentada em pacientes jovens. A incidência de retocolite ulcerativa (RCU) junto com DM I também já é descrita, enquanto a incidência de doença celíaca e RCU ainda são questionáveis. No entanto, a coexistência dessas 3 doenças é rara, e isto justifica a relevância da descrição deste caso. RELATO DE CASO: DFC, 22 anos, natural e procedente de SBC, solteiro. Paciente chega ao serviço da FMABC em 2013 com quadro de fezes pastosas e sanguinolentas há um ano. Refere evacuações $3 \mathrm{x}$ ao dia associadas a dor abdominal e muco nas fezes. Exame físico sem alterações. Após 5 meses, teve piora do quadro com fezes líquidas $5 \mathrm{x}$ ao dia associadas a sangue e muco. Então, realizou colonoscopia e foi diagnosticado com RCU. Após 3 meses sob tratamento para RCU, continuou mantendo o quadro diarreico associado a dor abdominal em cólica. Assim, foi encaminhado para biópsia duodenal e teste genético, cujo resultado foi compatível com DC, tendo positividade para HLA DQ8 e DQ2. De antecedentes pessoais, é portador de DM I desde os 14 anos de idade e de antecedentes familiares, nega outras doenças autoimunes. CONCLUSÂO: O relato descreve um paciente com doenças autoimunes em que há considerável sobreposição clínica e patogênica. Enquanto HLA é um fator de risco entre essas enfermidades, fatores genéticos e ambientais adicionais provavelmente desempenham papel importante na iniciação delas. Dessa forma, pacientes com doença autoimune têm de ser sistematicamente fenotipados e testados para um painel de autoanticorpos, já que essas abordagens fornecem informações precisas sobre a prevalência da coexistência e também da ordem cronológica de eventos do paciente, contribuindo para uma terapêutica direcionada e melhor qualidade de vida. O papel da abordagem nutricional é fundamental para o tratamento deste paciente.

Palavras-chave: diabetes mellitus tipo I; doença celíaca; retocolite ulcerativa; doença auto imune.

\section{RCL-16 REAÇÃO ANAFILÁTICA À PRÓTESE DE CROMO: RELATO DE CASO}

Emy Kikugawa, Ariane Anzai, Sandra Mitie Ueda Palma, Anete Sevciovic Grumach

Email: kikugawaemy@yahoo.com.br

INTRODUÇÃO: A anafilaxia é a manifestação mais abrupta e grave das reações de hipersensibilidade, e pode ser fatal, envolvendo múltiplos órgãos e sistemas. Os fatores desencadeantes de quadros graves e de reação imediata mais comum são os medicamentos e alimentos. É rara a descrição de reações à próteses na literatura mundial. Os autores descrevem dados clínico-laboratoriais de paciente que apresentou anafilaxia grave após cirurgia para colocação de prótese de joelho. RELATO DE CASO: Paciente de 46 anos, sexo masculino, encaminhado para o Ambulatório de Imunologia devido a crises de Angioedema com edema de glote recorrente. Relata que após 3 meses da cirurgia para prótese em joelho desenvolveu crises de edema em lábios, pálpebras, língua e face. No início, a frequência era semestral, passando a mensal e, finalmente, semanal. Ao angioedema acompanhava dispneia e tratava com adrenalina intramuscular e anti-histamínico com melhora. Após atendimento, solicitamos teste cutâneo de contato, com resultado positivo para bicromato de potássio, hidroquinona e neomicina. Inicialmente, foi introduzida levocetirizina $15 \mathrm{mg} /$ dia, prednisona $40 \mathrm{mg} /$ dia e adrenalina intramuscular para crises. Como não houve melhora, sugeriu-se a troca da prótese composta por cromo e realizada nova cirurgia trocando-se por prótese de titânio. O paciente mantém-se assintomático desde então. CONCLUSÂO: A reação anafilática costuma ocorrer precocemente após a exposição ao agente causal, entretanto, algumas reações podem manifestar-se tardiamente, como no caso relatado, dificultando o diagnóstico precoce. O teste cutâneo de contato permitiu identificar o possível agente causador.

Palavras-chave: anafilaxia; cromo; prótese de joelho; testes cutâneos.

\section{RCL-17 RELATO DE CASO DE LNH COM MANIFESTAÇÃO ATÍPICA}

Juliana Jorge Romano, Carolina de Arruda Garcia, Ana Luiza Giamelaro Hanania, Gabriela Camilo Teixeira, Clarisse Kaori Fujishige, Tiago Donizeti Bertolacini Silva, Elisa Couto Peres Ribeiro, Jairo Cartum, Daniel Zorato

\section{Email: julianajromano@uol.com.br}

INTRODUÇÃO: Linfomas é a segunda neoplasia maligna mais frequentemente diagnosticada em crianças e adolescentes, com menos de 16 anos. São classificados em dois tipos: de Hodgkin ( $\mathrm{LH}$ ) e não-Hodgkin (LNH). Na infância, o LNH é mais comum do que o $\mathrm{LH}$, sendo $60 \%$ dos casos representados pelos linfomas não-Hodgkin e $40 \%$ pelos linfomas de Hodgkin. O tipo mais frequente de linfoma não-Hodgkin é o linfoma difuso de grandes células B,corresponde a cerca de 10$20 \%$ dos casos de linfoma não Hodgkin pediátricos e tem maior ocorrência entre os 10 e 20 anos de idade. O objetivo deste estudo consiste em relatar o caso de um paciente jovem, 12 anos, que foi diagnosticado com Linfoma não-Hodgkin de grandes células $\mathrm{B}$, com apresentação clínica incomum e recebendo tratamento com Rituximab e poliquimioterapia, com sucesso. RELATO DE CASO: Paciente do sexo masculino, 12 anos e 11 meses, com queixa álgica em região dorsal desde outubro de 2015. Procurou ortopedista, quando foi solicitada uma radiografia de coluna vertebral, não demonstrando alterações. Procurou pediatra, que realizou tomografia $(01 / 2016)$ a qual evidenciou múltiplas lesões osteolíticas e fraturas patológicas. Veio encaminhado para a Oncologia Pediátrica da Faculdade de Medicina do ABC em 02/2016, queixando-se de dor em região coxo-femural e perda ponderal de aproximadamente $10 \mathrm{~kg}$. Sem outras queixas. Ao exame físico encontrava-se em regular estado geral, descorado e hidratado, acianótico, anictérico, afebril, eupneico. Foi realizado punção liquórica e mielograma. Ambos retornaram com diagnóstico de Linfoma não-Hodgkin de grandes células B. CONCLUSÂO: O caso em questão está de acordo com a literatura em quesitos epidemiológicos. Entretanto, difere em relação à manifestação clínica da doença, que se mostrou atípica (dor em região lombar, e posteriormente dor em região coxo-femoral). Assim podemos concluir que se tratava de uma lesão extranodal. O linfoma primário do osso é uma condição extremamente rara. Mulligan et al. enfatizaram predomínio de envolvimento 
de ossos longos, porém, em nosso estudo, o paciente tinha envolvimento de corpo vertebral. A raridade desta manifestação atípica e a ausência de achados clássicos como febre e linfonodomegalia podem dificultar a suspeita clínica, e o diagnóstico, podendo influenciar no prognóstico da doença. Este caso demonstra a importância da imuno-histoquímica no diagnóstico.

Palavras-chave: Manifestação atípica; linfoma não Hodgkin; fraturas patológicas; lesão extranodal.

\section{RCL-18 RELATO DE CASO: DIAGNÓSTICO DE DISCINESIA CILIAR PRIMÁRIA NO BRASIL}

Fatima Elisa D'Ippolito Alcocer, Amanda Bosio Quinzani, Adriana Cristina Viesti Domingues, Emely Rocha Melo, Carolina Ricci Castelan, Daniela Alves Ferreira, Maria Fernanda Botelho Hernandez Perez

\section{Email: fah_elisa@ hotmail.com}

INTRODUÇÃO: Este relato visa apresentar um caso de um paciente com Discinesia Ciliar Primária (DCP) e discutir as dificuldades de diagnóstico. A DCP pode incapacitar o paciente, sendo necessária sua descrição. RELATO DE CASO: NFB, 18 anos, feminino, estudante, natural de São Caetano do Sul. Mãe relata que aos 4 meses o bebê começou a ter chiado no peito. Aos 3 anos, teve amigdalite purulenta e, dois anos mais tarde, broncopneumonia e pneumonia, sendo diagnosticada atelectasia de lobo inferior esquerdo. Além disso, detectou-se broncorreia e rolhas de secreção amarelada e espessa predominando em brônquios do lobo inferior esquerdo. Aos 6 anos, apresentou secreção e crise de chiado e RX de tórax com colapso do hemitórax esquerdo e bronquiectasias. Em 2005 e 2006, realizou teste de sacarina (sentiu sabor amargo após $24 \mathrm{~min}$.) e anatomopatológico de lobo inferior esquerdo (parênquima pulmonar com broncopneumonia aguda associada a áreas de hemorragia intra-alveolar, fibrina junto dos alvéolos, moderada dilatação bronquiolar e discreta fibrose da parede dos brônquios), sendo sugestivo de bronquiectasia associada à broncopneumonia. Em 2007, fez cirurgia de ressecção do lobo inferior esquerdo, com drenagem de tórax anterior e posterior. Em 2008, biópsia nasal inferior e de processo unciforme indicou metaplasia escamosa e ausência de cílios. Em 2010, apresentou melhora e em 2015 não referiu queixas. CONCLUSÂO: A DCP é genética, rara, predominantemente autossômica recessiva, cursa com alteração na ultraestrutura e/ou da função ciliar, causando uma disfunção da mobilidade dos cílios. A incidência é de cerca de 15-30 mil nascidos vivos e independe de sexo ou etnias. Pode causar síndrome da angústia respiratória do $\mathrm{RN}$, rinorreia mucopurulenta contínua e atelectasia pulmonar súbita, além de otites médias de repetição, pneumonias e rinossinusites. Evolui com pneumonias de repetição predominantemente em lobo inferior, médio e língula, tosse produtiva crônica e hipoacusia de transmissão, podendo levar a bronquiectasias, hipocratismo digital e déficit de crescimento. Cerca de 50\% dos adultos apresentam a forma clássica (Sd. de Kartagener completa: sinusite, bronquiectasia e situs inversus total) e na outra metade predomina tosse produtiva, sinusopatias e otite média de repetição (Sd. de Kartagener incompleta). É comum levar a infertilidade em ambos os sexos e a gravidez ectópica.

Palavras-chave: Discinesia Ciliar; Pneumologia; Diagnóstico DCP.

\section{RCL-19 RELATO DE CASO: NEUROBLASTOMA TORÁCICO}

Olívia Achur Antonio de Faria Alvim e Clarisse Kaori Fujishige, Ana Luiza Giamelaro, Carolina de Arruda Garcia, Gabriela Camilo Teixeira, Juliana Jorge Romano, Tiago Donizeti Bertolacini Silva e Vivian Costa e Silva, Sérgio Augusto Fernandes Perlamagna, Adriana Karin Sapuppo e Danie Henrique Gonçalves Zorato

\section{Email: oliviaalvim@terra.com.br}

INTRODUÇ̃̃O: Neuroblastoma é o câncer mais comum até o $1^{\circ}$ ano de vida e faz parte do grupo de tumores neuroblásticos. Destaca-se por seu amplo espectro clínico, caráter heterogêneo, com variada histopatologia, caracteres biológicos e localização. Sua sintomatologia reflete o sítio do tumor primário, a extensão da doença e presença de doença metastática. RELATO DE CASO: GLM 1 ano, iniciou paraplegia de membros inferiores no $12^{\circ}$ dia de infecção por varicela, quando procurou serviço hospitalar. No $5^{\circ}$ dia de internação foi avaliada pela Neuropediatria e foi solicitada ressonância de coluna, na qual se evidenciou massa tumoral insinuando-se no canal medular através de forames intervertebrais, causando compressão e deslocamento da medula. Tomografia de tórax confirmou volumosa massa para-mediastinal e vertebral, ocupando grande parte do hemitórax, até porção média e posterior do mediastino, deslocando coração, tronco da pulmonar e aorta, com áreas de liquefação e necrose, sobretudo junto aos corpos vertebrais. Imunohistoquímica foi positiva para Enolase Neuro Específica e Sinaptofisina, compatível com diagnóstico de Neuroblastoma. Devido à extensão e infiltração torácica o tumor mostrou-se irressecável, paciente foi encaminhada para tratamento ambulatorial e iniciou protocolo Neuro-IX 2000 para posterior avaliação cirúrgica. CONCLUSÂO: O neuroblastoma pode se desenvolver em qualquer lugar do corpo através do sistema nervoso simpático. Os sítios primários mais comuns são glândula adrenal (40\%), abdominal (25\%) e tórax (15\%). A forma torácica, embora não a mais comum pode causar importante sintomatologia, como desvio e estreitamento de traquéia, síndrome da veia cava superior e compressão medular (emergência oncológica) presente em $7-15 \%$ das crianças, que deve ser resolvida rapidamente para evitar ou diminuir sequelas neurológicas. Os tumores considerados irressecáveis passam por um primeiro estágio de citorredução com quimioterapia intensa, para diminuir foco primário e metastático. Com posterior avaliação de possibilidade de ressecção cirúrgica e período de consolidação com altas doses de quimioterapia ou, no caso de paciente estágio IV, considera-se transplante de medula óssea como forma de consolidação do tratamento. Apesar do tratamento intenso, cerca de 60\% das crianças consideradas alto risco apresenta recaída, com maior chance de óbito no curso do tratamento.

Palavras-chave: neuroblastoma torácico; compressão medular; neuroblastoma massa mediastinal.

\section{RCL-20 SÍFILIS MALIGNA PRECOCE EM PACIENTE HIV POSITIVO: RARA MANIFESTAÇÃO DA DOENÇA}

Lucas Prezotto Giordani, Juliana Altieri Vasconcelos, Ana Paula Toledo Mota, Lara Aguiar Marchetti Maia, João Victor dos Santos Teixeira, Caroline da Freiria Castilho Reche, Mariana Jancis Rigolo, Giovana de Lima Cebrian, Lucia Mioko Ito, Carlos D’Apparecida Santos Machado Filho, Rafaela Ferreira da Silva.

\section{Email: lucaspg_lucas@hotmail.com}

INTRODUÇÃO: Sífilis maligna precoce é uma forma rara de sífilis secundária, mais frequentemente associadas a pacientes coinfectados pelo HIV. Suas manifestações são diferentes da apresentação clássica da sífilis secundária pela morfologia $e$ gravidade das lesões. As lesões cutâneas da sífilis maligna são precedidas por febre prodrômica, cefaléia, artralgia e mialgia de intensidade variável e são caracterizadas pelo aparecimento de pústulas, nódulos pleomórficos e úlceras com período de incubação relativamente curto. As mucosas podem ser comprometidas, podendo haver aumento dos linfonodos e hepatoesplenomegalia. RELATO DE CASO: Paciente masculino, 63 anos, natural do Piauí e procedente de São Bernardo do Campo, balconista de bar, chegou ao ambulatório de Dermatologia com queixa de infecção no corpo há um mês. Ao exame, constatavam-se em toda a pele, com exceção de palmas, pápulas eritemato-infiltradas bem delimitadas, algumas com crostas hemáticas e descamação periférica. Referia que as lesões surgiram inicialmente nos braços um mês antes, associadas a febre e leve prurido. Solicitou-se biópsia das lesões, além de VDRL, o qual se mostrou reagente 1/16. FTA-Abs e sorologia para HIV também se confirmaram reagentes. O histopatológico revelou paraqueratose com ninhos de neutrófilos, degeneração vacuolar na camada basal com marcante exocitose de linfócitos e infiltrado perivascular linfoplasmocitário com células epitelioides em derme papilar. A pesquisa de BAAR resultou negativa. O diagnostico confirmado foi de Sífilis Maligna Precoce. Em punção de LCR não houve alterações e o VDRL veio negativo. O tratamento foi feito com penicilina benzatina 2400000 IM em duas doses, havendo reversão completa do quadro em 8 dias. DISCUSSÃO: Antes do surgimento da infecção pelo HIV, a sífilis maligna era um diagnóstico raro. Atualmente, estima-se que até $7 \%$ dos casos de sífilis em pacientes infectados pelo HIV sejam de sífilis maligna, mas ainda não está claro por que apenas alguns infectados pelo T. pallidum desenvolvem essa forma da doença. A progressão deste tipo de sífilis pode ocorrer devido a imunocomprometimento do hospedeiro, uma cepa mais virulenta da bactéria, ou até uma resposta imunológica exacerbada. Devido ao aumento do número de casos de sífilis, médicos devem estar atentos para a conseguirem reconhecer casos de sífilis malignas e tratá-los adequadamente. Palavras-chave: sífilis maligna precoce; Treponema pallidum; HIV; imunocomprometimento.

\section{RCL-21 SÍNDROME DE HIPER-IGM LIGADA AO $\mathbf{X}$ : RELATO DE CASO}

Georgia Neme, Nara Yuri Yamada Kushikawa

\section{Email: georgia.neme@icloud.com}

INTRODUCÃO: A Síndrome do Hiper-IgM (SHIM) é uma imunodefiência primária, caracterizada pela incapacidade de plasmócitos (células B) sofrerem mudanças de isótopo, ela é então subdividida: o tipo I, relatado neste trabalho, é ligado ao cromossomo X e resultado de mutação nos genes codificadores do ligante a CD40 (CD40L) que estarão ausentes em células T; enquanto os tipos II, III e IV, apesar de também associados à mutações genéticas, não têm seus cromossomos sexuais alterados. O distúrbio relatado é caracterizada por níveis normais ou elevados de IgM no soro, com ausência ou níveis reduzidos de outros isotipos. A ativação da molécula CD40 é crucial para proliferação de células B e troca de classe de imunoglobulina, ocorrendo através da interação de CD40 com seu ligante expresso em células T ativas. A ausência dessa interação favorece o impedimento da reação do organismo contra um agente infeccioso. RELATO DE CASO: A metodologia deste relato se deu a partir das informações obtidas por meio de revisão do prontuário, entrevista com a equipe envolvida no caso e revisão da literatura. O presente caso relata o quadro clínico do lactente MVLS, nascido em 13 de julho de 2014 que deu entrada no Hospital Santo Amaro (Guaruja, SP) devido ao quadro neurológico crise convulsiva com cianose em repetição - e posteriormente, 06 de abril de 2015 , transferido para o Hospital Guilherme Álvaro (Santos, SP), onde foi diagnosticado e se manteve até o dia 28 de julho de 2015. Então, foi conseguido seguimento no Hospital Albert Einstein, por iniciativa filantrópica, para posterior transplante de medula óssea - hoje, considerado melhor prognóstico para pacientes de SHIM 
Todas as variáveis (idade, estado clínico e centro de transplante especializado) eram favoráveis ao desfecho. No entanto, a opção da família do paciente em se mudar para o Rio Grande do Norte caracteriza abandono de caso, apesar dos bons resultados e possibilidades. CONCLUSÃO: O relato de caso do lactente MVLS possibilita a exposição de sua singularidade e promove revisão literária em conjunto com experiência clínica. O diagnóstico complexo, porém efetivo, associado ao tratamento multidisciplinar adequado viabiliza expressar o caso como satisfatório, apesar do cenário com desfecho ideal negado.

Palavras-chave: Síndrome de Imunodeficiência com Hiper-IgM Tipo 1; Lactente; Ligante de CD40.

\section{RCL-22 TRISSOMIA DO CROMOSSOMO $13 \mathrm{E}$ AGAMAGLOBULINEMIA CONGÊNITA}

João Victor dos Santos Teixeira, Anderson Abdon Barbosa, Anete Sevciovic Grumach

\section{Email: joaovictorteixeira.med@gmail.com}

INTRODUÇÃO: A síndrome de Patau resulta da presença de um cromossomo 13 adicional levando a uma constituição genética com 47 cromossomos. A grande maioria dos fetos é abortada espontaneamente e dos fetos que nascem somente $9 \%$ alcançam o primeiro ano de vida. Na trissomia do cromossomo 13 observam-se malformações congênitas como fendas orofaciais, microftalmia e/ou anoftalmia e polidactilia pós-axial de membros. A agamaglobulinemia ligada ao X, por sua vez é uma imunodeficiência primária (IDP) decorrente de defeito no desenvolvimento de células B e sua prevalência é estimada em um de cada 100000 indivíduos. As infecções em trato respiratório, digestivo ou sistêmicas são frequentes nesta IDP. Os autores relatam um paciente com Síndrome de Patau associada à agamaglobulinemia. Trata-se do primeiro relato na literatura desta associação. RELATO DE CASO: Paciente de 14 anos, masculino, com infecções de repetição desde o nascimento (pneumonias de repetição, otites médias agudas e furunculoses) com piora a partir dos 2 anos de idade, quando foi diagnosticada agamaglobulinemia. Apresentou catarata precoce, retardo neuropsicomotor e convulsões. Aos 2 anos foi diagnosticada agamaglobulinemia confirmada pela mutação do gene BTK, portanto, ligada ao cromossomo X. Durante a evolução desenvolveu hipotireoidismo e plaquetopenia. Recebe gamaglobulina endovenosa mensal e antibioticoterapia profilática. CONCLUSÃO: A associação da trissomia do cromossomo 13 com defeitos de imunidade humoral não foi relatada anteriormente na literatura. A apresentação não completa da Síndrome de Patau pode estar relacionada à sobrevida do paciente e as medidas terapêuticas como a administração de gamaglobulina podem ter melhorado a evolução deste paciente. Este relato sugere a necessidade de avaliar pacientes com esta síndrome quanto a defeitos da imunidade humoral, embora as mutações ocorram em cromossomos diferentes.

Palavras-chave: Patau; agamaglobulinemia; imunodeficiência; Bruton.

\section{MONOGRAFIA}

\section{MON-01 A FRAGILIDADE COMO AGRAVANTE DE RISCO NO PERÍODO PERIOPERATÓRIO}

Luisa Rebelo Ayoub, Bianca Cristina Romão da Cunha, Amanda Vitiello

Pereira Brosco, Isabela Hohlenwerger Schettini, Caio Cesar Ferreira

Fernandes, João Fernando Monteiro Ferreira, Carlos Palandri Chagas

\section{Email: lurebelo82@ hotmail.com}

INTRODUÇÃO: O termo fragilidade advém do francês frêle que significa pequena resistência. Pode também ser definida com uma maior vulnerabiliadade e/ou uma deficiência do retorno ao estado de homeostase de um organismo acometido por um agente estressor agudo, crônico ou iatrogênico. Constitu uma síndrome biológica de natureza inflamatória que persiste por tempo indefinido, em baixa intensidade, mesmo após a retirada do agente desencadeante. Ela independe da magnitude do impulso externo, os pacientes fragéis, desenvolvem uma descompensação clínica intensa, que comprovadamente se associa a uma miríade de desfechos clínicos adversos como mortalidade, aumento de tempo de internação, infartos, AVCs, infecções, eventos trombóticos, quedas e delirium. OBJETIVO: Avaliar o impacto da fragilidade no perioperatório de cirurgia cardíaca. MÉTODO: Foram compilados artigos científicos do banco de dados do PubMed que estudam a relação entre a fragilidade e os resultados das intervenções cirúrgicas cardíacas. RESULTADO: Após revisão de artigos, observa-se a correlação positiva entre a presença e diversos desfechos adversos no âmbito de recuperação pós-cirurgia cardíaca. "Atualmente considera-se a fragilidade como um dos fatores de risco não mensuráveis" não captados pela avaliação clínica perioperatória tradicional. Falências cardíacas são a maior causa de hospitalização em idosos. São também pacientes com risco para quedas, maior mortalidade pós-operatória e hospitalização prolongada. Escores pré-operatórios são limitados por superestimar a idade cronológica na avaliação da vulnerabilidade para diversos agravos à saúde. O conceito de fragilidade contempla ao mesmo tempo tanto as particuliaridades inter-individuais de uma determinada doença quanto os diversos estágios de evolução das possíveis comorbidades. CONCLUSÃO: A fragilidade é um conceito prático e unificador. Sua aplicação pode reduzir a necessidade do diagnóstico subespecializado relacionado a sistemas orgânicos particulares, fundamentado em exames sofisticados, muitas vezes indisponíveis, para constituir um método mais simples, geral e reprodutível de predição de eventos adeversos.

Palavras-chave: Fragilidade; periodo perioperatorio; fatores de risco; cirurgia cardíaca.

\section{MON-02 ARTIGO DE REVISÃO: MANEJO E PREVENÇÃO SECUNDÁRIA DE FENÔMENOS TROMBÓTICOS}

Mariana Affonso Tappi, Priscila Fernandez Contreiro, Mariana Karakida Hashimoto, Aline Gisele Pena Boanova, Davimar Miranda Maciel Borducchi, José Jorge Namura, Vitor Augusto Queiroz Mauad

\section{Email: tappimariana@gmail.com}

INTRODUÇÃO: Pacientes com trombose venosa profunda (TVP) e tromboembolismo pulmonar (TEP) são frequentes. Novos guidelines e medicamentos tornam pertinente a revisão do tema. OBJETIVO: Revisar a literatura atual sobre o manejo e a profilaxia secundária em pacientes com fenômenos trombóticos. MÉTODO: Foram levantados 173 artigos na base de dados da Bireme com as palavras-chave: trombofilias, trombose e anticoagulantes. Tendo como guia o protocolo recente da ACCP, revisamos e discutimos detalhes do manejo e profilaxia secundária, complementando com outros artigos julgados relevantes no decorrer do trabalho. RESULTADO: Depois de avaliados priorizando nível de evidência, foram selecionados 22 artigos. Novos artigos foram pesquisados para suplementar dúvida adicionais, totalizando 33 artigos participantes dessa revisão. As conclusões foram sintetizadas na discussão e conclusão do artigo. Além de pouco sensível, a pesquisa de trombofilias hereditárias geralmente não altera conduta. A SAF parece ter impacto significativo. A anticoagulação perene tem indicação individual, pelo cruzamento de risco trombótico e hemorrágico. O risco hemorrágico com os NOACs parece ser inferior aos da warfarina, logo pode ser extrapolado de scores validados para inibidores de vitamina $\mathrm{K}$ com alguma segurança. Novo guideline ACCP diminui o tempo padrão de anticoagulação para 3 meses. CONCLUSÃO: A pesquisa de trombofilias hereditárias é realizada nos casos duvidosos para anticoagulação perene: episódio único, sem fator de risco transitório e com baixo risco hemorrágico; e pacientes com trombose em sítio anômalo. A pesquisa para SAF deve ser feita independentemente de fatores hereditários. O risco hemorrágico pode ser calculado com segurança e simplicidade pelo score HAS BLED e fatores individuais, como risco de quedas, também merecem atenção. NOACs tem seu uso recomendado em pacientes sadios, mas subgrupos específicos podem ter restrições, em especial pacientes com alteração de função renal e hepática, além de pacientes oncológicos, por não terem sido devidamente abordados nos estudos. Anticoagulação perene está claramente indicada apenas em pacientes com 2 ou mais fenômenos trombóticos. O tempo mantido em anticoagulação está cada vez mais restrito. Uso do Dímero D e USG seriado para cessar anticoagulação em tromboses distais pende maior comprovação.

Palavras-chave: trombose; anticoagulação; trombofilias hereditárias.

\section{MON-03 EPILEPSIA DO LOBO TEMPORAL: UMA REVISÃO Murilo Medeiros Alvarenga, Arthur Cukiert}

Email: muriloalvarenga91@gmail.com

INTRODUÇÃO: Epilepsia é definida como uma doença cerebral caracterizada pela predisposição persistente do cérebro em gerar crises epilépticas e pelas alterações neurobiológicas, cognitivas, psicológicas e sociais dessa condição. A epilepsia do lobo temporal (ELT) é responsável pela maioria das epilepsias focais e se relaciona intimamente com a esclerose hipocampal (EH), sua maior etiologia. A ELT quando não diagnosticada e tratada pode aumentar o risco para disfunção cognitiva e psicossocial, além de levar à morte súbita na epilepsia OBJETIVO: Realizar uma revisão literária sobre epidemiologia, anatomia, fisiologia, fisiopatologia, diagnóstico clínico (semiologia, imagens e eletroencefalograma) e tratamento clínico e cirúrgico da epilepsia do lobo temporal. MÉTODO: Foi realizado um levantamento epidemiológico, anatômico, fisiológico, fisiopatológico, clínico e cirúrgico nas bases de dados PubMed e LILACS, desde o início da série histórica até o ano de 2016. RESULTADO: Existem 50 milhões de pessoas no mundo com epilepsia, apresentando distribuição diferente entre os países desenvolvidos e subdesenvolvidos. A ELT é a mais prevalente das síndromes epilépticas e o foco epileptogênico (FE) está presente no hipocampo em $80 \%$. A principal etiologia para a ELT é a EH ( $33,6 \%$ a $66 \%$ dos casos), seguida pelos tumores. Destes os gangliogliomas e tumores desembrioblásticos neuroepiteliais são responsáveis por $77 \%$ das neoplasias acometidas no lobo temporal. No tratamento, $60 \%$ dos pacientes ficarão livres das crises com a administração do primeiro fármaco, porém $30 \%$ serão refratários ao tratamento medicamentoso. Quando indicado, a cirurgia para os pacientes refratários apresenta índice de resolução de 70-80\%. A ELT é responsável pela maioria das crises focais, tendo como etiologia mais prevalente a EH seguido por tumores associados. A clínica da ELT se divide em mesial ou cortical, possuindo características particulares para cada área. Exames complementares, como a ressonância magnética, PET-scan e eletroencefalograma são importantes para a confirmação do FE, possibilitando traçar a melhor conduta para cada paciente. CONCLUSÃO: A ELT apresenta alta prevalência. Quando diagnosticada e tratada pode aumentar a qualidade de vida dos pacientes e diminuir o risco de morte súbita além do impacto negativo da doença na população economicamente ativa. Palavras-chave: Epilepsia; Lobo Temporal; Epidemiologia; Clínica. 


\section{MON-04 HIPOGLICEMIA EM PACIENTES COM DIABETES MELLITUS TIPO 1 E 2 E SUAS REPERCUSSÕES CLÍNICAS}

Mira Zlotnik, Ana Carolina Nemeth Calvo, Arthur de Almeida Rescigno, Gustavo Bertollini Lamy, Lucas Oléa Madeira, Lucca Cirillo Lima, Maria Isabel Sacchi Mendonça, Augusto Cezar Santomauro Junior

\section{Email: mirazlot@gmail.com}

INTRODUÇÃO: A glicose é o principal substrato para obtenção de energia pelo metabolismo celular. A Hipoglicemia é um distúrbio caracterizado pela concentração de glicose no plasma abaixo de $70 \mathrm{mg} / \mathrm{dL}$, podendo afetar pessoas diabéticas ou não. Em pacientes diabéticos pode ocorrer a hipoglicemia iatrogênica, consequente ao tratamento com aplicações de insulina e/ou hipoglicemiantes orais que visam controlar a hiperglicemia que caracteriza essa doença. A Diabetes pode ser causada por insuficiência de produção de insulina, o que ocorre principalmente em pacientes com Diabetes Mellitus tipo 1, e por resistência à insulina, típica de pacientes com Diabetes Mellitus tipo 2. Em ambos os tipos pode haver episódios de hipoglicemia cujos sintomas e sinais característicos são: tremores, palidez, transpiração, sonolência, confusão e, em casos mais graves, coma e óbito OBJETIVO: Analisar por meio de um estudo descritivo transversal as manifestações da hipoglicemia em pacientes com Diabetes Mellitus dos tipos 1 e 2, bem como suas causas, grupos de risco, consequências, além de seu desenvolvimento fisiopatológico. Com isso, objetiva-se descrever a sintomatologia mais frequente da condição e suas repercussões clínicas. MÉTODO: Foi realizado um estudo descritivo transversal por meio da análise de artigos publicados entre 1991 e 2016, em inglês e português, tendo como base de dados bibliográficos o PubMed, Scielo e American Diabetes Association. A reunião de artigos foi sustentada pela pesquisa sobre o desencadeamento e o prognóstico da hipoglicemia em pacientes portadores de Diabetes Mellitus tipo 1 e 2. RESULTADO: A hipoglicemia é uma importante adversidade no tratamento do Diabetes Mellitus tipo 1 e 2 tendo como consequências diversas comorbidades. CONCLUSÃO: A Hipoglicemia em pacientes com Diabetes Mellitus tipo 1 e 2 possui causa iatrogênica e gera repercussões a curto e longo prazo em diversos sistemas do corpo humano. Suas principais consequências envolvem distúrbios neurológicos, aumento da mortalidade por complicações cardiovasculares, decréscimo da função renal, entre outros prejuízos para a qualidade de vida, evidenciando a relevância do quadro.

Palavras-chave: Hipoglicemia; Diabetes Mellitus; Insulina; latrogenia

\section{MON-05 MORTE SÚBITA EM ATLETAS JOVENS: COMO EVITAR}

Bárbara Carolina Miguel Jorge, Cinthia Emy Endo Amemiya, Ramon Félix Martins Fernandes, Carmen Silvia Molleis Galego Miziara

\section{Email: barbaracmj@ hotmail.com}

INTRODUÇÃo: Morte Súbita (MS) em atletas tem despertado grande atenção da sociedade. Em 2005, a Sociedade Brasileira de Medicina do Esporte como forma de evitar que novos casos de MS acontecessem, instituiu a Diretriz sobre a Morte Súbita no Exercício e no Esporte. A incidência de MS em jovens atletas é superior quando comparada a jovens não atletas e está associada ao exercício físico extenuante e as cardiopatias prévias. A detecção de fatores desencadeantes/ precipitantes e a determinação de condutas preventivas e curativas de MS foram estabelecidas por diretrizes, com critérios de elegibilidade instituídos pela American Heart Association and European Society of Cardiology. OBJETIVO: descrever a importância da avaliação pré-participação para evitar a morte súbita em atletas jovens; expor a Diretriz brasileira para a prevenção da Morte Súbita no exercício físico. MÉTODO: trata-se de estudo transversal descritivo realizado por revisão de literatura nas principais bases, como PUBMED e SCIELO, além de livros sobre o assunto. RESULTADO: a MS acomete uma ampla faixa etária desde jovens atletas até indivíduos acima de 35 anos. Observou-se em um estudo que nem todos os atletas brasileiros realizam exames periódicos, tanto ecocardiograma como eletroforese de hemoglobina, como foram preconizados pelas Diretrizes da Sociedade Brasileira de Medicina do Esporte, a qual recomenda a realização de exames para identificar atletas assintomáticos e que desconhecem os fatores predisponentes à MS. Dentre os exames, a realização de eletrocardiograma (ECG) é de suma importância e tem por finalidade detectar doenças cardiovasculares em atletas assintomáticos e, assim, o exame físico e a história médica podem ser considerados complementares ao ECG. CONCLUSÃO: é de extrema importância a adesão aos protocolos da Diretriz da Sociedade Brasileira de Medicina do Esporte para que a MS de atletas jovens seja evitada. Para que isso ocorra, os clubes necessitam seguir as recomendações contidas na diretriz através de investimentos em políticas de prevenção e de deteç̧ão precoce de fatores preditivos de MS que é uma forma de morte evitável Palavras-chave: morte súbita; atletas; prevenção e controle; política de saúde.

\section{MON-06 O HEART TEAM COMO ESTRATÉGIA DECISÓRIA EM PACIENTES CARDIOLÓGICOS COMPLEXOS}

Isabela Hohlenwerger Schettini, Amanda Vitiello Pereira Brosco, Bianca Cristina Romão da Cunha, Luisa Rebelo Ayoub, Antonio Carlos Palandri Chagas, João Fernando Monteiro Ferreira, Caio Cesar Ferreira Fernandes medicina. O conceito Heart Team (HT) tem sido desenvolvido em centros cardiológicos, baseia-se na formação de uma equipe com, no mínimo, um cirurgião cardíaco, um cardiologista clínico e um hemodinamicista para discussão de casos cardiológicos complexos. OBJETIVO: Avaliar criticamente as evidências que subsidiem a implementação do HT em hospitais. MÉTODO: Foram pesquisadas na plataforma Pubmed as palavras-chave Heart Team, coronary heart disease, TAVI (trans-aortic valve implantetion) e CABG (coronary artery bypass graft), identificando ensaios clínicos que avaliassem a eficácia do HT, relatos da experiência de centros pioneiros e a opinião de pesquisadores. RESULTADO: A colaboração entre subespecialidades cardiológicas recebeu maior destaque após publicação de duas pesquisas: O SYNTAX (Synergy Between PCI with Taxus and Cardiac Surgery) feita em coronariopatas e o PARTNER (Placement of Aortic Transcenter Valves), em valvopatas. A partir daí, notou-se a importância de uma estratégia que não privilegie a opinião de um único especialista. Recentemente, um novo membro foi incluso ao HT: o paciente, capaz de opinar sobre tratamento, ao se transportar a evidência técnica-científica para sua realidade. Considerado evolução na prática médica, hoje o HT tem recomendação classe I em consensos de revascularização miocárdica apesar de poucos centros o utilizarem, havendo escassa literatura sobre o tema. Tratar casos de modo integrado torna diagnóstico e conduta menos suscetíveis a vieses, uma vez que a decisão não é baseada em apenas uma vivência médica. Ao compartilhar opiniões, associa-se a melhor evidência científica às peculiaridades do indivíduo, tornando o resultado satisfatório para médicos e pacientes. Porém, há dificuldade na coleta de dados prospectivos capazes de comprovar benefícios do HT. Perduram problemas práticos sobre a estruturação da equipe e questiona-se qual é o perfil do paciente escolhido para a discussão. Deste modo, são essenciais estudos que avaliem o contento do paciente, estrutura hospitalar necessária e custo-efetividade do HT. CONCLUSÃO: O HT é promissor na decisão terapêutica em pacientes com doenças cardíacas graves. Todavia, apesar de moderno e inovador, sua utilização ainda é incipiente, necessitando melhores ensaios clínicos para difusão por hospitais.

Palavras-chave: Heart Team; doença coronária; time multidisciplinar.

\section{VÍDEO}

\section{VID-01 ACESSO VIDEOLAPAROSCÓPICO PARA CORREÇÃO DE HÉRNIA PERINEAL - RELATO DE CASO}

Yan Cachoni Sen, Carolina Yone, Renata Gomes Castello, Beatriz Gregio Soares, Paulo Roberto Zamfolini Zachêu, Lívia Yadoya Vasconcelos, Ricardo Moreno, Mauricio Campanelli

\section{Email: yancs@hotmail.com}

INTRODUCC̃̃O: Hérnia Perineal é uma complicação rara de cirurgias pélvicas, com incidência $<1 \%$ em pós-operatóros de amputação abdominoperineal de reto. Teve como objetivo relatar um caso de hérnia perineal, cuja correção ocorreu por acesso videolaparoscópico e técnica combinada. RELATO DE CASO: Paciente homem de 65 anos, submetido à colostomia derivativa de urgência por abdômen agudo obstrutivo por adenocarcinoma de reto médio, em Julho de 2010. Neste mesmo ano, foi submetido à radioterapia neoadjuvante e, em Janeiro de 2011 à retossigmoidectomia com quimioterapia adjuvante. Evoluiu com recidiva tumoral em anastomose coloanal, sendo submetido, então, à amputação abdomino-perineal de reto, em Março de 2012. Evoluiu com hérnia incisional perineal de grande volume. Após investigação radiológica com tomografia computadorizada, foi submetido, em Julho de 2015, à hernioplastia perineal com acesso videolaparoscópico. No intraoperatório, devido a firmes aderências de alça de delgado em região ântero-superior do saco herniário, optado por técnica combinada e acesso perineal ao saco herniário para lise de aderências. Após, refeito pneumoperitôneo e locado tela separadora de tecidos $\left(\right.$ Proceed $\left.^{\oplus}\right)$ de $21 \mathrm{~cm} \times 20 \mathrm{~cm}$, sendo seu maior eixo o ântero-posterior, respeitando-se o overlap de $5 \mathrm{~cm}$. A tela foi fixada com grampos em região de púbis, ligamentos de Cooper e inguinais, e em sacro. Observou-se excelente acomodação das vísceras sobre a tela quando o paciente retirado da posição de Trendelemburg. Há poucos estudos dos meios de acesso cirúrgico para correção de hérnia perineal, dessa forma, nã havendo consenso, a escolha do método e acesso da hernioplastia deve ser individualizada, levando-se em consideração, dentre outros fatores, as condições clinicas do paciente e a experiência do serviço. CONCLUSÃO: Apesar de ser uma complicação rara da cirurgia pélvica, deveria haver mais estudos sobre a hérnia perineal, para se estabelecer consenso sobre o método de escolha sobre sai correção.

Palavras-chave: Hérnia; Perineal; Videolaparoscópica; Correção.

\section{VID-02 BLEFAROPLASTIA COM EMAGRECIMENTO DO ROOF}

Sandra Carina Lopez Calcines, Mustapha Mohamed Mourad, Thiago Cavenaghi Castanheira, Giulianna Nasi Domingues de Oliveira Kenzo Saito Tomishige, Rodrigo Scabora, Carolina Nicolela Susanna, Rafael Cunha de Almeida

Email: tc_castanheira@ hotmail.com

INTRODUÇÃO: A blefaroplastia é um procedimento empregado frequentemente nos dias atuais, devido às exigências estéticas e também funcionais da atual sociedade, 
tanto em mulheres como em homens. Na blefaroplastia de pálpebra superior elimina-se pele excessiva da prega cutânea superior e também tecido gorduroso, se em excesso. Teve como objetivo demonstrar técnica de blefaroplastia personalizada com emagrecimento do ROOF. RELATO DE CASO: Paciente, do sexo feminino, 62 anos de idade, procedente e natural de Santo Andre foi previamente submetida a cirurgia de blefaroplastia comum superior em ambos os olhos, tendo ficado insatisfeita com o resultado. Em uma nova abordagem, optou-se por uma blefaroplastia com emagrecimento do ROOF. Nesta técnica, optou-se por uma incisão superior com o objetivo de preservar uma maior porção do músculo orbicular sobre o tarso. Após cirurgia personalizada, melhora significativa da ptose palpebral, melhorando a estética e a autoestima da paciente. Embora existam diversas formas de realizar o procedimento de blefaroplastia e normalmente se opte por fazer uma blefaroplastia mais simples e mais rápida, para ter um resultado estético final desejado, o procedimento cirúrgico deve ser personalizado em cada caso. CONCLUSÃO: para melhor resultado cirúrgico final, a indicação de blefaroplastia deve ser individualizada, personalizada para cada caso. Existem vários elementos que podem ser aprimorados para cada paciente.

Palavras-chave: blefaroplastia; plastica ocular; oftalmologia.

\section{VID-03 CISTECTOMIA LAPAROSCÓPICA RADICAL COM RETIRADA TRANSRETAL DA PEÇA}

Andrea Perovano Pardini, Olivia Achur Antonio de Faria Alvim, Alexandre Kyoshi Hidaka, Marcos Tobias Machado, Jônatas Luiz Pereira, Pericles Rios Auad

\section{Emaill: deaperovano@gmail.com}

INTRODUÇÃO: A cistectomia laparoscópica radical (CLR) é um procedimento cujo objetivo é reduzir a morbidade da cirurgia convencional, onde a retirada da peça ocorre pela parede abdominal tendo como complicação pós-operatória o desenvolvimento de hérnia incisional ou evisceração. Reportar a viabilidade da extração transretal de peça de cistectomia radical e os resultados iniciais RELATO DE CASO 5 pacientes com idades entre 70 e 85 anos,com diagnóstico de carcinoma urotelial de alto grau invasivo muscular e ressecção endoscópica prévia. Devido ao caráter paliativo do tratamento optou-se pela cistectomia radical laparoscópica com ureterostomia cutânea bilateral. Todos foram submetidos a um preparo intestinal com solução de manitol e antibioticoterapia profilática com Mefoxim TM (Cefoxitin). Com a parte ablativa da cistectomia já completada, procedemos aos seguintes passos cirúrgicos: 1) a aplicação de um endocath bag de $15 \mathrm{~mm}$ por via retal; 2) incisão de $5 \mathrm{~cm}$ do reto na linha da tênia no ponto de visualização laparoscópica da ponta do endocath; 3 ) entrada do endocath para a cavidade abdominal pela incisão no reto; 4) abertura do saco; 5) ensacamento da peça; 6) extração da peça pelo reto; 7) reparo da extremidades da incisão retal com fios de poliglactina 910;8) aplicação de stapler linear de 60 $\mathrm{mm}$ tangencial interessando toda parede do reto; 9) sutura continua da muscular com poliglactina 910 3-0 10)drenagem com dreno túbulo laminar. Todos foram operados com sucesso. O tempo operatório total médio foi de 180 minutos, tendo gasto uma média de 25 min para extração da peça e reconstrução do reto. O tempo médio de internação foi 8 dias. As complicações pós-operatórias relatadas foram 1 atelectasia (melhora após fisioterapia) e 1 seroma em uma das incisões dos trocantes sem sinais de infecção. Não houve complicações maiores ou a necessidade de reabordagem. O seguimento mínimo foi de 6 meses,com consultas a cada 3 e tomografia a cada 6. Não foram observadas recidivas ou qualquer manifestação clinica. CLR aplicada como tratamento paliativo, a fim de aliviar os sintomas de câncer de bexiga. Nossa proposta sugere uma taxa de complicações menor ao longo da parede abdominal e retal e melhor qualidade de vida CONCLUSÃO: A CLR com extração da peça por via transretal é uma técnica viável, reprodutível e segura. Mais estudos são necessários para validar os resultados iniciais

Palavras-chave: Cistectomia radical; Videolaparoscopia; Câncer de bexiga

\section{VID-04 FACOEMULSIFICAÇÃO EM PACIENTE ALTO MÍOPE PÓS TRANSPLANTE COM BAIXA CONTAGEM DE CÉLULAS ENDOTELIAIS}

Luciano Rabello Netto Cirillo, Cristina Nery Carbajo, Mariana Gameiro lerardi, Thiago Cavenaghi Castanheira, Gabriel Castilho Sandoval Barbosa, Carolina Akyko Uehara, Beatriz Jeronymo Pardi, Kenzo Saito Tomishige, Fabio Henrike Ferrari Nassar, Fernando Martins de Oliveira, Vagner Loduca Lima

\section{Email: lucianocirillo22@gmail.com}

INTRODUÇÃO: Catarata é a denominação dada a qualquer opacidade do cristalino, afetando ou não a visão. Segundo a OMS é a maior causa de cegueira tratável no mundo. Diversos fatores de risco podem acelerar ou provocar o seu aparecimento como substâncias tóxicas, doenças metabólicas, doença ocular, cirurgia ocular prévia, sendo o envelhecimento o principal fator. Atualmente, para tratamento, a facoemulsificação (Faco) é o procedimento cirúrgico mais utilizado, em razão de consistir em uma menor incisão, menor trauma ao olho, rápida recuperação visual e reduzido índice de complicações pós-operatórias. Relatar um caso de paciente com múltiplas comorbidades oculares tratado com cirurgia de catarata, buscando melhora da acuidade visual (AV) sem o auxílio de refração. RELATO DE CASO: SR, masculino, 60 anos, procurou o serviço de Oftalmologia da FMABC com uma queixa de baixa AV progressiva em olho esquerdo (OE) há 6 meses. Relata de antecedentes pessoais um quadro de ceratocone tratado com transplante endotelial bilateral há 15 anos, além de facectomia em olho direito (OD) há 4 anos. Em uso de lente de contato rígida em $\mathrm{OE}$. Ao exame na admissão, apresentou AV sem correção de 20/250 em OD e refração de $-2,00 \mathrm{DE}-2,00 \mathrm{DC}$ a 130 alcançando uma visão de 20/60 em OD e -25,00 DE -6,00 DC a 15 atingindo uma visão de 20/200 parcial em OE. A biomicroscopia em OE mostrava catarata cortical de $2+$ em eixo visual, subcapsular posterior e nuclear. Aos exames complementares de $\mathrm{OE}$ apresenta astigmatismo regular simétrico na topografia e microscopia especular computadorizada com uma contagem de células de $850 / \mathrm{mm} 2$. Como hipótese diagnóstica temos ceratocone com transplante penetrante em ambos os olhos e catarata em OE, cuja conduta é a Faco de OE e programação da melhor lente intraocular para tentar corrigir total ou parcialmente a ametropia do paciente, visando a melhor AV possível sem correção. Paciente apresentou em pós operatório imediato: edema de córnea $2+/ 4+$, reação de câmara anterior $2+/ 4+$, lente centrada, evoluindo com melhora da AV em OE. Diante de um paciente com ceratocone, alta miopia e catarata, optamos pela realização da Faco como método de tratamento para catarata, objetivando melhora da AV sem necessidade de correção. CONCLUSÃO: $\mathrm{O}$ Faco para este caso foi a melhor conduta encontrada para atingir o objetivo da queixa e corrigir a patologia.

Palavras-chave: Facoemulsificação; Catarata; Acuidade visual.

\section{VID-05 NEFRECTOMIA PARCIAL LAPAROSCÓPICA PURA SEM CLAMPEAMENTO APLICADA AOS TUMORES DE ALTA COMPLEXIDADE}

Pedro Ivo Sanches Martins, Alexandre Kyoshi Hidaka, Carolina Barrios, Breno Pinn, Olivia Achur, Andrea Pardini, Marcos Tobias Machado

Email: pedrobivo@ hotmail.com

INTRODUÇÃO: A nefrectomia parcial laparoscópica clássica utiliza a isquemia quente no rim, que reduz o aporte sanguíneo renal temporariamente para que a exerese e reconstrução renal sejam realizadas de maneira mais precisa. Entretanto, se o tempo de isquemia for prolongado, o dano renal pode ser irreversível Nos últimos anos alguns pesquisadores tentam desenvolver técnicas que permitam realizar a cirurgia sem isquemia renal. Existem poucos relatos dessa técnica aplicada aos tumores de alta complexidade. OBJETIVO: Reportar os resultado oncológicos e funcionais da nossa técnica de nefrectomia parcial laparoscópica pura sem clampeamento para tumores de alta complexidade. MÉTODO: 12 pacientes diagnosticados com tumor renal de alta complexidade de acordo com o R.E.N.A.L Score e com CICr $>60$ foram submetidos a nossa abordagem laparoscópica sem clampeamento, utilizando técnica de escavação com bisturì harmônico e elevação do pneumoperitoneo durante a ressecção da porção mais profunda do tumor. Avaliamos gênero, idade, índice de massa corpórea, RENAL Score, Charlson score e reportamos os resultados demográficos, perioperatórios, oncológicos e função renal por até 1 ano após a cirurgia. RESULTADO: 11 casos foram bem sucedidos sem a necessidade de clampeamento hilar. O tempo de isquemia temporária para o caso que necessitou de clampeamento foi de $11 \mathrm{~min}$. Tempo operatório médio entre 168 min (140-180). Perda sanguínea média de 423,75 ml (360-485 ml), requeriu 1 transfusão sanguínea. Tivemos 1 complicação pós operatória, 1 urinoma retroperitoneal que necessitou drenagem e duplo $\mathrm{J}$. O exame anatomopatológico revelou $64 \%$ dos casos como carcinoma renal, sendo $16 \%$ tumores benignos. As margens cirúrgicas foram positivas focalmente em 1 caso, sem evidencia de recidivas num período de 2 anos. Nenhum dos pacientes evolui com insuficiência renal após seguimento maior que 1 ano. DISCUSSÃO: Quando iniciamos esse estudo 5 anos atras procuramos determinar os reais efeitos da nefrectomia parcial aplicada a pacientes com função renal preservada, e por isso selecionamos casos com $\mathrm{ClCr}>60$. Atualmente as vantagens dessa técnica já estão consagradas quando aplicadas aos casos de pacientes com rim único. CONCLUSÃO: A nefrectomia parcial laparoscópica pura sem clampeamento é viável e segura, apresentando resultados oncológicos excelentes.

Palavras-chave: Tumor Renal; Nefrectomia Parcial; Videolaparoscopia.

\section{VID-06 PIELOLITOTRIPSIA RETROPERITONEAL POR INCISÃO ÚNICA (LESS): ABRODAGEM ALTERNATIVA A NEFROLITORIPSIA PERCUTÂNEA NO TRATAMENTO DE CÁLCULOS RENAIS}

Breno Pinn de Castro, Jonatas Luiz Pereira, Pericles Rios Auad, Carolina Ulhoa Rodrigues, Andrea Perovano Pardini, Alexandre Kyoshi Hidaka Pedro Ivo Sanches Martins, Olivia Achur Antonio de Faria Alvim, Marcos Tobias Machado

\section{Email: breno.pinn@gmail.com}

INTRODUÇÃO: A Nefrolitotripsia Percutânea é o tratamento padrão-ouro para a remoção de cálculos renais maiores que $2 \mathrm{~cm}$. Entretanto, alguns casos podem ser desafiadores pelo acesso percutâneo, especialmente em casos em que há presença de uma grande e densa massa pielocaliceal sem dilatação no trato urinário. Apresentamos nossa experiência com a Pielolitotomia Retroperitoneal Lateral por incisão única (LESS). RELATO DE CASO: Homem, 51 anos. Apresenta cólica lombar e episódios prévios de pielonefrite. Tomografia computadorizada evidenciou um grande cálculo pielico de $2,5 \mathrm{~cm}$ x $2,0 \mathrm{~cm}$ no rim direito, sem dilatação pielocaliceal. Optamos pelo acesso retroperitoneal lateral por LESS devido a localização da massa e historia previa de múltiplas pielonefrites. Foi realizada uma 
urografia excretora antes do procedimento para uma melhor visualização do trato urinário. Conduzimos uma cistoscopia e implante de cateter duplo J à direita com o paciente posicionado em posição de litotomia. Feito isso, colocamos o paciente em posição de decúbito lateral direito, para realizar o acesso retroperitoneal lateral. Após a dissecação e confecção do espaço retroperitoneal com pneumoretroperitonio, seguimos para a identificação do ureter e da pelve renal. Usando instrumentos laparoscópicos convencionais, realizamos a pielolitotomia, identificação e remoção dos cálculos renais e então o fechamento da região. Dreno foi alocado na incisão. A duração do procedimento foi de 140 minutos, sem complicações operatórias. O cateter da bexiga foi removido na primeira drenagem pos-operatória e o dreno no segundo dia após receber alta. A convalescência terminou após 3 semanas,e o paciente esteve livre dos sintomas dos cálculos após 1 ano. O tratamento padrão-ouro para cálculos renais maiores que $2 \mathrm{~cm}$ é a lithotripsia percutânea. Contudo em alguns casos, podemos indicar nossa técnica como uma alternativa a abordagem percutânea. Indicamos a técnica para os casos de litíase pielocaliceal maior que $2 \mathrm{~cm}$, com ausência de dilatação pielocaliceal, podendo estar associado com quadro de rins ectópicos, em ferradura ou malrodados. Nesses casos, pode existir alguma ma formação vascular e alterações do trajeto ureteral, dificultando o acesso à pelve renal pela via percutânea, aumentando as chances de iatrogenia. CONCLUSÃO: Esta via é segura e factível, além de apresentar baixa morbidade.

Palavras-chave: Laparoscopia; Litiase renal; Rim.

\section{VID-07 PROSTATECTOMIA RADICAL VIDEOLAPAROSCÓPICA COM LINFADENECTOMIA ESTENDIDA PARA PACIENTES COM CÂNCER DE ALTO RISCO LOCALIZADO}

Carolina Ulhoa Rodrigues Barrios, Alexandre Kyoshi Hidaka, Andrea Perovano Pardini, Olívia Achur Antonio de Faria Alvim, Pedro Ivo Sanches, Breno Pinn de Castro, Jônatas Luiz Pereira, Péricles Rios Auad, Marcos Tobias-Machado

Email: kkarrollinna@gmail.com

INTRODUÇÃO: Câncer de próstata é o segundo câncer mais diagnosticado e o quinto que mais causa mortes entre os homens. Prostatectomia Radical com Linfanadectomia estendida (PRLE) é indicado para pacientes com câncer de alto risco (CAR), com tumores confinados. A indicação cirúrgica para esse tipo de câncer está crescendo devido a estudos à longo prazo. OBJETIVO: Descrever nossa técnica de linfadenectomia estendida para CAR e informar nossos resultados preliminares do pós-operatório oncológico. MÉTODO: A doença nos pacientes foi classificada como CAR localizado (PSA $\geq 20 \mathrm{ng} / \mathrm{mL}$ ou Gleason $\geq 8$ ou $\geq \mathrm{cT} 2 \mathrm{c}$ ) entre 2011 a 2015. A média de idade dos pacientes foi 64 anos. Cirurgia foi a primeira opção terapêutica e os pontos técnicos principais foram: abordagem transperitoneal linfadenectomia pélvica estendida; separação do reto, próstata e vesícula seminal; abertura da fáscia endopélvica lateral à próstata; seção do colo da bexiga sem preservação das fibras; controle dos pedículos prostáticos sem preservação do feixe neurovascular; dissecção meticulosa da região apical; dissecção bilateral entre o reto e a uretra e reconstrução do colo vesical posterior antes da anastomose. RESULTADO: O tempo médio de operação foi de 210 minutos, com uma média de perda sanguínea de $250 \mathrm{ml}$. Os pacientes ficaram, em média, 3 dias hospitalizados. As médias das taxas de PSM pT2; PSM pT3 e PSA foram, respectivamente, 2; 2,2 e 8,1. Na biópsia, média Gleason 8. DISCUSSÃO: O motivo principal da cirurgia não ter sido considerado uma alternativa viável à radioterapia foi devido às morbidades da $\mathrm{PR}$ e a crença de que esses pacientes são geralmente incuráveis com terapias locais. Vários estudos contradizem esse princípio diretamente, o que explica o aumento do uso da cirurgia para CAR ao longo da última década e a revisão das orientações de melhores práticas para referir isso. Diretrizes recentes da Associação Europeia de Urologia sobre câncer de próstata recomendou que PRLE deva ser feito em todos os pacientes, refletindo não somente sua importância prognóstica, mas também seu benefício terapêutico com nível 1 de evidência. CONCLUSÃO: Cirurgia laparoscópica adotando princípios oncológicos pode ser utilizada com eficácia para pacientes selecionados com câncer de próstata de alto risco localizado ou localmente avançado mantendo as vantagens da abordagem cirúrgica minimamente invasiva.

Palavras-chave: Prostatectomia radical; linfadenectomia; videolaparoscopia.

\section{VID-08 SUBSTITUIÇÃO DE METATARSOS POR ENXERTO FIBULAR E TRATAMENTO COM PLÁSTICO ESTÉRIL.}

Pedro Augusto Soffner Cardoso, Marcel Arnaud Sanchez, Natália Rebeque Modolo, Paulo Victor Dias Macedo, Rodrigo Mattner Gaspar, Márcio Aurélio Aita, Rafael Saleme, Luiz Felipe Fernandes Longuino

Email: pedro.soffner.cardoso@gmail.com

INTRODUCÃO: O trauma tornou-se uma doença muito significativa no cenário hospitalar. Cada vez mais o número de vítimas sobe e, estas, com uma característica preocupante: envolver uma faixa etária que compreende adultos e jovens economicamente ativos. A amputação de um membro em decorrência das lesões sofridas causa um impacto social ainda maior. Ferimentos nas extremidades dos membros, em queda de motocicleta, são extremamente comuns, podendo variar de simples escoriações, até complexas mutilações. OBJETIVO: Mostrar a substituição do $4^{\circ}$ e $5^{\circ}$ metatarsos do pé direito com enxertia de fíbula, abaixo de uma ferida tratada com plástico estéril. MÉTODO: Foram executadas duas etapas cirúrgicas. Na primeira, realizou-se amplo desbridamento, observando grande perda cutânea do $4^{\circ}$ e $5^{\circ}$ metatarsos, substituindo-os por cimento ósseo guiado por fios de Kirschner. Para tratar a ferida cutânea complexa no dorso do pé e na região plantar utilizou-se plástico estéril (parte transparente do coletor de urina). A segunda etapa foi substituir o osso sintético por enxerto fibular, retirando o terço médio da fíbula para tal procedimento. RESULTADO: Paciente apresentou ótima recuperação da ferida no tecido cutâneo tratando-a com o plástico estéril. Com isso facilitou o ato cirúrgico de substituição dos metatarsos por enxerto fibular. Recuperando um pé com prognóstico de amputação parcial, tornando-o futuramente funcional DISCUSSÃO: A utilização do plástico estéril no tratamento de lesões complexas tem mostrado ótimos resultados no tratamento de feridas, por favorecer a formação de tecido de granulação. Isso facilitou de forma excepcional o procedimento cirúrgico de substituição dos metatarsos perdidos no acidente, por tornar um local desfavorável à atos cirúrgicos em um ambiente favorável para a enxertia fibular. Esta cirurgia proporcionará ao paciente uma recuperação funcional do pé, já que as partes retiradas da fíbula possuíram uma composição e forma muito parecidas com os metatarsos perdidos. CONCLUSÃO: O baixo custo (4 reais aproximadamente) e a ótima recuperação do tecido demonstram o excelente custo benefício do plástico estéril, comparado a outros métodos conhecidos. Já que proporcionam uma qualidade de tecido cutâneo favorável para cirurgias complexas como a de substituição de metatarsos por enxerto fibular.

Palavras-chave: plástico estéril; enxerto fibular; substituição dos metatarsos; baixo custo. 


\section{Índice remissivo por Autores}

\section{A}

Abreu LC
Abreu YLB.
Adami F
Agena J
Aguiar ASJ
Aita MA
Akaishi DY
Alcocer FED
Aliberti GM
Almeida GE
Almeida RC
Almeida SKA
Alvarenga MM
Alves KHCR
Alvim OAAF
Alvo CS
Ambrosano TCS

\section{B}

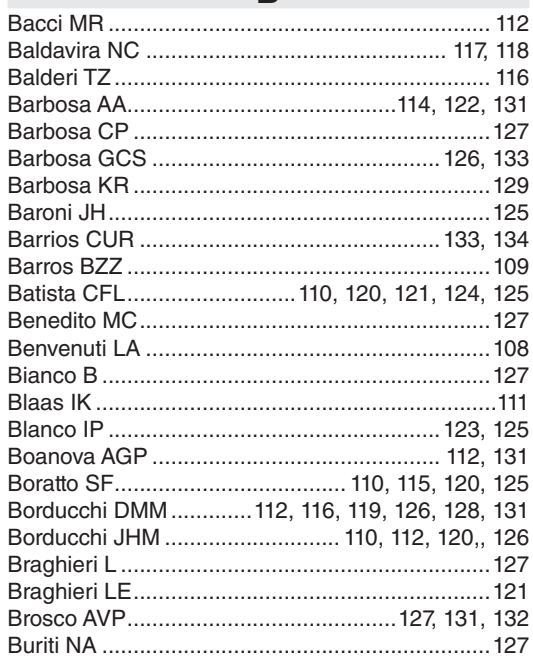

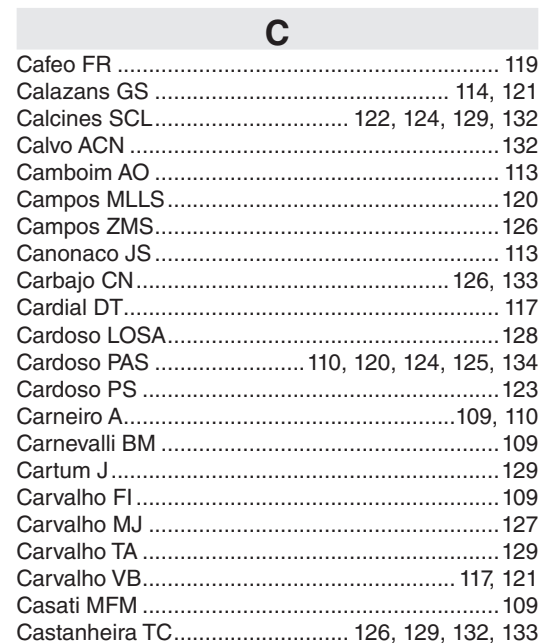

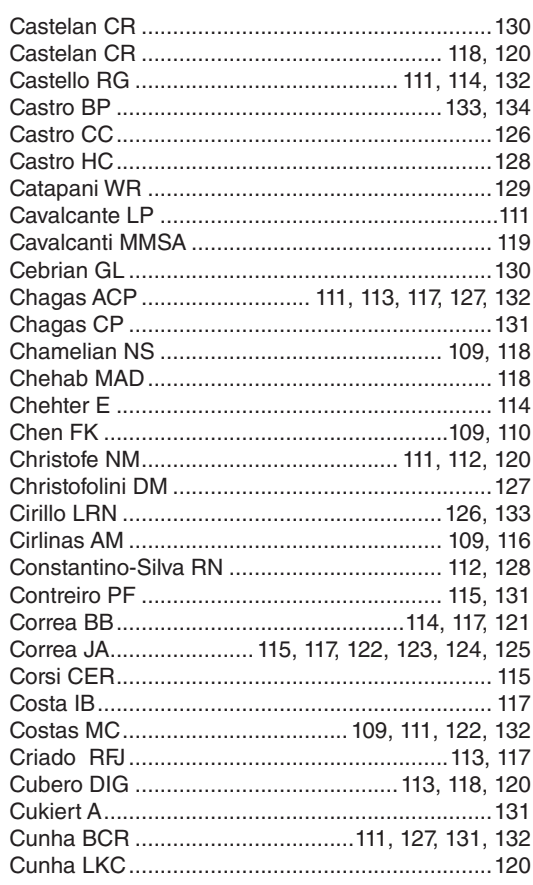

\section{D}

Danziere FR............................................ 122, 124 Defino MP...................................................... 117 Domingues ACV ..................................... 128, 130

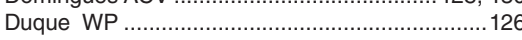

\section{$E$}

Estevez Júnior R..............................................125

\section{$\mathbf{F}$}

Falcone BEG

Feder D

.

Fernandes CCF ....................................127, 131, 132

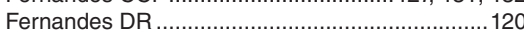
Fernandes LF ............................................ 123 Fernandes RFM.............108, 109, 115, 116, 117, 122, $123,124,125,127,129,132$ Ferrandez CA ……......................................... 113

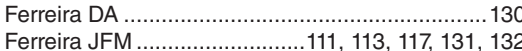

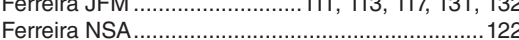

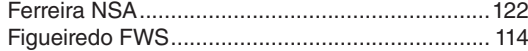
Fonseca AT ........................................................... 118

Fonseca MCM ….................................................... 113

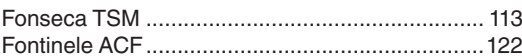

Fontinele ACF …............................................12

Fujishige CK ...............................113, 128, 129, 130

\section{G}

Galego SJ.....................115, 117, 122, 123, 124, 125 Garcia CA ............................................. 129, 130 Garcia MA.................................................... 108, 113 Gaspar RM ....................................... 123, 124, 134 Genzini T ................................................ 124, 122

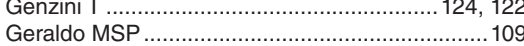
Gerardi Filho VA........................................ 124, 125 Gerardi VA …................................................ 121 Giacovone CV............................................111, 116 Giglio AD.................................................... 118, 120

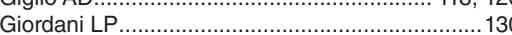

Gomes GAM ..........................................111, 121
Gonelli EG

Gouveia MC.....

125,124

Grumach AS

Guilherme Bes Borba ....................................... 128

$112,114,128,129,131$

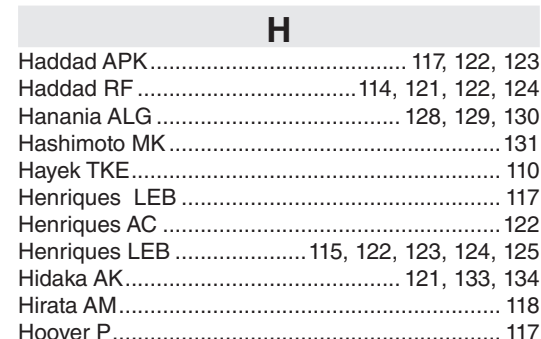

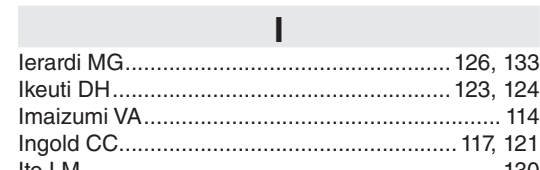

to LM

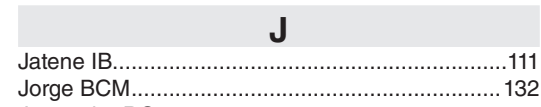

Jorge $\mathrm{BCM} \ldots \ldots \ldots \ldots \ldots \ldots \ldots \ldots \ldots \ldots \ldots \ldots \ldots \ldots \ldots \ldots \ldots \ldots \ldots \ldots \ldots \ldots \ldots \ldots \ldots \ldots \ldots \ldots \ldots \ldots \ldots \ldots \ldots \ldots \ldots \ldots \ldots \ldots$
Junqueira RC

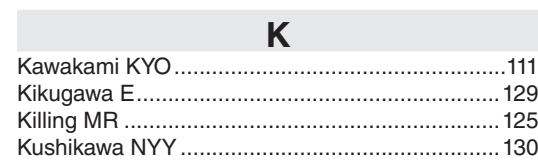

\begin{tabular}{|c|}
\hline $\mathbf{L}$ \\
\hline Lamy GB \\
\hline$\ldots \ldots \ldots \ldots \ldots \ldots \ldots . . .114$ \\
\hline 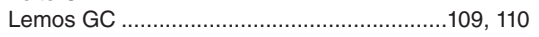 \\
\hline Lima GHV ....... \\
\hline Lima LC ................ \\
\hline Lima SMAAL... \\
\hline Lima VL.......... \\
\hline Lobão NTM... \\
\hline$\ldots \ldots \ldots \ldots \ldots \ldots \ldots \ldots \ldots \ldots \ldots \ldots \ldots \ldots . . .124$ \\
\hline$\ldots \ldots \ldots \ldots \ldots .123,125,134$ \\
\hline 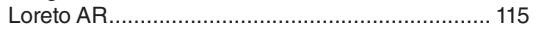 \\
\hline Lucena DMM ..........115, 117, 119, 122, 123, 124, 125 \\
\hline
\end{tabular}

M

Macedo PVD …................. 121, 122, 124, 125, 134

Machado Filho CDS ......... 113, 130

Machado MT............................................. 133, 134

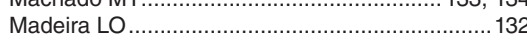

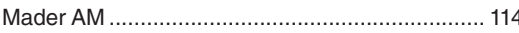

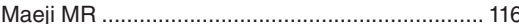

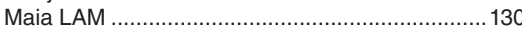

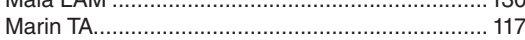

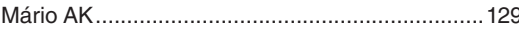

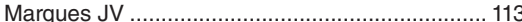

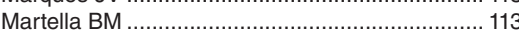

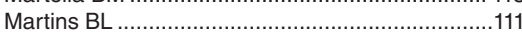

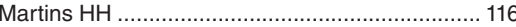

Martins LA …....................................................... 115

Martins LC ..................................................115, 116

Martins PIS .................................................... 133, 134

Massabki PRG................................................... 115

Masuda M......................................................... 114

Matar MR ..................................115, 122, 123, 124 


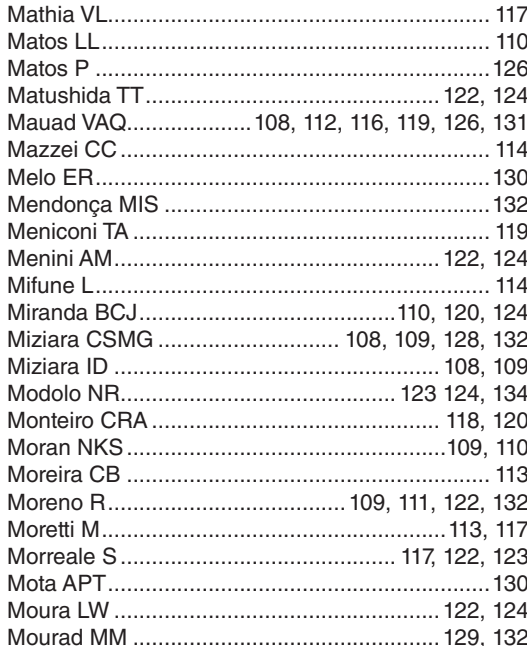

\section{N}

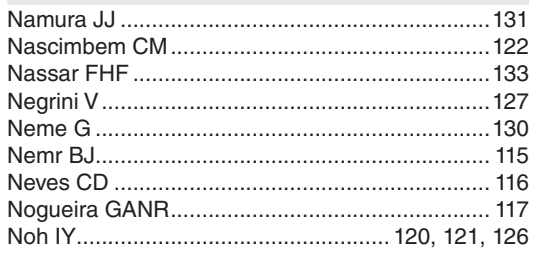

Noh IY........................................ 120, 121, 126

Novalo-Goto ES................................................. 126

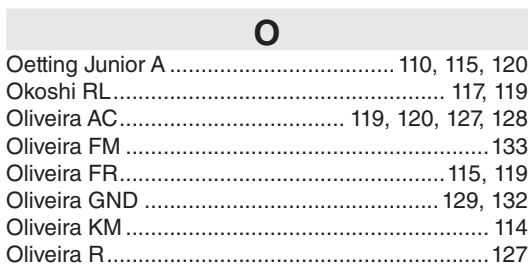

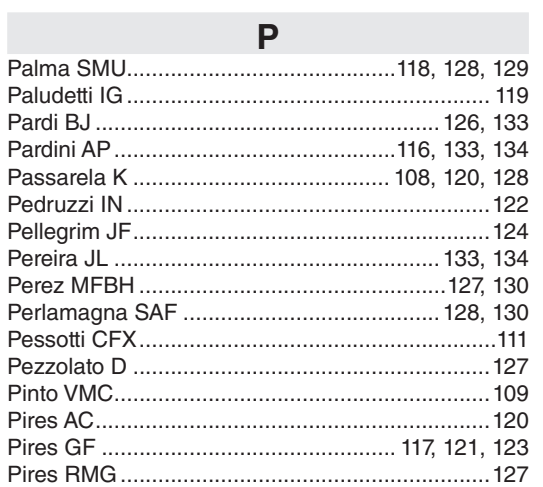

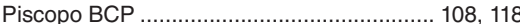

Polly M.

Q
Qing XX
Quinzani AB

\section{$\mathrm{S}$}

Sakuma GYK..................117, 121

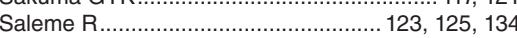
Sanches BAC ................................................ 108 Sanchez MA .................................. 121, 124, 134 Santomauro Junior AC ....................................... 132 Santos EJ ............................................. 108, 126 Santos FDB …............................................ 125

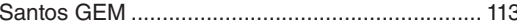

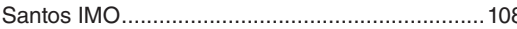

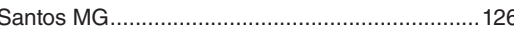
Saporito WF ..................................................... 120 Sapuppo AK ……............................................ 130 Scabora R........................................126, 129, 132 Scaff MRC ...................................................... 112 Schettini IH ......................................127, 131, 132 Schoeps DO … Schoueri JHM ...................................................... 120

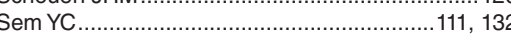

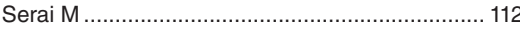

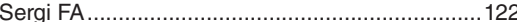
Sergi Filho FA ...........................................122, 124

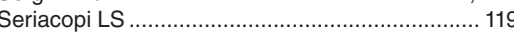

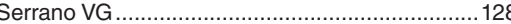

Sette CVM .............118, 120

Shimaoka GA.................................................... 120

Shiroma OM ............................................... 123, 125

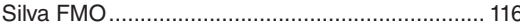

Silva GHF .................................................. 122

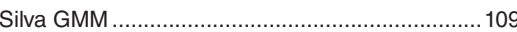

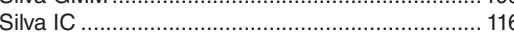

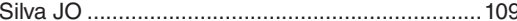

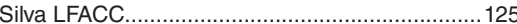

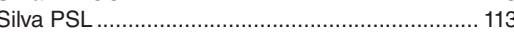

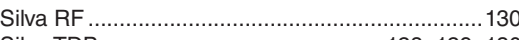

Silva TDB ........................................ 128, 129, 130

Silva VC ................................................... 128, 130

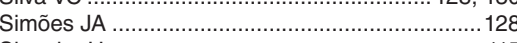

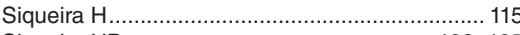

Siqueira HB …...................................... 123, 125

Soares BG ................................................111, 132

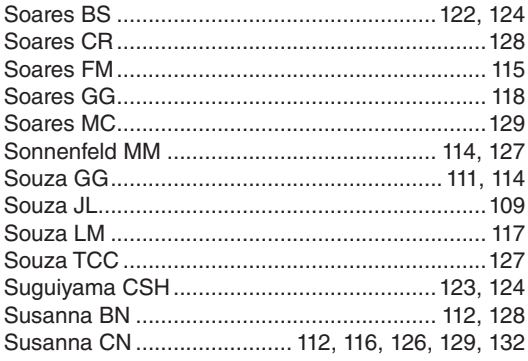

\section{$T$}

Takahashi LAR ....................................114, 115, 120 Takara ME........................................................ 116 Tamanini JM ................................................ 113 Tamashiro CY ..............................111, 114, 116, 132 Tappi MA...................................................... 131 Tavares HDA ................................. 108, 118, 119, 128 Teixeira GC ..................................... 128, 129, 130 Teixeira JVS...................................... 120, 130, 131 Tolentino ALN ..........................................120, 128 Tomishige KS.......................... 126, 129, 132, 133

Trevisan CM.................................................. 127

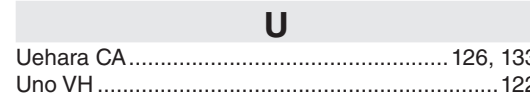

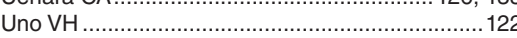

\begin{tabular}{|c|}
\hline V \\
\hline 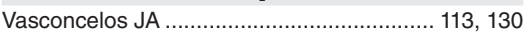 \\
\hline Vasconcelos KDB \\
\hline$\ldots \ldots \ldots .111,122,124,132$ \\
\hline Vassoler GC ..................... \\
\hline$\ldots \ldots \ldots \ldots \ldots \ldots \ldots \ldots \ldots \ldots \ldots \ldots . . .112,119$ \\
\hline ................ 109 \\
\hline 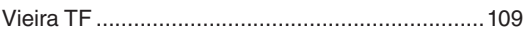 \\
\hline Vizentini GC................... \\
\hline
\end{tabular}

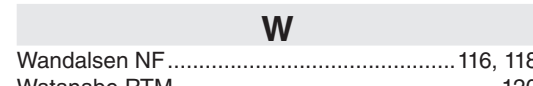

Watanabe RTM

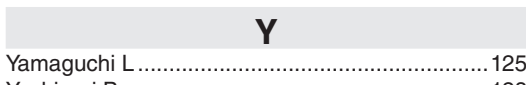

Yoshinari B .................................................. 125

\section{Z}

Zacarelli-Marino MA Zacarelli-Marino MA ..................................... 115
Zachêu PRZ ................ 111, 122, 123, 124, 125, 132

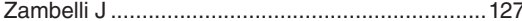

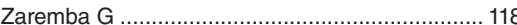

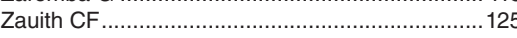

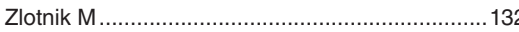

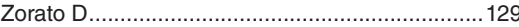

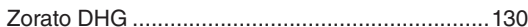

